\title{
Estimation of Free Radical Polymerization Rate Coefficients using Computational Chemistry
}

by

Siziwe Bebe

A thesis submitted to the Department of Chemical Engineering

In conformity with the requirements for

the degree of Doctor of Philosophy

Queen's University

Kingston, Ontario, Canada

April 2008

Copyright @Siziwe Bebe, 2008 


\begin{abstract}
Acrylic free radical polymerization at high temperature proceeds via a complex set of mechanisms, with many rate coefficients poorly known and difficult to determine experimentally. This problem is compounded by the large number of monomers used in industry to produce coatings and other materials. Thus, there is a strong incentive to develop a methodology to estimate rate coefficients for these systems. This study explores the application of computational chemistry to estimate radical addition rate coefficients for the copolymerization of acrylates, methacrylates and styrene.
\end{abstract}

The software package Gaussian is used to calculate heats of reaction $\left(\Delta H_{\mathrm{r}}\right)$ values for monomer additions to monomeric and dimeric radicals, using minimum energy structures identified and characterized for the reactants and products. The Evans-Polanyi relationship is applied to estimate reactivity ratios from the relative differences in $\Delta H_{\mathrm{r}}$. The validity of this methodology is tested through a comparison of calculated monomer and radical reactivity ratios for acrylate, methacrylate, vinyl acetate, ethene and styrene systems to available experimental data for copolymerization systems. The methodology is found to work for some systems while there is computational breakdown in others due to steric crowding and/or breakdown of the Evans-Polanyi relationship. 


\section{Acknowledgements}

The journey to the completion of my PhD. thesis was no "walk in the park". It was filled with challenges which I feel were instrumental in making me the person I am today. I now have a greater understanding of and appreciation for polymer kinetics and computational chemistry. Although I was tested beyond what I thought were my limits, I succeeded, and consequently evolved into a stronger, more patient and determined individual. This however was possible due to the overwhelming support and encouragement I received from many people.

Firstly, I express my gratitude to my supervisor, Professor Robin Hutchinson. You have been a great inspiration over the course of my PhD. Your enthusiasm, patience and dedication went a long way in making polymer kinetics enjoyable for me. I greatly appreciate your encouragement and involvement through the provision of ideas and feedback while I was writing my thesis. I could not ask for a better supervisor! Thanks also to members of my research group past and present who made learning and working in the Hutchinson lab fun.

Additionally, I am grateful to Dr. Linda Broadbelt and her group at Northwestern University (Chicago) who introduced me to computational chemistry which I have employed extensively in this work. I am thankful to Erin R. Johnson and Owen J. Clarkin for providing vital information, advice and discussions on the simulations I was working with. Dr. M. J. Bhala of National University of Science and Technology (Zimbabwe), inspired me to work with polymers and for this I am very grateful.

Although I am unable to list everyone who helped me in any way, I know that I am indebted to many people (especially in the Chemical Engineering department) for providing a conducive environment for me to learn and grow amidst my misfortunes. I appreciate your help, support and or encouragement and thank you greatly. I cannot end without thanking my family and friends for their unending support. In particular, I acknowledge Nosizo (my daughter), Jesse Mgcini (my son), Gelice (my mum) 
and Sipho, Sithabile, Sibonile (my siblings), whose constant encouragement and love I have relied on throughout my time at Queen's University. Their unflinching support, encouragement, love and conviction that I will make it one way or the other, will always inspire me. It is to them that I dedicate this work. 


\section{Table of Contents}

Abstract.................................................................................ii

Acknowledgements...............................................................ii

Table of Contents....................................................................

List of Figures....................................................................vii

List of Tables.......................................................................

List of Schemes................................................................

Nomenclature......................................................................xii

1.0 Introduction.......................................................................1

2.0 Literature Review..............................................................4

2.1 Free Radical Polymerization Kinetics and Mechanisms..........................

2.1.1 Secondary Mechanisms................................................ 9

2.1.2 Copolymerization Propagation Kinetics..................................... 12

2.2 Exploration of Chemistry with Electronic Structure Method........................20

2.2.1 Computational Chemistry Methods......................................22

2.2.2 Calculation of Thermodynamic Properties.................................28

2.2.3 Isodesmic Reactions................................................... 30

2.2.4 Benson Group Additivity............................................ 31

2.3 Application of Computational Approach.....................................33

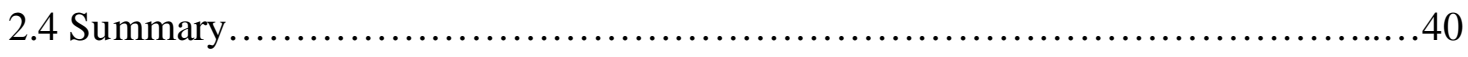

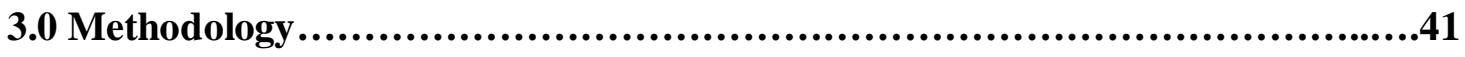


3.1 Geometry, starting structure and optimization

3.2 Thermochemistry Calculation.................................................. 45

3.2.1 Isodesmic Reaction Method.................................................49

3.2.2 Verification of Computational Technique.......................................52

3.3 Monomer Reactivity Ratio Calculation.....................................54

4.0 Results -Monomer addition to monomeric radicals............................58

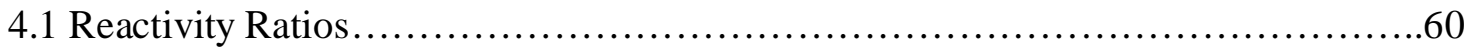

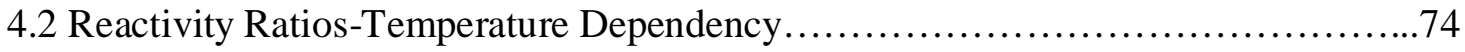

4.3 Heats of Reaction-Structure reactivity trends................................. 75

5.0 Results-Monomer addition to dimeric radicals..................................81

5.1 Reactivity Ratios- Penultimate Models........................................82

5.2 Reactivity Ratios- Midchain Reactions.....................................93

6.0 Conclusions/Future Work..................................................96

6.1 Conclusion.................................................................. 96

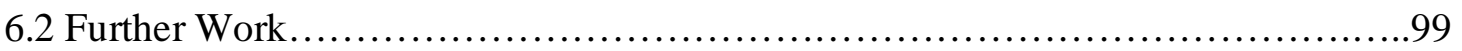

7.0 References...................................................................101

Appendix A.......................................................................

A.1Styrene/ $\alpha$-Methyl Styrene.................................................. 108

A.2 Methyl Acrylate/Methyl Methacrylate........................................ 112

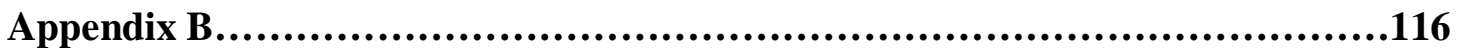




\section{List of Figures}

Figure 2.1 A worked example of Benson's Group Additivity Method.

Figure 2.2 Comparison of monomeric radicals.

Figure 3.1 Plot of a potential energy scan of the backbone dihedral angles for MMA-MA radical.

Figure 3.2 The structural pictures of the monomers and radicals that are used for the calculation of the reactivity ratios for the terminal model in the MA/MMA copolymerization system.

Figure 4.1 Conformations of MMA from different optimization schemes

Figure 4.2 Relationship between MMA(1)/VAc(2) copolymer $\left(F_{p 1}\right)$ and 64 monomer $\left(f_{l}\right)$ composition, calculated from computed reactivity ratios summarized in Table1(System IX), and from literature values $\left(r_{1}=25\right.$; $\left.r_{2}=0.05\right)$.

Figure 4.3 Relationship between copolymer $\left(\mathrm{F}_{\mathrm{p} 1}\right)$ and monomer $\left(\mathrm{f}_{1}\right)$ composition, calculated from computed reactivity ratios summarized in Table 1 (Systems IV, VII, IX), and from literature values.

Figure 4.4 Relationship between copolymer $\left(\mathrm{F}_{\mathrm{p} 1}\right)$ and monomer $\left(\mathrm{f}_{1}\right)$ composition calculated from computed reactivity ratios for MMA/MA (Table 4.1, System I) and styrene with MMA and MA (Table 4.3).

Figure 4.5 Structures of acrylate radicals used to study relative reactivities computationally.

Figure 5.1 Relationship between copolymer $\left(\mathrm{F}_{\mathrm{p} 1}\right)$ and monomer $\left(\mathrm{f}_{1}\right)$ composition calculated from computed reactivity ratios for MA/MMA (Table 4.1 System I and Table 5.1, system 1A).

Figure 5.2 Relationship between copolymer $\left(\mathrm{F}_{\mathrm{p} 1}\right)$ and monomer $\left(\mathrm{f}_{1}\right)$ composition 85 calculated from computed reactivity ratios for MA/St (Table 4.2, System I and Table5.1, system II1 A). 
Figure 5.3 Relationship between rate of copolymerization $\left(\mathrm{k}_{\mathrm{p} \text { copo }} \mathrm{L} / \mathrm{mol}-\mathrm{s}\right)$ and monomer $\left(\mathrm{f}_{\mathrm{MA}}\right)$ composition, calculated from computed reactivity ratios for MA/MMA systems compared to literature ratios for penulmate and terminal models.

Figure 5.4 Relationship between rate of copolymerization ( $\left.\mathrm{k}_{\mathrm{p} \text { cop }}-\mathrm{L} / \mathrm{mol}-\mathrm{s}\right)$ and monomer $\left(\mathrm{f}_{\mathrm{St}}\right)$ composition, calculated from computed reactivity ratios for MA/St system compared to literature ratios for the penultimate model and terminal model

Figure A1 Comparison of St/AMS system with MA/MMA system reactions 


\section{List of Tables}

Table 2.1 Arrhenius $k_{p}$ parameters for various monomers determined by PLP-SEC. ${ }^{a}$

Table 2.2 Monomer reactivity ratios of different monomers reacting with Styrene.

Table 2.3 Effect of level of theory on calculated $\mathrm{E}_{\mathrm{a}}$ and $\Delta \mathrm{H}_{\mathrm{r}}$ for the addition of a methyl radical to ethylene. The basis sets are $6-31 \mathrm{G}(\mathrm{d})$.

Table 2.4 Experimental Enthalpies of formation for isolated atoms from table provided by Curtis ${ }^{(42)}$ in $\mathrm{kcal} / \mathrm{mol}$.

Table 2.5 Notations used for the group contribution concept

Table 3.1 Reproducibility of Gaussian values for Ethylene addition to a methyl radical

Table 3.2 Estimated heats of formation for MA using different methods.

Table 4.1 Calculated $-\Delta H_{r}(\mathrm{~kJ} / \mathrm{mol})$ and reactivity ratios (in brackets) for monomer addition to monomeric radicals compared to literature values for polymer systems. ${ }^{\text {a,b }}$

Table 4.2 The effect of radical chain length on computed $-\Delta H_{r}(\mathrm{~kJ} / \mathrm{mol})$ values for homopropagation of methyl acrylate (MA).

Table 4.3 Calculated $-\Delta H_{r}(\mathrm{~kJ} / \mathrm{mol})$ and monomer reactivity ratios for styrene (S) 66 copolymerized with methyl acrylate (MA) and methyl methacrylate (MMA), compared to literature values for polymer systems.

Table 4.4 Calculated $\mathrm{E}_{\text {est }}(\mathrm{kJ} / \mathrm{mol})$ and reactivity ratios (in brackets) for monomer addition to PEst* and EEst* compared to literature values from Fischer and Radom's work.

Table 4.5 Calculated $-\Delta H_{r}(\mathrm{~kJ} / \mathrm{mol})$ for different monomer addition to different monomeric radicals with varying pendant groups. 
Table 4.6 Experimental reactivity ratio data for different BA (1) methacrylate (2) 78 copolymerization systems showing the effect of change in pendant groups. ${ }^{30}$

Table 5.1 Calculated $-\Delta H_{r}(\mathrm{~kJ} / \mathrm{mol})$ and reactivity ratios ( $r$ and $s$ in brackets) for 87 monomer addition to dimeric radicals compared to literature values for polymer systems.

Table 5.3 Calculated $-\Delta H_{r}(\mathrm{~kJ} / \mathrm{mol})$ and reactivity ratios for monomer addition to $\sim$ MA midchain radical and $\sim$ MA endchain radical ( $\sim$ MA represents a trimeric species)

Table A1 Calculation of heats of formation and heats of reaction using Group Additivity for S/AMS system.

Table A2 Monomer reactivity ratios and radical reactivity values for S/AMS, 110 calculated at $323 \mathrm{~K}$

Table A4 Monomer reactivity ratios and penultimate unit effect for MA/MMA, 114 calculated at $298.15 \mathrm{~K}$ 


\section{List of Schemes}

Scheme 2.1 Basic free radical homopolymerization mechanism.

Scheme 2.2 High temperature side reactions in acrylate polymerization.

Scheme 3.1 Monomer addition to a monomeric radical for a copolymerization reaction.

Scheme 3.2 Monomer addition to dimeric radical for styrene and $\alpha$-methyl styrene copolymerization. (all $\Delta \mathrm{H}$ values are in $\mathrm{kcal} / \mathrm{mol}$ )

Scheme 5.1 MA midchain radicals reacting with different monomers of varying structure.

Scheme A1 Monomer addition to a monomeric radical for Styrene and $\alpha$-methyl 109 styrene copolymerization. ( $\Delta \mathrm{H}$ values are in $\mathrm{kcal} / \mathrm{mol}$ )

Scheme A2 Monomer addition to dimeric radical for styrene and $\alpha$-methyl styrene copolymerization. (all $\Delta \mathrm{H}$ values are in $\mathrm{kcal} / \mathrm{mol}$ )

Scheme A3 Monomer addition to dimeric radical for methyl acrylate and methyl 113 methacrylate copolymerization. (all $\Delta \mathrm{H}$ values are in $\mathrm{kcal} / \mathrm{mol}$ ) 


\section{Nomenclature}

\begin{tabular}{|c|c|c|}
\hline Symbol & Units & Definition \\
\hline$\overline{A A}$ & & Frequency pre-exponential factor \\
\hline AM1 & & Austin Model 1 \\
\hline AMS & & $\alpha$-Methyl Styrene \\
\hline AN & & Acrylonitrile \\
\hline BA & & $n$-butyl acrylate \\
\hline BMA & & n-butyl methacrylate \\
\hline B3LYP & & Becke 3 parameters and the Lee Yang Parr functionals \\
\hline DFT & & Density Functional Theory \\
\hline DMF & & Di-methyl formate \\
\hline$D_{n}$ & & Dead polymer of length $n$ \\
\hline$D P_{n}$ & & Number average degree of polymerization \\
\hline$E_{a}$ & $\mathrm{~kJ} / \mathrm{mol}$ & Activation energy \\
\hline$E_{0}$ & $\mathrm{~kJ} / \mathrm{mol}$ & Intrinsic barrier to reaction \\
\hline$E_{e l}$ & $\mathrm{~kJ} / \mathrm{mol}$ & Sum of electronic zero-point Energies-zero-point correction \\
\hline $\mathrm{E}-\mathrm{P}$ & & Evans-Polanyi Relationship \\
\hline EPUE & & Explicit penultimate unit effect \\
\hline$f$ & & Initiator decomposition efficiency \\
\hline$f_{i}$ & & Mole fraction of monomer $i$ \\
\hline$F_{i}$ & & Instantaneous polymer composition $i$ \\
\hline GA & & Group additivity \\
\hline GMA & & Glycidyl methacrylate \\
\hline GPC & & Gel permeation chromatography \\
\hline$\Delta G_{p}$ & $\mathrm{~kJ} / \mathrm{mol}$ & Total free energy change of the reaction \\
\hline HEA & & Hydroxyethyl acrylate \\
\hline HEMA & & Hydroxyethyl methacrylate \\
\hline $\mathrm{HF}$ & & Hartree-Fock \\
\hline $\mathrm{HO}$ & & Harmonic oscillator \\
\hline
\end{tabular}


HR

$\mathrm{H}_{\text {therm }}$

$\Delta H_{r}$

$\Delta H_{p}$

I

$I^{*}$

$k_{11}, k_{22}$

$k_{d}$

$k_{\text {dep }}$

$k_{p_{i j}}$

$k_{p}$

$k_{p, c o p o}$

$k_{t}$

$k_{t r, M}$

$k_{t r, s}$

$\mathrm{LCH}$

$[M]$

$\mathrm{M}^{*}$

$M_{i}$

MA

MEA

MMA

PLP

$P_{n}$

$P_{n}^{i \bullet}$

$q$

$q_{r o t}$
Hindered rotor

$\mathrm{kJ} / \mathrm{mol} \quad$ Ethalpy

$\mathrm{kJ} / \mathrm{mol} \quad$ Enthalpy change of reaction

$\mathrm{kJ} / \mathrm{mol} \quad$ Homopolymerization heat of reaction

Initiator

Primary radical species

$L / \mathrm{mol} \cdot \mathrm{s} \quad$ Propagation rate constant for monomer 1 and monomer 2

$1 / s$

Coefficient of Decomposition

$1 / s$

Depropagation rate constant

$L / \mathrm{mol} \cdot \mathrm{s} \quad$ Propagation rate coefficient for addition of monomer $j$ to radical $i(i, j=1,2)$

$L / \mathrm{mol} \cdot \mathrm{s} \quad$ Rate coefficient for chain propagation

$L / \mathrm{mol} \cdot \mathrm{s} \quad$ Average propagation rate constant in copolymerization

$L / m o l \cdot s \quad$ Termination rate coefficient

$L / m o l \cdot s \quad$ Transfer rate coefficient to monomer

$L / \mathrm{mol} \cdot \mathrm{s} \quad$ Transfer rate coefficient to solvent

Long Chain Hypothesis

$\mathrm{mol} / \mathrm{L} \quad$ Monomer concentration

Monomer radical

Monomer $i(i=1,2)$

Methyl acrylate

Methyl ethacrylate

Methyl methacrylate

Pulsed laser polymerization

Growing Polymer Radicals

Polymeric radical $i$ with chain length $n$

Partition function

Rotational partition function 


\begin{tabular}{|c|c|c|}
\hline$q_{\text {trans }}$ & & Translational partition function \\
\hline$q_{v i b}$ & & Vibrational partition function \\
\hline QSSA & & Radical stationarity or the quasi-steady state assumption \\
\hline $\mathrm{R}$ & & Universal Gas Constant \\
\hline$r_{1}, r_{2}$ & & Monomer reactivity ratios \\
\hline$R_{\text {init. }}$ & & Net formation of polymeric radical \\
\hline$R_{\text {init }}+R_{t r}$ & & The total rate of polymer radical formation \\
\hline$R_{p o l}$ & & Rate of polymerization \\
\hline$R_{p}$ & & Rate of propagation \\
\hline$S$ & & Transfer agent \\
\hline$s_{1}, s_{2}$ & & Radical reactivity ratios \\
\hline SEC & & Size Exclusion Chromatography \\
\hline $\mathrm{St}$ & & Styrene \\
\hline$\Delta S$ & $\mathrm{~J} / \mathrm{mol} \cdot \mathrm{K}$ & Entropy change \\
\hline$T$ & $K$ & Temperature \\
\hline TCE & & Enthalpy correction to enthalpy \\
\hline THF & & Tetrahydrofuran \\
\hline UFF & & Unrestricted Force Fields \\
\hline VOC & & Volatile Organic Content \\
\hline VAc & & Vinyl acetate \\
\hline $\mathrm{ZPE}$ & $\begin{array}{l}\text { Hartrees/ } \\
\text { Particle }\end{array}$ & Zero-point energy \\
\hline$\alpha$ & & Reaction transfer coefficient \\
\hline$\Psi$ & & Wave function \\
\hline$\varepsilon_{0}$ & hartrees & Sum of electronic and zero-point Energies \\
\hline$\delta$ & & Fraction of termination events that occur by disproportion \\
\hline
\end{tabular}




\section{Chapter 1 \\ Introduction}

Automobile coatings have evolved greatly from the 1900s, when the polymer binders were based on oleoresinous material, to currently, where the coatings have much improved stability against mechanical and chemical attack as well as excellent appearance. However the industry is still continuously undergoing changes in technology due to pressure from raw material prices and increasingly stringent environmental demands. ${ }^{1}$

The binder component in many coatings formulations is a complex copolymer of styrene, acrylates and methacrylates, with the monomers selected to provide a balance of properties important for application as well as end-use properties. These resins are produced by free-radical polymerization, well known for being a reliable, cost-effective method of polymer synthesis preferred among polymer manufacturers because it does not require expensive monomer and/or solvent purification. ${ }^{2}$ Due to environmental regulations (Volatile Organic Content (VOC) control) these solventborne resins are produced with low solvent and high polymer content and low molecular weight, achieved with high amounts of initiator and high polymerization temperatures under semi-batch starved feed conditions. ${ }^{3}$

Even though there are a wide variety of production recipes for many different types of resins in use today, new resins are still being designed with minimal consideration of the 
process; the main focus is on the properties of the final product. The typical synthetic approach is tailored to ensure that the final resin has an average chain length of less than 100 monomeric units. ${ }^{1}$ It is also essential that all chains contain sufficient functionality to take part in cross-linking reactions that are needed to form a tough and durable coating. A rather conservative method of operation and control ${ }^{4}$ is adopted because there is insufficient knowledge of the kinetics of the complex reactions due to the difficulty in characterizing multimonomer polymer structure and the absence of effective on-line measurement. Most resins are currently produced at high temperatures $\left(>120{ }^{\circ} \mathrm{C}\right)$, promoting the occurrence of side reactions that influence polymerization rate and polymer structure, but are difficult to study experimentally. Important mechanisms to consider include methacrylate depropagation $^{5}$ and acrylate chain branching and scission. ${ }^{6}$ These complex reactions have only recently been addressed in the extant models of multi-component free radical polymerization. Li et al. ${ }^{7,8,9}$ also showed that these models are easy to adapt for similar multicomponent polymerization systems.

The general problem is made even more difficult by the large number monomers used in industrial recipes today. Recent studies ${ }^{10}$ done with advanced and improved experimental techniques, have greatly improved the general understanding of free radical polymerization and indicate that polymerization kinetic coefficients follow generalized behaviour related to monomer structure. In addition, great advances in computational approaches have occurred. This study seeks to develop a methodology to estimate unknown rate coefficients of acrylic based systems. 
The software package Gaussian is used to calculate heats of reaction $\left(\Delta H_{\mathrm{r}}\right)$ values for monomer additions to monomeric and dimeric radicals, using minimum energy structures identified and characterized for the reactants and products. The Evans-Polanyi relationship is applied to estimate reactivity ratios from the relative differences in $\Delta H_{\mathrm{r}}$. The validity of this methodology is tested through a comparison of calculated monomer and radical reactivity ratios for acrylate, methacrylate, vinyl acetate, ethene and styrene systems to available experimental data for copolymerization systems. Systems that have computational challenges are identified and successes and limitations of the techniques are outlined. 


\section{Chapter 2 \\ Literature Review}

Free radical polymerization (FRP) is one of the most important commercial processes for preparing polymers of different properties. It can be applied to almost all vinyl monomers under mild reaction conditions over a wide temperature range and, although requiring the absence of oxygen, is tolerant of water. Multiple monomers can be easily copolymerized via FRP, leading to the preparation of an endless range of copolymers with properties dependent on the proportion of the incorporated comonomers. This chapter provides a brief overview of free-radical polymerization kinetic mechanisms and kinetics, and computational chemistry. Literature applying computational techniques for the estimation of rate coefficients is also reviewed, to provide a proper context for the current project.

\subsection{Free Radical Polymerization Kinetics and Mechanisms}

The basic free radical polymerization mechanisms - initiation, propagation, termination, and transfer to monomer and solvent or transfer agent - are shown in Scheme 2.1.

Subscript $n$ is the number of monomeric units in growing polymer radicals $\left(P_{n}\right)$ and dead polymer chains $\left(D_{n}\right)$. The initiator $(I)$ forms two primary radicals $\left(I^{*}\right)$ on decomposition with an efficiency $f$ and rate coefficient $k_{d}$. When the primary radical adds to monomer $M$, chain initiation occurs and the addition of more monomer units to the radical occurs rapidly via chain propagation, with rate coefficient $k_{p}$. When two growing chains meet, 
termination occurs either by combination or dispropotionation. (The rate coefficients for the two reactions are $k_{t c}$ for the former and $k_{t d}$ for the latter.) Chain growth can also be stopped by transfer reactions, where there can be hydrogen abstraction from monomer or other molecules (solvent or chain-transfer agent, represented by $S$ ) in the system to form a dead polymer chain and a new radical that starts another chain propagation reaction. (The rate coefficients for the reactions are given by ${k_{t r}}^{\text {mon }}$ and $k_{t r}{ }^{\text {sol }}$ respectively.)

$$
\begin{array}{ll}
\text { Initiator Decomposition } & I \stackrel{k_{d}}{\longrightarrow} 2 f I^{*} \\
\text { Chain Initiation } & I^{*}+M \stackrel{k_{i}}{\longrightarrow} P_{1} \\
\text { Chain Propagation } & P_{n}+M \stackrel{k_{p}}{\longrightarrow} P_{n+1} \\
\text { Chain Termination } & \\
\quad & P_{n}+P_{m} \stackrel{k_{t c}}{\longrightarrow} D_{n+m} \\
\quad & P_{n}+P_{m} \stackrel{k_{t d}}{\longrightarrow} D_{n}+D_{m} \\
\text { By Combination } & \\
\text { Chain Transfer } & P_{n}+M \stackrel{k_{t r}^{\text {mon }}}{\longrightarrow} D_{n}+M^{*} \\
\quad & M^{*}+M \stackrel{k_{i}^{\text {mon }}}{\longrightarrow} P_{1} \\
\quad & P_{n}+S \stackrel{k_{t r}^{s o l}}{\longrightarrow} D_{n}+S^{*} \\
\quad & S^{*}+M \stackrel{k_{i}^{s o l}}{\longrightarrow} P_{1}
\end{array}
$$

Scheme 2.1 Basic free radical homopolymerization mechanism

The set of rate laws that can be written from Scheme 2.1 is as follows:

$$
\begin{array}{ll}
\text { Initiator Decomposition } & R_{d}=k_{d}[I] \\
\text { Chain Initiation } & R_{\text {init }}=2 f k_{d}[I] \\
\text { Chain Propagation } & R_{p}=k_{p}[M]\left[P_{t o t}\right]
\end{array}
$$


Chain Termination

Chain Transfer

$$
R_{\text {term }}=\left(k_{t c}+k_{t d}\right)\left[P_{t o t}\right]^{2}=k_{t}\left[P_{t o t}\right]^{2}
$$

$$
R_{t r}=\left(k_{t r}^{m o n}[M]+k_{t r}^{s o l}[S]\right)\left[P_{t o t}\right]
$$

where $P_{t o t}$ represents the concentration of all polymer radicals in the system:

$$
\left[P_{\text {tot }}\right]=\sum_{n=1}^{\infty}\left[P_{n}\right]
$$

Whether termination occurs by combination or disproportionation has no effect on the overall termination rate, and therefore the following nomenclature gives an expression of the two events:

$$
k_{t}=k_{t c}+k_{t d} ; \quad \delta=\frac{k_{t d}}{k_{t c}+k_{t d}}
$$

where $\delta$ is the fraction of the termination events that occur by disproportionation.

There are assumptions that are widely accepted and usually valid in FRP systems, these being:

- The small radical species $I^{*}, M^{*}$, and $S^{*}$ are converted to polymeric radicals with $100 \%$ efficiency. These do not accumulate in the system and are not consumed by side-reactions, hence, the total rate of polymer radical formation is given by $\left(R_{\text {init }}+\right.$ $\left.R_{t r}\right)$ Transfer events both consume and create a polymeric radical species and therefore the net formation of polymeric radicals is $R_{\text {init }}$.

- An equilibrium is achieved instantaneously between radical generation and consumption, such that $R_{\text {init }}=R_{\text {term }}$. This is often referred to as radical stationarity or the quasi-steady-state assumption (QSSA), it leads to the well-known analytical expression for total radical concentration: 


$$
\left[P_{\text {tot }}\right]=\left(\frac{R_{\text {init }}}{k_{t}}\right)^{1 / 2}=\left(\frac{2 f k_{d}[I]}{k_{t}}\right)^{1 / 2}
$$

- Monomer is consumed by chain-initiation, transfer events or propagation. The former two processes are negligible compared to the latter. This is called the long-chain hypothesis $(\mathrm{LCH})$, and it must be true if high molecular weight polymer is being produced. Thus the rate of polymerization (disappearance of monomer) can be taken as equal to the rate of propagation $\left(R_{p o l}=R_{p}\right)$ with the rate of heat generation proportional to the reaction.

Under these (generally valid) assumptions, the classic expressions for rate of polymerization $\left(R_{p o l}\right)$, kinetic chain length $(v$, the average number of monomer units on a living chain), and instantaneous degree of polymerization $\left(\mathrm{DP}_{\mathrm{n}}{ }^{\text {inst }}\right.$, the average number of monomer units on a dead polymer chain formed at any instant) are:

$$
\begin{gathered}
R_{p o l}=k_{p}[M]\left[P_{t o t}\right]=k_{p}[M]\left(\frac{2 f k_{d}[I]}{k_{t}}\right)^{1 / 2} \\
v=\frac{R_{p}}{R_{t e r m}+R_{t r}}=\frac{k_{p}[M]}{k_{t}\left[P_{t o t}\right]+k_{t r}^{\text {mon }}[M]+k_{t r}^{s o l}[S]} \\
\mathrm{DP}_{\mathrm{n}}^{\text {inst }}=\frac{k_{p}[M]}{\left(k_{t d}+0.5 k_{t c}\right)\left[P_{t o t}\right]+k_{t r}^{m o n}[M]+k_{t r}^{s o l}[S]}
\end{gathered}
$$

Termination by combination yields a single polymer chain such that the chain length of dead polymer formed $\left(\mathrm{DP}_{\mathrm{n}}{ }^{\text {inst }}\right)$ is greater than the chain length of polymer radicals $(v)$ in the system at the same instant and a difference arises between Eqs 2.10 and 2.11. 
With the advent of pulsed laser assisted techniques, propagation rate coefficients are fairly well known for many monomers like styrene, methacrylates and acrylates. ${ }^{10}$ Termination and transfer coefficients are available but less precisely known as can be seen by looking in the Polymer Handbook, ${ }^{12}$ where even for the same polymerization conditions there is a significant scatter in the data for common monomers such as styrene and methyl methacrylate. Secondary reactions and many copolymerization parameters are even less well known and hence the focus of this report.

Table 2.1 Arrhenius $k_{p}$ parameters for various monomers determined by PLP-SEC. ${ }^{10,21}$

\begin{tabular}{lllll}
\hline Monomer & $\begin{array}{l}E_{p} \\
(\mathrm{~kJ} / \mathrm{mol})\end{array}$ & $\begin{array}{l}\Delta V_{p} \\
\left(\mathrm{~cm}^{3} / \mathrm{mol}\right)\end{array}$ & $\begin{array}{l}A_{p} \\
(\mathrm{~L} / \mathrm{mol} \cdot \mathrm{s})\end{array}$ & $\begin{array}{l}k_{p} \text { at } 50{ }^{\circ} \mathrm{C} \& \\
1 \mathrm{~atm}(\mathrm{~L} / \mathrm{mol} \cdot \mathrm{s})\end{array}$ \\
\hline Ethylene & 34.3 & -27.0 & $1.88 \times 10^{7}$ & 54 \\
Styrene & 32.5 & -12.1 & $4.27 \times 10^{7}$ & 238 \\
Methyl methacrylate & 22.4 & -16.7 & $2.67 \times 10^{6}$ & 648 \\
Butyl methacrylate & 22.9 & -16.5 & $3.78 \times 10^{6}$ & 757 \\
Dodecyl methacrylate & 21.0 & -16.0 & $2.50 \times 10^{6}$ & 995 \\
Glycidyl methacrylate & 22.9 & -15.0 & $6.19 \times 10^{6}$ & 1230 \\
Cyclohexyl & 23.0 & -16.2 & $6.29 \times 10^{6}$ & 1204 \\
methacrylate & & & & \\
2-Hydroxypropyl & 20.8 & n.d. & $3.51 \times 10^{6}$ & 1504 \\
methacrylate & & & & \\
Vinyl acetate & 20.7 & -10.7 & $1.47 \times 10^{7}$ & 6625 \\
Methyl acrylate & 17.7 & -11.7 & $1.66 \times 10^{7}$ & 22,900 \\
Butyl acrylate & 17.4 & n.d. & $1.81 \times 10^{7}$ & 27,900 \\
Dodecyl acrylate & 17.0 & -11.7 & $1.79 \times 10^{7}$ & 32,000 \\
\hline
\end{tabular}

Table 2.1 shows a summary of experimental $k_{p}$ results as measured by Pulsed Laser Polymerization (PLP)/Size Exclusion Chromatography (SEC) technique. The family behaviour observed (eg. all methacrylates have very similar values for activation energies and values) suggest it may be possible to correlate rate coefficients to the structural 
characteristics of the propagating radicals and monomers. A discussion of how the kinetics of copolymerization is affected by monomer and radical structure is presented in Section 2.3.

\subsubsection{Secondary Mechanisms}

Scheme 2.1 describes the basic mechanisms common to all radical polymerizations.

However, other reactions are known to occur in polymerizations conducted at higher reaction temperatures. These side reactions can be very important and greatly influence the rate of polymerization and the polymer structure. Some of the reactions that are relevant to high temperature polymerization are shown in Scheme 2.2, as written for methyl acrylate (MA).

1)
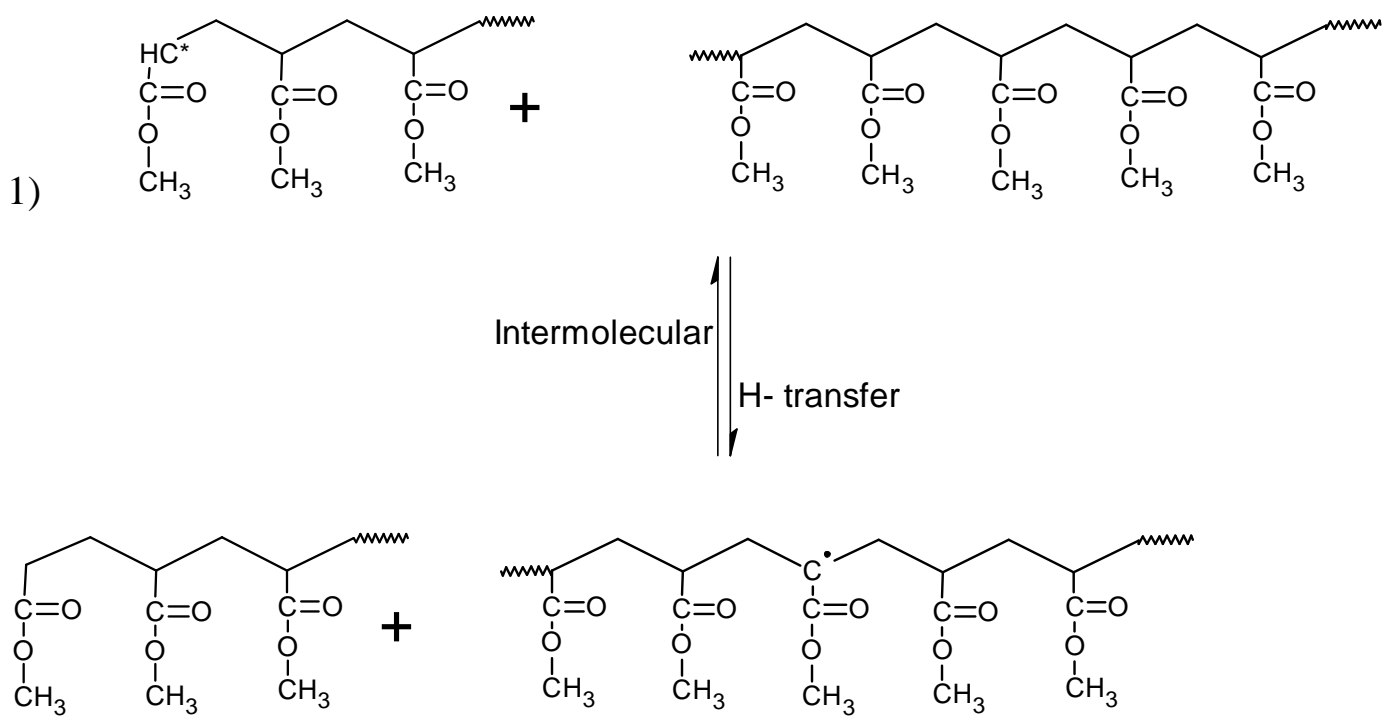
2)
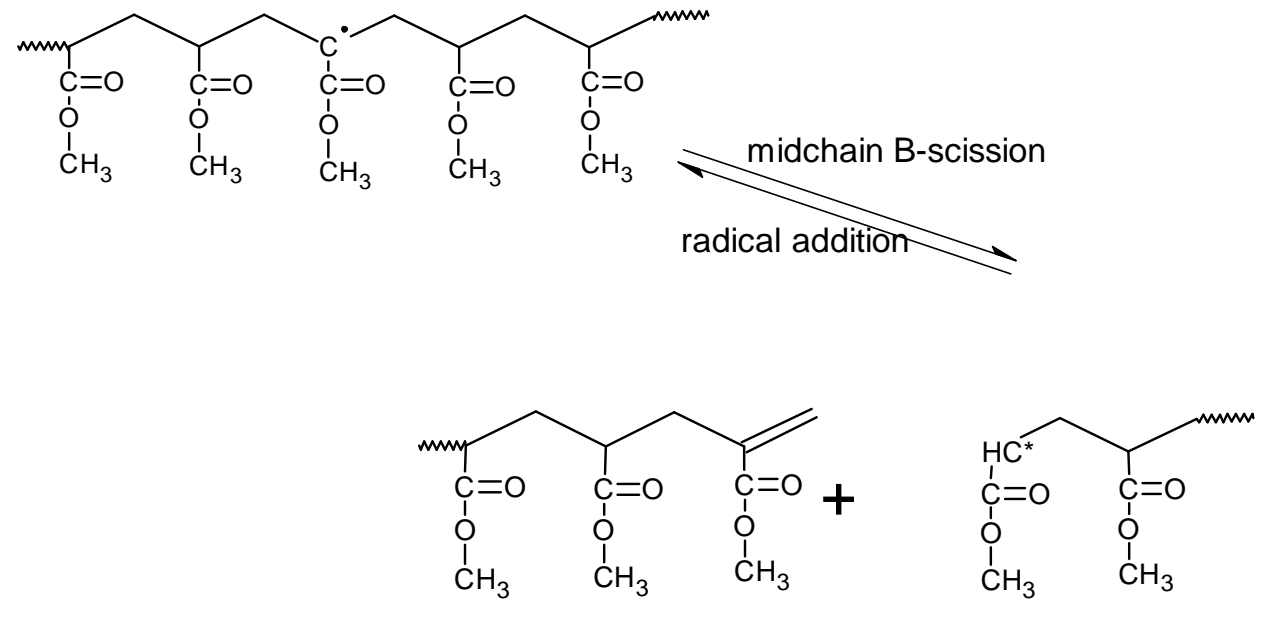

3)
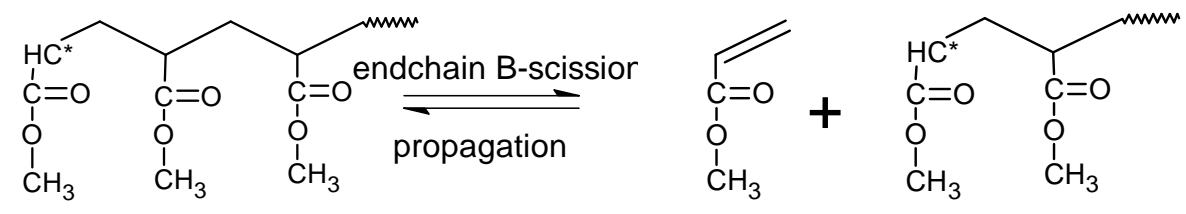

4)
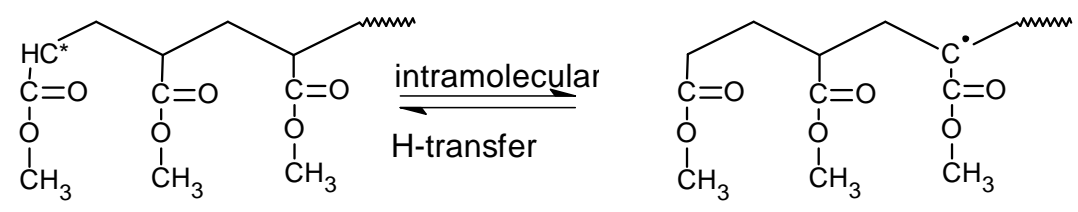

Scheme 2.2 High temperature side reactions in acrylate polymerization. 
Reactions 1 and 4 in Scheme 2.2 show intermolecular and intramolecular H-atom transfer, respectively. The radical abstracts a $\mathrm{H}$-atom from the polymer chain in the case of reaction 1 and in the case of reaction 4 the radical abstracts a pendant $\mathrm{H}$-atom on the $\delta$ carbon leaving a radical on that carbon. The rate of chain transfer to polymer will depend on both the reactivity of the radical and the ease with which the hydrogen atom can be abstracted from the unit in the polymer chain. For the case of copolymerization intramolecular chain transfer, the situation is more complicated; in acrylate/methacrylate systems, it can be assumed that the methacrylate radical is not reactive enough to backbite and that the acrylate radical can only abstract hydrogen if the pen-penultimate unit on the chain is also an acrylate unit. ${ }^{4}$

Reactions 2 and 3 involve $\beta$ scission. Scission occurs at the $\beta$ carbon to yield an alkene and another radical as products. The radical can continue to react with another monomer unit, and the alkene product is also reactive. Scission events are more important at elevated temperatures as they are known to have a high activation energy. Reaction 3 (depropagation) is important for methacrylates but not for acrylates.

It is evident that good process and product design requires a thorough knowledge of these reactions and the relationship between monomer/radical structure and the kinetics. 


\subsubsection{Copolymerization Propagation Kinetics}

Copolymerization models are used to predict the overall propagation rate of a free radical reaction involving multiple monomers, and the composition and microstructure of the resulting copolymer as a function of the feed ratio of the comonomers and a small set of characteristic parameters. To derive such models, it is necessary to characterize the rates of the different types of propagation reactions that may occur in a given copolymerization system. In theory, this task might seem impossible because countless different types of propagating radicals (differing in their chain lengths, composition, and microstructure) are likely to be present in any given copolymerization. Assumptions are made as to the factors that influence the rate of the propagation step, thereby reducing the number of types of reactions to be considered and hence simplifying the task of rate characterization. It has been found that generally, the copolymer composition and sequence are well described by the terminal model of monomer addition, of which the main assumption is that only the chain-end propagating radicals influence its reactivity. ${ }^{13}$ In the early studies of copolymerization, the terminal model was developed and widely used because of its ability to describe copolymer composition. In 1944 Mayo and Lewis ${ }^{14}$ along with Alfrey and Goldfinger, ${ }^{15}$ based on the terminal model, developed the polymer composition equation and introduced the concept of monomer reactivity ratios. The assumptions for this development are:

1 The activity of radicals is independent of chain length. 
2 The penultimate unit on the growing radical does not influence the radical activity.

3 There is no depropagation reaction during the polymerization reaction.

4 The degree of polymerization is significantly large such that initiation and termination does not influence the polymer composition. This assumption is known as the long chain hypothesis, $\mathrm{LCH}$.

5 Steady state assumption, also known as quasi-steady-state assumption, QSSA: Radical lifetime is short so that an equilibrium rate is instantaneously reached between radical generation and consumption, such that the transformation of radical 1 to radical 2 is equal to the rate of transformation of radical 2 to radical 1. Addition of monomer- $j$ to a growing polymeric chain ending in radical- $i$ is described by rate coefficient $k_{p_{i j}}$ :

$$
P_{n}^{i}+M_{j} \stackrel{k_{p_{i j}}}{\longrightarrow} P_{n+1}^{j}
$$

Taking into consideration a monomer mix of two components $\mathrm{M}_{1}$ and $\mathrm{M}_{2}$ and the four different reactions that can take place at the reactive chain end terminating in either monomer $\left(\mathrm{M}^{*}\right)$ with their reaction rate constants $k$ : 


$$
\begin{aligned}
& M_{1}^{*}+M_{1} \stackrel{k_{p 11}}{\longrightarrow} M_{1} M_{1}^{*} \\
& M_{1}^{*}+M_{2} \stackrel{k_{p 12}}{\longrightarrow} M_{1} M_{2}^{*} \\
& M_{2}^{*}+M_{1} \stackrel{k_{p 21}}{\longrightarrow} M_{2} M_{1}^{*} \\
& M_{2}^{*}+M_{2} \stackrel{k_{p 22}}{\longrightarrow} M_{2} M_{2}^{*}
\end{aligned}
$$

and with reactivity ratios defined as

$$
r_{1}=k_{p_{11}} / k_{p_{12}} \text { and } r_{2}=k_{p_{22}} / k_{p_{21}}
$$

the copolymer equation is given as:

$$
\frac{d\left[M_{1}\right]}{d\left[M_{2}\right]}=\frac{\left[M_{1}\right]\left(r_{1}\left[M_{1}\right]+\left[M_{2}\right]\right)}{\left[M_{2}\right]\left(\left[M_{1}\right]+r_{2}\left[M_{2}\right]\right)}
$$

or

$$
F_{1}^{i n s t}=\frac{r_{1} f_{1}^{2}+f_{1} f_{2}}{r_{1} f_{1}^{2}+2 f_{1} f_{2}+r_{2} f_{2}^{2}}
$$

with the concentration of the components given in square brackets (equation 2.13), $f_{i}$ being the mole fraction of monomer $i\left(\right.$ e.g., $\left.f_{1}=\left\{\left[\mathrm{M}_{1}\right] /\left(\left[\mathrm{M}_{1}\right]+\left[\mathrm{M}_{2}\right]\right)\right\}\right)$ and $F_{l}{ }^{\text {inst }}$ the mole fraction of repeat unit 1 in the polymer at that instant (equation 2.14). This Mayo-Lewis equation can be used to estimate $r_{1}$ and $r_{2}$ by measuring polymer composition as a function of monomer composition. Knowledge of these ratios allows the prediction and control of the polymer composition by manipulating composition of the monomer mixture. 
The copolymer-averaged propagation rate coefficient derived by the terminal model is expressed by the equation:

$$
k_{p, \text { copo }}=\frac{r_{1} f_{1}^{2}+2 f_{1} f_{2}+r_{2} f_{2}^{2}}{\left[r_{1} f_{1} / k_{p 11}\right]+\left[r_{2} f_{2} / k_{p 22}\right]}
$$

where

$$
R_{p o l}=k_{p, c o p o}\left(\left[M_{1}\right]+\left[M_{2}\right]\right)\left(\left[M_{1}^{*}\right]+\left[M_{2}^{*}\right]\right)
$$

Obviously, the polymer composition is only a function of reactivity ratios while the average propagation rate coefficient is a function of all four individual propagation coefficients.

Although generally providing a good description of copolymer composition, the terminal model does not adequately represent polymerization rate, without introduction of physically unrealistic cross-termination reaction rates. ${ }^{16}$ However, Fukuda et al. ${ }^{13}$ show that these rate deviations result from the failure of the terminal model to explain the propagation kinetics, not from the application of diffusion controlled termination reactions. A model that gives a good description of the influence of the penultimate monomer unit in the growing chain on the kinetics of monomer addition has been developed. ${ }^{11,13,17}$ In this model, the radical reactivity is also affected by the identity of the unit next to the terminal radical. Accordingly, propagation in a two-monomer system is represented by eight addition reactions. 


$$
P_{n}^{i j}+M_{k} \stackrel{k_{p_{i j k}}}{\longrightarrow} P_{n+1}^{j k}
$$

The rate coefficient is given by $k_{p_{i j k}}$ for the reaction of radical $P_{n}^{i j}$ with monomer $M_{k}$.

The reactivity ratios are defined by the following equations:

$$
\begin{gathered}
r_{11}=k_{p_{111}} / k_{p_{112}} \\
r_{12}=k_{p_{122}} / k_{p_{121}} \\
r_{21}=k_{p_{211}} / k_{p_{212}} \\
r_{22}=k_{p_{222}} / k_{p_{221}} \\
s_{1}=\frac{k_{p_{211}}}{k_{p_{111}}} \quad s_{2}=\frac{k_{p_{122}}}{k_{p_{222}}}
\end{gathered}
$$

The parameters $s_{1}$ and $s_{2}$, called radical reactivity ratios, reflect the effect of the penultimate unit on the addition rate of monomer. A value of greater than unity for $s_{i}$ means that a comonomer unit- $j$ in the penultimate position facilitates the addition of monomer- $i$ to radical- $i$ compared to the homopolymerization case. Based on this penultimate unit model, Fukuda et al. ${ }^{13}$ deduced the ratio of the consumption of $\mathrm{M}_{1}$ and $\mathrm{M}_{2}$ thereby giving the instantaneous polymer composition as:

$$
F_{1}=\frac{\bar{r}_{1} f_{1}^{2}+f_{1} f_{2}}{\bar{r}_{1} f_{1}^{2}+2 f_{1} f_{2}+\bar{r}_{2} f_{2}^{2}}
$$

The average propagation rate coefficient in copolymerization penultimate model is:

$$
k_{p . \text { copo }}=\frac{\overline{r_{1}} f_{1}^{2}+2 f_{1} f_{2}+\overline{r_{2}} f_{2}^{2}}{\left(\frac{\overline{r_{1}} f_{1}}{\overline{k_{11}}}\right)+\left(\frac{\overline{r_{2}} f_{2}}{\overline{k_{22}}}\right)}
$$


where, $\bar{r}_{1}$ and $\bar{r}_{2}, \overline{k_{11}}$ and $\overline{k_{22}}$ are functions of the feed composition, ${ }^{13}$ and defined as:

$$
\begin{array}{ll}
\overline{r_{1}}=\frac{r_{21}\left(f_{1} r_{11}+f_{2}\right)}{f_{1} r_{21}+f_{2}} & \overline{r_{2}}=\frac{r_{12}\left(f_{2} r_{22}+f_{1}\right)}{f_{2} r_{12}+f_{1}} \\
\overline{k_{11}}=\frac{k_{111}\left(r_{11} f_{1}+f_{2}\right)}{r_{11} f_{1}+\left(f_{2} / s_{1}\right)} & \overline{k_{22}}=\frac{k_{222}\left(r_{22} f_{2}+f_{1}\right)}{r_{22} f_{2}+\left(f_{1} / s_{2}\right)}
\end{array}
$$

As previously mentioned, the terminal model is capable of representing polymer composition but not reaction rate, leading to the development of the so-called "implicit penultimate unit effect" (IPUE) model. In the IPUE, both the terminal and penultimate units of the polymer radical are assumed to affect radical reactivity, as represented by the radical reactivity ratios. The magnitude of the penultimate unit effect, however, is independent of the identity of the reacting monomer and thus does not affect the selectivity of the radical, solely determined by the terminal unit such that $r_{11}=r_{21}$ and $r_{12}=r_{22}$. It has been shown that most copolymerization systems are best represented by the implicit penultimate model. ${ }^{10,13}$ Copolymer composition is still represented by the terminal model (Equation 2.4), but $k_{p, \text { copo }}$ is a function of all six IPUE parameters.

Previous researchers ${ }^{10,18,19,20}$ have demonstrated that copolymerization kinetics and reactivity ratios could be generalized according to family-like behaviour for acrylate/methacrylate systems as well as ethylene /acrylate and ethylene/methacrylate systems. Table 2.2 shows how variation of the ester group substituents affect the reactivity of methacrylates with styrene. 
Table 2.2: Monomer reactivity ratios of different monomers reacting with Styrene(2).

\begin{tabular}{lll}
\hline System & $r_{1}$ & $r_{2}$ \\
\hline MMA $/ \mathrm{St}^{12}$ & $0.42-0.46$ & $0.43-0.47$ \\
$\mathrm{BMA} / \mathrm{St}^{7}$ & $0.30-0.6$ & $0.50-0.9$ \\
$\mathrm{GMA} / \mathrm{St}^{21}$ & $0.56-0.78$ & $0.40-0.44$ \\
$\mathrm{HEMA} / \mathrm{St}^{22}$ & $0.49-0.5$ & 0.4 \\
\hline
\end{tabular}

When MMA reacts with styrene $r_{1} \approx r_{2}$ and an alternating polymer is produced as both values are less than unity. A styrene radical tends to react with itself more than it does with a methacrylate monomer due to steric effects, and because of the electron donating tendencies that renders the monomer less electrophilic. The only difference between the MMA and the BMA molecule is the change in the ester side group on the molecule (COOR) from methyl $\left(\mathrm{CH}_{3}\right)$ to butyl $\left(\mathrm{C}_{4} \mathrm{H}_{9}\right)$. Although these side groups are somewhat further away from the reactive site, they have a tendency to influence the reactivity of the monomer or radical to some extent and hence we see the different monomer reactivity ratios for the two monomers.

Some variations to these general trends are found when functional acrylates or methacrylates are used, such as glycidyl (meth)acrylate (GMA) or 2-hydroxyethyl (meth)acrylate (HEMA). Polar groups affect relative reactivity more compared to alkyl methacrylates. HEMA is electrophilic, with additional electron withdrawal due to the presence of oxygen in the hydroxyl part of the molecule that is attached to the ester group. The electron withdrawal, dominated by the carbonyl in the ester part of the molecule, is enhanced. The same effect is seen for GMA, because of the withdrawal 
tendencies of the oxygen in the cyclic part of the molecule although this might not be as pronounced due to the electron cloud in the ring. It is not obvious which electron effect is dominating in the case of GMA.

Sánchez-chaves et al., ${ }^{22}$ in their study of the copolymerization of HEMA and styrene (St), found that the solvent effects had an influence on the monomer reactivity ratios. Thus, the reactivity ratio of styrene was found to be approximately two times higher in DMF than in bulk, whereas the reactivity ratio of HEMA remained practically unchanged. However, both monomer reactivity ratios hardly changed in toluene. This behavior apparently indicates that when the solvent has a low polarity (toluene), the reactivities of the two radicals are not affected, whereas a solvent with a high polarity (DMF) does not significantly affect the reactivity of the PHEMA radical, but greatly affects the reactivity of the PSt radical. Therefore, the comonomer ratio available for a growing polymer radical may show a solvent effect in polar systems. Studies of composition, overall rate of copolymerization, and rate of conversion for each monomer throughout the whole range of conversion confirmed the validity of the apparent monomer reactivity ratios found in DMF for the HEMA-St system. As such, since solvent effects play a role in influencing the kinetics, experimental results for polar systems might not be comparable with computational results (done for isolated molecules in gas phase). However solvent effects are not important for most monomer ${ }^{12}$ systems and their $r$ values can be compared with computational values. 
Penultimate effects on $k_{p, c o p o}$, have been observed for methacrylate/acrylate, acrylate/styrene and methacrylate/styrene systems as reviewed by Fukuda et al. ${ }^{10}$ and Beuerman and Buback. ${ }^{10}$ Recently, Li et al. ${ }^{8}$ carried out experiments for St/BMA copolymer, over a temperature range of $50-150^{\circ} \mathrm{C}$. At this temperature range there is little depropagation to complicate the system. Using PLP/SEC method, $k_{p, c o p o}$, the copolymeraveraged propagation kinetic rate coefficient was measured. It was shown that penultimate propagation kinetics have a strong effect on the measured $k_{p, c o p o}$. The data obtained for the composition and $k_{p, c o p o}$, are well represented by the penultimate model. The obtained temperature independent radical reactivity ratios show an adequate fit of the strong penultimate effect at elevated temperatures, thus suggesting a strong entropic contribution to the penultimate chain growth kinetics. There is also work in progress in Hutchinson's group, where the penultimate unit effects are being examined for St/GMA system, with similar effects observed.

\subsection{Exploration of Chemistry with electronic Structure methods}

Rate coefficients are generally represented using the Arrhenius equation:

$$
k=A \exp \left(-E_{d} / R T\right)
$$

where $k$ is the reaction rate coefficient, $A$ is the frequency pre-exponential factor, $E_{a}$ the activation energy, $R$ universal gas constant and $T$ the temperature of the reaction. Thermodynamic properties are important parameters as they are the chief input to adsorption coefficients, equilibrium constants and kinetic estimation techniques. 
Quantum mechanical calculations using ab initio methods are used to estimate thermodynamic properties ${ }^{28,29}$ (enthalpy, entropy, free energy etc) which are used to relate molecular structure to reactivity using known relationships. The quantum mechanical calculations utilize the geometry and energy of the reactants and products as well as the transition state in some cases. For this study the transition state will not be considered. Traditionally the reactivities of monomer and radicals have been studied by means of copolymerization data. The computational studies on small radicals can lead to the development of estimation techniques for radical and monomer reactivities using thermodynamic data, capturing the differences in the relative energies between reactants and products. For many free radical reactions it is has been found that a linear relationship exists between the activation energy $E_{a}$ and the enthalpy of reaction $\Delta H_{r}$ for a family of reactions. ${ }^{30}$ This is called the Evans Polanyi Relationship described by the following equation.

$$
E_{a}=\alpha \Delta H+E_{0}
$$

where $\alpha$ is the reaction transfer coefficient and $E_{0}$ is termed the intrinsic barrier to reaction. The Evans Polanyi relationship describes the effect of enthalpic effects on the activation energy and this can be used to calculate monomer reactivity ratios assuming that the frequency factor $A$ for a reaction family is constant for different reactants in the same family. This assumption is due to the fact that the reaction coordinates are similar thus making no change in the entropy of the transition state and reactants of the different reactants. The monomer reactivity ratio therefore becomes a function of only the change in enthalpy. 


\subsubsection{Computational Chemistry Methods}

Exploring chemistry with electronic structure methods can improve understanding of systems that are difficult to study in the laboratory experimentally. The two broad areas of computational chemistry that are devoted to the structure of molecules and their reactivity are molecular mechanics and electronic structure theory. ${ }^{31}$ These compute the energy of particular structures, and predict properties related by performing geometry optimizations to locate the lowest energy molecular structure and computing the vibrational frequencies of molecules resulting from interatomic motion.

Molecular mechanics use the laws of classical physics to predict the structures and properties of molecules and the calculations do not treat the electrons in a molecular system but are based upon the interactions among the nuclei. The inclusion of the electronic effects is through parameterization in force fields. The advantage of this approximation is that it makes the computations inexpensive and useful for very large systems containing many atoms. However, chemical problems where electronic effects are prevalent cannot be treated because of the neglect of the electrons, and good results of each force field are limited to a class of molecules for which the force field is parameterized. 
Electronic structure methods use quantum mechanics for their computations. The basis is that the energy and other related properties of a molecule may be obtained by solving the Schrödinger equation.

$$
\mathrm{H} \Psi=\mathrm{E} \Psi
$$

where, $\mathrm{H}$ is the Hamiltonian operator (corresponding to the total energy of the system), $\mathrm{E}$ is the numerical value of the energy (an eigenvalue), and $\Psi$ is the wave function (an eigenfunction) which depends on the coordinates of all the particles and the spin coordinates in the system. The Schrödinger equation is a numerical eigenvalue problem for which multiple solutions can be found, each characterized by certain wave function and corresponding energy. ${ }^{28}$ The solutions of the Schrödinger equation are called the stationary states and the state with the lowest energy is called the ground state. Stationary states with higher energies correspond to the excited states. This is not particularly important for our purposes in this research, as the ordinary radical addition and transfer reactions involve reactions between molecules in their ground state.

There are two major classes of electronic structure methods and these are semi-empirical methods and ab initio methods. Semi-empirical methods use parameters derived from experimental data to simplify the computation, while the ab initio methods use no experimental data but base their computations solely on the laws of quantum mechanics and on a small number of physical constants such as the speed of light, the mass and charges of electrons and Planck's constant. For both classes there are tradeoffs between computational costs and accuracy. Semi-empirical calculations give reasonably accurate 
qualitative descriptions of molecular systems and quantitative predictions of energy and structures for systems where good parameter sets exist. They are computationally inexpensive. Austin Model 1 (AM1) is one such method that will be utilised in our research. ${ }^{9}$ For some very large molecules, semi-empirical calculations are the only practical quantum mechanical methods that can be applied. In some cases they are used as a first step to obtain a starting structure for a subsequent Hartree- Fock (HF) or Density Functional Theory (DFT) optimization, and in some instances qualitative information about a molecule and energy trends arising from substituent effects can be obtained. $A b$ initio computations give high quality predictions for broad range of systems with no limitation to class. However, the cost is higher, computationally. Among the procedures for obtaining solutions to the Schrödinger equation in the ab initio computations the molecular orbital (MO) theory stands out as this is easily implemented in computational procedures and therefore forms the basis of the majority of theoretical studies. In practice the molecular orbitals are expressed as linear combinations of basis functions. The actual form of the basis functions is based on the form of atomic orbitals obtained analytically for the hydrogen atom and hence they can be defined as $s, p, d, f, \ldots$ type orbitals according to their angular momentum properties. ${ }^{32}$ The Pople- Gaussian basis sets ${ }^{28}$ are frequently used for their simplicity to solve the Schrödinger equation and they give fairly reasonable results. These include the minimal basis sets like STO-3G and the slightly better split valence basis sets like 3-21G and 6-31G. Although these sets do a good job of solving the equation, they can not take into account any distortion from atomic symmetry and hence greater flexibility of the electron movement in the orbitals, is facilitated by 
adding polarization functions, i.e. more orbitals to the basis sets. For example 6-31G becomes $6-31 \mathrm{G}(\mathrm{d})$, which can also be denoted as $6-31 \mathrm{G}^{*}$. Generally the approximate Schrödinger equation solution improves when greater flexibility is given to the electron movement: the bigger the size of the basis set the more accurate the solution but the higher the cost of the computation. However studies have been done to lower computational costs and yet get reliable theoretical results. Gomez-Balderas et al. ${ }^{33}$ in their study for calculating the rate of methyl radical addition to carbon-carbon double and triple bonds found out that the geometry optimization and frequency calculations of reactants, products and transition structures yielded the same results at low and high computational levels. In general the geometries and frequency factors are relatively insensitive to the level of theory. However, the barriers and enthalpies are sensitive to the level of theory and could only be accurately estimated at high levels. More studies by Johnson et al. ${ }^{34}$ and DiLabio et al. ${ }^{35,36}$ show that AM1 seems to be as reasonably accurate as Becke 3 parameters and the Lee Yang Parr functionals ${ }^{37,38}$ (B3LYP) in geometry optimization of molecules. Recent efforts described later in this chapter, suggest that the computational approach provides a valuable tool to investigate the kinetics of polymerization systems for which experimental data are not available, and that different levels of theory can be applied in the approach without jeopardising the results but reducing computational costs. A similar approach is adopted in this work using Gaussian $03 .^{26}$ 
Given the availability of improved computer resources, $a b$ initio molecular orbital methods are the most accurate of all the possible approaches to computing thermo chemical data and will be used in this project. Gaussian was developed with the objective of making it possible to

1) be applicable to any molecular system in a non complicated manner,

2) be computationally efficient so that it could be widely applied,

3) reproduce experimental data to an acceptable degree of accuracy and

4) give similar accuracy for species whose data is not available.

Quantum mechanics can be used to provide estimates of the enthalpy, entropy and heat capacity for many different types of molecules. Specifically, the output of a typical quantum chemistry simulation will contain the optimum geometry of the molecule and the ground- state electronic energy. These data can be used to calculate the normal vibrational modes of the molecule which, when combined with statistical mechanics, yield the zero point energy (and thus the enthalpy), heat capacity, and entropy of the molecule. Thus the heat capacities and entropies can be directly obtained from quantum chemical simulations. Knowledge of vibrational frequencies plays a very important role in determining the thermal contributions to enthalpy, $\Delta \mathrm{H}_{\mathrm{vib}}(\mathrm{T})$ and entropy, $\mathrm{S}_{\mathrm{vib}}(\mathrm{T}){ }^{41}$ Small frequencies contribute more to the thermal contributions to enthalpy and entropy than larger frequencies do. The use of scaling factors allows vibrational frequencies and thermochemical information of useful accuracy to be obtained from procedures of only modest computational cost. ${ }^{17,40}$ In their work, Scott and Radom ${ }^{40}$ 
determined optimum frequency scale factors suitable for the prediction of vibrational fundamentals, low frequency vibrations, zero-point vibrational energies and thermal contributions to enthalpy and entropy from harmonic vibrational frequencies.

Assessment by Curtiss et al. ${ }^{41}$ for computation of enthalpies of formation showed that the four objectives were achieved with the smallest average absolute deviation using B3LYP, one of the basic density functional theory (DFT) methods that was investigated. There are of course some more accurate composite methods that can be used but these are very expensive in terms of time and for the purposes of developing a model the basic methods will suffice. It is not straightforward to obtain a reliable theoretical description of radical addition $^{42}$ and therefore it is important to assess which level of theoretical method is convenient to use. This can be seen from the assessment done by Fischer and Radom ${ }^{23,24}$ for the addition of a methyl radical $\left(\mathrm{CH}_{3}\right)$ to ethylene $\mathrm{CH}_{2}=\mathrm{CH}_{2}$ using different levels of theory to develop approximate solution to the Schrödinger equation. As summarized in Table 2.3, there is an inverse relationship between the theory and accuracy. As the level of theory increases the deviation of the results from experimental values decreases.

Table 2.3 Effect of level of theory on calculated $\mathrm{E}_{\mathrm{a}}$ and $\Delta \mathrm{H}_{\mathrm{r}}$ for the addition of a methyl radical to ethylene. The basis sets are $6-31 \mathrm{G}(\mathrm{d}) .^{23}$

\begin{tabular}{lll}
\hline Level & $\mathrm{E}_{\mathrm{a}}(\mathrm{kJ} / \mathrm{mol})$ & $\Delta \mathrm{H}_{\mathrm{r}} 0 \mathrm{~K}(\mathrm{~kJ} / \mathrm{mol})$ \\
\hline AMI & 7.1 & -157.5 \\
UHF & 39.4 & -107.7 \\
UMP2 & 60.1 & -123.6 \\
UMP4 & 53.7 & -116.9 \\
UB-LYP & 13.2 & -107.1 \\
UB3LYP & 14.6 & -119.8 \\
Expt & 21.3 & -113.1 \\
\hline
\end{tabular}


The computational methods used for this study given all the factors discussed above are the density functional theory methods (B3LYP/6-31G(d) (Becke's Three Parameter Hybrid Functional Using the LYP Correlation Functional), B3P86/6-311G(2d,2p) (Becke's Three Parameter Hybrid Functional with Perdew 86) and B971/6-311G(2d,2p)). There is no advantage to AM1 over B3LYP for optimizations except speed and cost. While B3LYP gives better geometries than AM1 in general, AM1 is reasonably accurate for most systems such that B3LYP//AM1 (B3LYP energy calculation following AM1 geometry optimization) results are essentially the same as B3LYP//B3LYP (B3LYP energy calculation following a B3LYP geometry optimization) for bond dissociation energies (BDEs). ${ }^{34-36}$

\subsubsection{Calculation of Thermodynamic Quantities}

The heats of formation are not a direct output of computational chemistry. The reason for this is that the enthalpies of elements, e.g. oxygen, in their standard state cannot be computed via quantum mechanics. Two common approaches exist for calculating the heat of formation for molecules from the output of quantum simulations, both of which use some empirical data.

A good review of the first method - calculating heats of formation via atomization energies - is given by Curtiss. ${ }^{41}$ The first step is to calculate the enthalpies of formation at $0 \mathrm{~K}\left(\Delta \mathrm{H}_{f}^{\circ}\right.$, described in equation 2.23$)$ of the species involved in the reaction by subtracting the atomization energy of the molecule $\left(\sum \mathrm{D}_{0}(\mathrm{M})\right.$, described in equation 2.22$)$ 
from the experimental enthalpies of formation for the isolated atoms. (Curtis's values are shown in Table 2.4.) The second step is to calculate the enthalpies of formation of the species at $298.15 \mathrm{~K},\left(\sum \mathrm{H}_{f}^{\circ}(\mathrm{M}, 298.15 \mathrm{~K})\right.$, described in equation 2.24. Enthalpy corrections of the atomic elements are used to convert the atomic heats of formation at 0 $\mathrm{K}$ to those at $298.15 \mathrm{~K}$, and are given for the elements in their standard states in Table 2.4. Correction for molecules is made via vibrational frequencies calculated with quantum chemistry extracted from the Gaussian thermochemistry output. An example of the procedure will be described in Chapter 3.

$$
\begin{gathered}
\sum \mathrm{D}_{0}(\mathrm{M})=\sum(\mathrm{E} 0)_{(\text {atoms })}-(\mathrm{E} 0+\mathrm{ZPE}(\text { molecule }) \\
\Delta \mathrm{H}_{f}^{\circ}(\mathrm{M}, 0 \mathrm{~K})=\sum x \Delta \mathrm{H}_{f}^{\circ}(\text { atoms }) \\
\Delta \mathrm{H}_{f}^{\circ}(\mathrm{M}, 298.15 \mathrm{~K})=\left(\Delta \mathrm{H}_{f}^{\circ}(\mathrm{M}, 0 \mathrm{~K})+\mathrm{H}_{0}^{\circ}(\mathrm{M}, 298.15 \mathrm{~K})-\mathrm{H}^{\circ}(\mathrm{M}, 0 \mathrm{~K})\right)
\end{gathered}
$$

Larger deviations between calculated and experimental heats of formation are found for more complex molecules such as aromatics and highly substituted hydrocarbons. ${ }^{43}$ The method of calculating $\Delta \mathrm{H}_{\mathrm{f}}$ values using isodesmic reactions offers more reliable results for a much broader range of molecules, and is also easier to understand than the method of atomization energies. 
Table 2.4: Experimental Enthalpies of formation, in $\mathrm{kcal} / \mathrm{mol}$, for isolated atoms from table provided by Curtis $^{31}$

\begin{tabular}{lcl}
\hline Atoms & $\Delta \mathrm{H}_{f}^{\circ}(0 \mathrm{~K})$ & $\mathrm{H}^{298}-\mathrm{H}^{0}$ \\
\hline $\mathrm{H}$ & $51.63 \pm 0.001$ & 1.01 \\
$\mathrm{Li}$ & $37.69 \pm 0.200$ & 1.10 \\
$\mathrm{Be}$ & $76.48 \pm 1.200$ & 0.46 \\
$\mathrm{~B}$ & $136.20 \pm 0.200$ & 0.29 \\
$\mathrm{C}$ & $169.98 \pm 0.100$ & 0.25 \\
$\mathrm{~N}$ & $112.53 \pm 0.020$ & 1.04 \\
$\mathrm{O}$ & $58.99 \pm 0.020$ & 1.04 \\
$\mathrm{~F}$ & $18.47 \pm 0.070$ & 1.05 \\
$\mathrm{Na}$ & $25.69 \pm 0.170$ & 1.54 \\
$\mathrm{Mg}$ & $34.87 \pm 0.200$ & 1.19 \\
$\mathrm{Al}$ & $78.23 \pm 1.000$ & 1.08 \\
$\mathrm{Si}$ & $106.60 \pm 1.900$ & 0.76 \\
$\mathrm{P}$ & $75.42 \pm 0.200$ & 1.28 \\
$\mathrm{~S}$ & $65.66 \pm 0.060$ & 1.05 \\
$\mathrm{Cl}$ & $28.59 \pm 0.001$ & 1.10 \\
\hline
\end{tabular}

\subsubsection{Isodesmic Reactions}

An isodesmic reaction is one in which all bond types are preserved between reactants and products. For example, if among the reactants there are four single and two double bonds, the same numbers and types of bonds must exist among reactants. A special type of isodesmic reaction is known as a homodesmotic reaction. In the case of a homodesmotic reaction, the reaction conserves not only the bond types present but also the electronic configuration of the atoms, e.g. the number of $\mathrm{sp}^{3}$ carbon atoms must be preserved. Isodesmic reactions are used to gain an estimate of the heat of formation of a compound. They must be written so that experimentally observed heats of formation are available for all reactants and products except the compound of interest, i.e., there is only one unknown heat of formation in the isodesmic reaction. If an estimate of the heat of reaction were available, then it would be a simple matter to estimate the heat of formation 
of the unknown compound. Performing quantum chemical calculations on all molecules in the isodesmic reactions allows for calculating an estimate of the heat of reaction.

Combining the quantum-chemical heat of reaction with the experimentally measured heats of formation for all but one species in the isodesmic reaction allows estimation of the heat of formation of the unknown species. Using isodesmic reactions is advantageous because the conservation of bonds in the reaction has the effect of cancellation of errors, further increasing accuracy. The fact that this technique includes experimental data, allows for different estimates of the heat of formation to be obtained from different isodesmic reactions. A common approach is to write three isodesmic reactions and take the average of the heat of formation obtained. Once again, an example of this procedure will be presented in Chapter 3 .

\subsubsection{Benson Group Additivity}

While Gaussian is a reliable method for computing enthalpies of reactions, there are other theoretical methods that can be used. One such technique is the Group Additivity (GA) method. In this method, the bond energy (which is the energy required to break a chemical bond and separate the fragments to infinite distance in the gas phase at $0 \mathrm{~K}$ ) approach is used. Bond energies cannot be used to calculate the enthalpy of formation but can be used to estimate the enthalpy of reaction having accounted for any additional energy effects such as ring strain. The Benson ${ }^{31}$ approach that deals with partial bond contributions to the gas phase enthalpy of formation at $298.15 \mathrm{~K}$ has been used successfully. It has also been demonstrated that this approach can be used to accurately 
predict unknown values of enthalpies of formation for species for which experimental data are not available. ${ }^{43}$ This is a natural extension of the bond energy approach where the effect on the stability and thermodynamic properties of the bond are addressed, thereby improving the estimation of the enthalpy of reaction. The improvement comes as a result of accounting for:

- the effects of the bonded environment around a group

- $\quad$ ring strain effects

- isomeric effects

- non-bonded interactions

In this method a molecule is broken down into sub structural units or groups. Each group has a constant amount that it contributes to a thermodynamic property of the molecule. In standard notation, a central polyvalent atom is listed first followed by a dash, followed by all the moieties bonded to that center. An example of the notation for the molecule like methyl acrylate is shown in Figure 2.1.

\begin{tabular}{clc}
\hline $\begin{array}{c}\text { Molecule } \\
(\mathrm{kcal} / \mathrm{mol})\end{array}$ & Groups & Contribution $\Delta \mathrm{H}_{\mathrm{f}}^{298 \mathrm{~K}}$ \\
\hline & $\mathrm{C}-(\mathrm{O})(\mathrm{H})_{3}$ & -8.1 \\
& $\mathrm{C}_{\mathrm{d}}-(\mathrm{H})_{2}$ & 6.26 \\
& $\mathrm{C}_{\mathrm{d}}-(\mathrm{CO})(\mathrm{H})$ & 5.0 \\
& $\mathrm{CO}-\left(\mathrm{C}_{\mathrm{d}}\right)(\mathrm{O})$ & -32.00 \\
& $\mathrm{O}-(\mathrm{CO})(\mathrm{C})$ & -43.1 \\
\hline
\end{tabular}

Figure 2.1: A worked example of Benson's group additivity method (Source of group contributions: Khan and Broadbelt ${ }^{43}$ ) 
The heat of formation of the molecule is the sum of the group contributions. In this case $\Delta \mathrm{H}_{\mathrm{f}}^{298 \mathrm{~K}}$ of MA molecule would be $-72.0 \mathrm{kcal} / \mathrm{mol}$ compared to the experimental value of -78.59 (NIST Chemistry Web book). Some details of the nomenclature are given in Table 2.5. This method may require correction for molecules having rings, isomers, repulsions or non bonded interactions.

Table 2.5: Notations used for the group contribution concept

\begin{tabular}{cll}
\hline Notation & Valence & Description \\
\hline $\mathrm{C}$ & 4 & Tetravalent carbon (alkanes) \\
$\mathrm{C}_{\mathrm{d}}$ & 2 & Double-bonded carbon (alkenes) \\
$\mathrm{C}_{\mathrm{b}}$ & 1 & Benzene-type carbon (aromatic) \\
$\mathrm{C}_{\mathrm{p}}$ & 3 & Aromatic carbon at ring junction (polyaromatics) \\
\hline
\end{tabular}

\subsection{Application of Computational approach to polymerization}

The feasibility of computational approach in estimation of kinetic rate coefficients is demonstrated by Broadbelt et al. ${ }^{30}$ where a hierarchical approach was used to estimate the rate coefficients required to describe hydrocarbon pyrolysis and polystyrene degradation. Where no literature data was available, rate coefficients were estimated using the EvansPolanyi relationship and enforcing thermodynamic consistency. Necessary thermochemical parameters including the heats of reaction, if not available from databases, were calculated using computational chemistry. In addition, the set of kinetic mechanisms and species needed to describe the complex polymer degradation system were generated with the help of automated tools: over 4500 reactions and 93 species were considered in the final model which accurately represented the rates and yields of low molecular weight species formed through pyrolysis of polystyrene. The reactions 
considered in their work, radical addition, radical recombination, inter and intramolecular $\mathrm{H}$ - abstraction and $\beta$-scission are those of importance in high temperature free radical polymerization.

Fischer and Radom ${ }^{23}$ provide a comprehensive summary of rate constants for the addition of unsaturated molecules to small carbon-centred radicals that include both experimental data and results calculated using computational chemistry. In their review, they examine the rate constants for the addition of carbon-centred radicals to alkenes and other unsaturated molecules, and the factors controlling them. These mainly involve the interplay of enthalpic, polar and steric effects. ${ }^{23,44}$ Fischer and Radom found that the main factor that creates enormous variation in the rate constants of the reactions is the structure of the radical. The Evans -Polanyi relationship provides a limiting case that must be corrected for various polar effects. In their study of factors controlling the addition of carbon-centred radicals to alkenes, they came up with the conclusion that even though enthalpy effects are always present, they may be obscured by the presence of other effects and that polar effects can decrease the barrier that is indicated by the enthalpy effect. ${ }^{45}$ Comparing tert-butyl, 2-hydroxy-2-propyl and hydroxymethyl radical additions to methyl radical additions to alkenes, the electron rich monomers react more slowly and the electron deficient alkenes react faster due to the strong nucleophilic polar effect of the radical. The radicals that carry a carboxyl or a cyano substituent react faster with alkenes if the species is primary, however if the species is tertiary they are slower but the reactivity pattern is similar. Steric effects of repulsion decrease $A$ and 
simultaneously increase $E_{a}$ and hence the rate constants are decreased. In the case where the attacking molecule is reacting with an alkene radical with different substituents, the substituent molecules on the attacked carbon hinder the reaction much more than the substituent molecules at the remote carbon.

Of most interest to this effort is the study in which Fischer and Radom ${ }^{24}$ looked at the reaction between $\mathrm{CH}_{3}-\mathrm{C}^{*}\left(\mathrm{C}_{4} \mathrm{H}_{9} \mathrm{COO}\right) \mathrm{H}\left(\mathrm{EEst}^{*}\right)$ and $\mathrm{CH}_{3}-\mathrm{C}^{*}\left(\mathrm{C}_{4} \mathrm{H}_{9} \mathrm{COO}\right)\left(\mathrm{CH}_{3}\right)\left(\mathrm{PEst}^{*}\right)$ with methyl acrylate (MA) and methyl methacrylate (MMA) and how the activity of the secondary and tertiary radicals affect the rate coefficients for monomer addition. The monomer reactivity ratios calculated using their results for small molecules show good agreement with the literature values that are available for long chain radical polymerization.<smiles>CCCCCCC(C)C</smiles>

PEst*<smiles>CCCCCCC(C)C</smiles>

EEst*<smiles>COC(C)(C)C</smiles>

$\mathrm{MMA}^{*}$

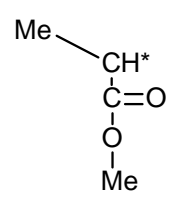

MA*

Figure 2.2: Structural comparison of EEst and PEst with MA and MMA monomeric radicals, where Me stands for methyl group. 
The EEst and PEst radicals are very similar in structure to the monomeric MA and MMA radicals, respectively (Figure 2.2), the difference being that for MA and MMA the $\left(\mathrm{CH}_{3} \mathrm{COO}\right)$ is attached to the radical while for EEst and PEst $\left(\mathrm{C}_{4} \mathrm{H}_{9} \mathrm{COO}\right)$ is attached to the radical. Comparison of the kinetics measured for the EEst /PEst system with FRP gives us an idea of how good a model the small molecule system is for FRP. The results indicate that steric effects (having a long chain polymeric fragment attached to the radical) on the radical do not affect the monomer reactivity to a considerable extent. The experimental finding suggests that, if computational techniques can be applied to accurately estimate relative reactivities for small molecule radical reactions, the results will also carry over to FRP. This will be discussed further in Chapter 4.

Coote et al. ${ }^{46}$ support and complement the application of ab initio computations to radical systems. In their work with gamma substitutions of propyl radical reaction to ethylene to determine stability and reactivity in free radical polymerization, they employ various $a b$ initio molecular orbital calculations. It is shown that the penultimate model, an obvious refinement of the terminal model, is required to predict the effects of radical substituents in copolymerization systems.

Coote and Davis ${ }^{17}$ studied the importance of the penultimate unit effect on radical stability and reactivity in free radical polymerisation. It was found that, although the penultimate unit can exert a significant effect on the stability of the propagating radical, only a small fraction of this effect appears to carry over to the reaction barrier. 
Furthermore, it appears that when penultimate unit effects on radical stability are large enough to affect the reaction barrier, polar interactions are also likely to be significant. This is probably because the radical substituents associated with large penultimate unit effects on radical stability are strong electron donors or acceptors. Phenyl substituted radicals are less subject to polar effects and therefore the reaction barrier is diminished while in the case of MA/MMA system the hydrocarbons, straight or conjugated, are subject to polar effects and hence the reaction barrier is increased. In further studies Coote and Davis ${ }^{17}$ calculate results that indicate that the reaction barrier is also dependent on the conformations of the reacting radical and the transition structure. They conclude that there are three important implications of these results for free radical polymerization kinetics. The first suggestion is that the dependence of the penultimate unit effect upon the conformation of the transition structure is influenced by the direct interactions involving the substituents at the penultimate position and substituents on the monomer. From this point the second suggestion coming from the dependency of the penultimate unit effect on the transition structure conformation, is that the overall reaction barrier will then depend on the frequency factors for the individual pathways. Finally since the relative barriers for the different reaction pathways depend on the penultimate unit, it follows that the tacticity of the resulting polymer will depend on the nature of the penultimate unit. They conclude that the penultimate unit effect in copolymerization is likely to be a general phenomenon. In their recent work, Coote et al. ${ }^{49}$ have shown the penultimate effects for the ATRP Activation step using propylene, methyl acrylate, and methyl methacrylate monomers. Their successful application of ${ }^{47} a b$ initio molecular 
orbital calculations to FRP will be extended in my work to acrylate/methacrylate systems. (It is also important to note that the feasibility of the Evans-Polanyi relationship is emphasized as the approach requires that the assumptions made for the family group $A$ values be valid for the homo propagation and cross propagation reactions. $)^{24,30,44-48}$ In this study we are considering both the penultimate unit effects as well as the terminal model in developing the methodology.

Heuts et al. ${ }^{48}$ tried to evaluate the best set of parameters from modelling the Arrhenius parameters for the propagation reaction of ethylene in free radical polymerization. They give a list of recommended basis sets for each step of the calculation. In general they found that the frequency factor is much less sensitive to the level of theory than the energy barrier.

Moscatelli et al., ${ }^{50}$ in their study have shown the capability of computational approach to evaluate kinetic constant for high temperature polymerization of styrene. They investigate the relative contribution of the reactions like backbiting, chain transfer to polymer, $\beta$ - scission and termination by disproportionation or addition reactions to the polymerization process. The average polymer molecular weight is determined by the ratio of the rate of propagation to that of termination. To get the rate-determining step of the termination it is necessary to investigate the kinetics of the degradation reactions. $A b$ initio calculations were performed for the investigation. Although small portions of the 
molecule are directly involved in the reaction, the challenge arises from the large number of atoms that have to be considered in each calculation. An approach using Quantum Mechanics /Molecular Mechanics (QM/MM) was used. That way the different part of the same molecule could be described at different levels of theory. ${ }^{51,52}$ The atoms that are directly involved in the reaction were treated with a high level of theory and the rest of the molecule treated with a much lower level of theory using molecular mechanics or a semi-empirical approach. The part of the molecule treated with the lower level of theory plays essentially a steric role in the whole scenario. In their work Moscatelli et al. used B3LYP for the atoms in the reaction region and Parametric Model number 3 $(\mathrm{PM} 3)^{53}$ for the molecule further away from the region. Three different stereochemical molecular models of styrene were used for the backbiting reactions because the stereochemistry has a significant impact on the polymerization kinetics, and for the propagation, $\beta$-scission and termination reaction only one model was used because these involve the formation or rupture of a single bond in a well defined zone which involves a few atoms that are close by. The most important kinetic constants involved in the process were calculated using classic and variational transition state theory on a Potential Energy Scan (PES) determined with a QM/MM approach. A development from this work is a new 7:3 backbiting reaction as well as consideration of the reversibility of all backbiting reactions. When the evaluated kinetic constants were used in a polymerization model, the results were in good agreement with the experiment. 


\subsection{Summary}

From the evaluation of all systems and methods reviewed, we have established that there is adequate experimental data to compare our results with. As not all rate coefficients can easily be evaluated experimentally, there is a need to develop a computational approach. Gaussian utilises an entire range of electronic structure methods, and is an ideal computational tool to use for model chemistries. By utilising the Evans - Polanyi relationship, reactivity ratios will be estimated for methacrylates, acrylates and styrene and compared to the experimental values. To examine if the methodology is useful, we will explore as to whether it is consistent with observed structure reactivity trends. 


\section{Chapter 3 \\ Methodology}

Design of a polymerization process is best initiated at a bench level and preferably involves design and scale up engineers from the outset. The kinetics of a reaction play a very important role in such process and product design considerations. However, the complexity of the reactions and large number of reactants involved in typical industrial processes can obscure the reaction kinetics of very important pathways that must be understood to better design products and optimizing the production process.

Computational chemistry simulates structures and reactions numerically based in part or in full on the fundamental laws of physics and chemistry. Some methods can be used not only to model stable molecules but also short-lived unstable intermediates and transition states that cannot be observed physically in the laboratory. Although these techniques have limitations, they may provide results with an improved accuracy compared to current experimental knowledge. This chapter explains the methodology developed to estimate rate coefficients computationally.

\subsection{Geometry, starting structure and optimization}

The minimum energies of all reactant and product species must be estimated to calculate the heats of reaction required for the application of the Evans-Polanyi relationship to estimate kinetic coefficients. Such calculations have been performed using the Gaussian software on the basis of structures drawn in the molecular editor of the Gaussian package called Gaussview. For simple structures such as MA* or MMA* radicals (small 
molecules), this procedure is found to be satisfactory. However, any results obtained in this way for larger species are more difficult because of the presence of multiple local minima in molecular structures such as dimeric radicals, and the difficult optimization procedure of Gaussian may not succeed on its own. ${ }^{38,45}$ A common problem with some cases that may prove difficult is that the force constants estimated by the optimization procedure differ substantially from the actual values. In this study, we are dealing with radicals and as such the geometry optimization initial guess for the second derivative matrix, derived from a simple valence force field, is poor. Therefore means of generating the force constants are employed, and can be conveniently used because in this project only the reactants and the products are considered. Dealing with the transition state (intermediate structures) in the reaction is more complicated and the force constants may have to be calculated at every optimization, a very expensive procedure.

The lowest energy conformation needs to be identified so as to minimize steric interaction between different parts of the molecule. Hence, techniques must be developed so that the energy minimization algorithm won't get 'caught' in any of the local minima that result from an arbitrarily drawn structure. Two approaches will be discussed and used to demonstrate how the minimum structure can be achieved for difficult cases, with resulting energetics compared to available experimental data.

The first procedure, which utilizes Unrestricted Force Fields (UFF), is reliable but time consuming. The starting conformation for the calculation is found by using a mechanics 
Unrestricted Force Field (UFF) run in Gaussian. The whole sequence of tasks is as follows:

- drawing the initial structure as a saturated molecule (This is done using Gauss View, a software package to draw and display molecular geometry, and that automatically generate a Z-Matrix representing the relative position of the atoms in the molecule, input for the energy minimum simulation.)

- using the mechanics Unrestricted Force Field (UFF) module in Gaussian to find the conformation with the lowest energy for the saturated structure

- using Hartree Fock with a low basis set UHF/3-21G* to find the energy minimum

- removing the hydrogen atom and resubmitting the job to find the minimum energy for the radical structure.

- Doing the optimization and frequency calculation with B3LYP/6-31G(d) with this structure.

The second procedure, which is long but straightforward compared to the UFF method, is the Potential Energy Scan (PES). To find the global minimum, a relaxed potential energy scan is performed on all the backbone dihedral angles of the molecule using AM1 geometry optimization. Ab initio single point calculations are then done on the minimum geometries obtained by the scans, using a higher level method such as B3LYP/6-31G(d). The geometry with the minimum energy from these calculations is then picked as the starting geometry for the final optimization and energy calculation for the molecule. An example is given for MMA-MA radical (see Figure 3.1) Overall energetics are calculated 
by combining AM1 geometry optimization and frequency calculations with a higher level single point energy calculation using B3LYP/6-31G(d); B3P86/6-311G(2d,2p), or B971/6-311G(2d,2p). ${ }^{37,38,56}$ These methods are high level DFT methods and have been seen to be very accurate but are very expensive if used to do geometry optimizations.

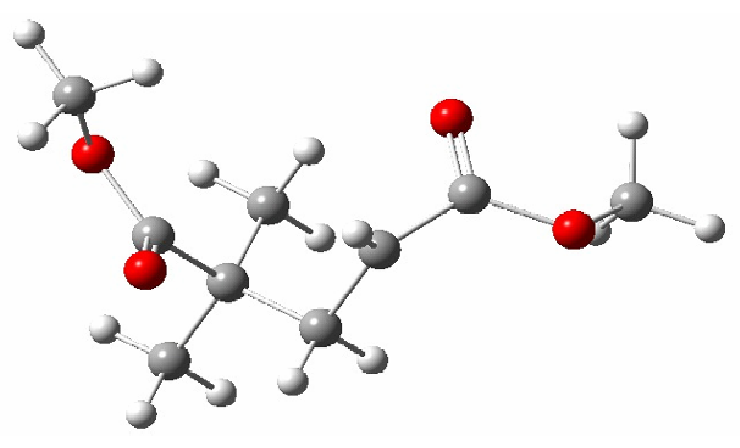

MMA-MA* radical

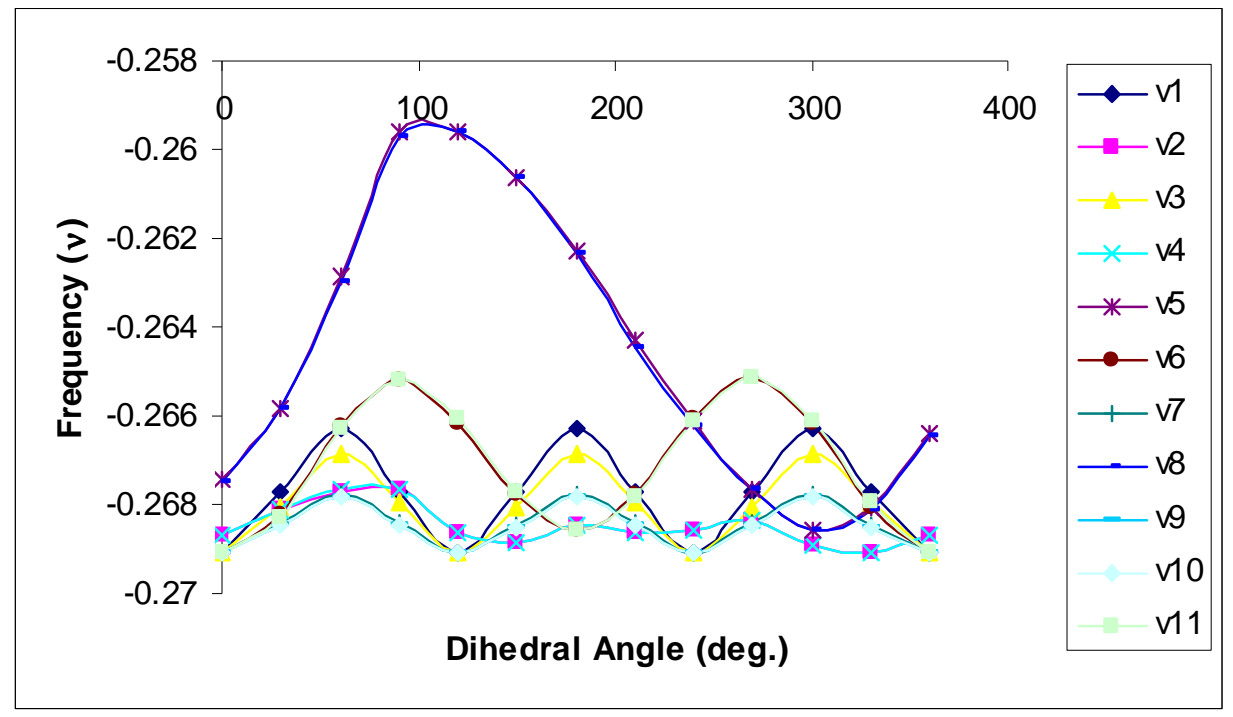

Figure 3.1: Result of a potential energy scan of the backbone dihedral angles for MMAMA radical, $v_{1}-v_{11}$ are dihedral angles of the radical structure pictured above. 


\subsection{Thermochemistry Calculation}

The ab initio calculations yield the thermochemistry data required to calculate the heats of formation of the reactants and products and thus the heats of reaction for the chemical reaction. It is very important to use structures for which the first derivatives are zero which is to say that structures at their minima and these are identified using the following criteria:

1. $E_{\theta}=0=E_{\theta}=360$

2. $E_{\theta}=0$ (or $\left.E_{\theta}=360\right)$ has the minimum energy.

The heat of reaction is then calculated using the thermochemistry data according to:

$$
\Delta H_{r}^{\circ}(298.15 \mathrm{~K})=\sum_{\text {products }}\left(E_{e l}+H_{\text {therm }}\right)-\sum_{\text {reactants }}\left(E_{e l}+H_{\text {therm }}\right)
$$

where $E_{e l}$ is the electronic energy of the molecule and $H_{\text {therm }}$ is the thermal and zero point correction to enthalpy. The value of $H_{\text {therm }}$ is calculated using statistical mechanics based on the partition function, $q$, using standard formulae. ${ }^{53}$ The partition function is defined as:

$$
q=\sum_{j} \exp \left(-\frac{\varepsilon_{j}}{k_{B} T}\right)
$$

and alternatively can be written as the product of various partition functions:

$$
q=q_{\text {trans }} \times q_{\text {rot }} \times q_{v i b} \times q_{e l}
$$

where $q_{\text {trans }}$ is the translational partition function, $q_{\text {rot }}$ is the rotational partition function, $q_{v i b}$ is the vibrational partition function, and $q_{e l}$ is the electronic partition function which is equal to one for species in their ground state. 
For the vibrational energy levels that are needed to calculate $q_{v i b}$, the harmonic oscillator (HO) model is a good approximation for high frequencies, while for low frequencies $\left(<200 \mathrm{~cm}^{-1}\right)$, a hindered rotor (HR) model represents these modes more accurately, since these low frequencies are essentially rotation modes. The partition function for the low frequency modes are treated as internal rotations and equation 3.3 becomes:

$$
q=q_{\text {trans }} \times q_{\text {rot }} \times q_{v i b} \times q_{\mathrm{int}, \text { rot }}
$$

The partition function of an internal rotation is:

$$
q_{\mathrm{int}, \text { rot }}=\frac{1}{\sigma_{\mathrm{int}}} \sum_{j} \exp \left(-\frac{\varepsilon_{j}}{k_{B} T}\right)
$$

in which $\sigma_{\text {int }}$ is the symmetry number of the rotation top and $\varepsilon_{j}$ are the energy levels of the internal rotation which can be solved based on a one-dimensional Schrödinger equation. ${ }^{54}$

Calculation of heats of formation and heats of reaction necessitate transforming the energies to the appropriate units and applying some correction factors. The procedures will be illustrated for the simple reaction:

$$
\mathrm{C}_{2} \mathrm{H}_{6}+\mathrm{H}_{2} \longrightarrow 2 \mathrm{CH}_{4}
$$

based upon calculations done at UB3LYP/6-31g(d) level of theory. The example will demonstrate how the results from a Gaussian frequency calculation are used to generate various thermochemical data (for example $E_{e l}$ and $H_{\text {therm }}$ ), which is used to calculate heat of reaction. The units are in Hartrees/particle and they are converted to kilocalories per mole after calculation using the conversion factor 1 Hartree $=$ 
$627.5026 \mathrm{kcal} / \mathrm{mol}$. Thermochemical data that is used for our purposes appears as follows for $\mathrm{CH}_{4}$ from Gaussian:

Zero-point correction=

Thermal correction to Energy=

Thermal correction to Enthalpy=

Thermal correction to Gibbs Free Energy=

Sum of electronic and zero-point Energies=

Sum of electronic and thermal Energies=

Sum of electronic and thermal Enthalpies=

Sum of electronic and thermal Free Energies=
0.045214

(Hartree/Particle)

0.048078

0.049022

0.027890

$-40.473175$

$-40.470311$

$-40.469367$

$-40.490499$

The following nomenclature is introduced:

$\varepsilon_{0}=$ Sum of electronic and zero-point Energies

$\mathrm{E}_{e l}=$ Sum of electronic and zero-point Energies - Zero-point correction

$\mathrm{ZPE}=$ Zero-point correction

$\mathrm{H}_{\text {therm }}=$ Thermal correction to Enthalpy

$\mathrm{TCE}-\mathrm{ZPE}=$ this gives the enthalpy correction for the molecule

Similar output is generated for ethane and hydrogen (not shown).

The usual way to calculate enthalpies of reaction is from heats of formation of reactants and products summed according to their stoichiometric coefficients. ( $v$ is +ve for products and -ve for reactants.)

$$
\Delta \mathrm{H}_{r}^{\circ}(298.15 \mathrm{~K})=\sum_{\text {products }}\left|v_{i}\right| \Delta H_{f i}-\sum_{\text {reactants }}\left|v_{i}\right| \Delta H_{f i}
$$


With the Gaussian output, a short cut can be used, equation 3.1, as this provides the sum of electronic and thermal enthalpies. The difference of the sums of these values for the reactants and the products is calculated and this gives the enthalpy of reaction. This treatment is valid because the number of atoms of each element is the same on both sides of the reaction; therefore all that is needed is the molecular data.

For the example above, the heat of reaction can be calculated as follows:

$$
\begin{aligned}
\Delta \mathrm{H}_{r}^{\circ}(298.15 \mathrm{~K}) & =\sum_{\text {products }}\left(E_{e l}+H_{\text {therm }}\right)-\sum_{\text {reactants }}\left(E_{\text {el }}+H_{\text {therm }}\right) \\
& =((-40.4694-1.10905)-(2 *(-79.750759))) * 627.5026 \\
& =0.02592 * 627.5026 \\
& =16.27867 \mathrm{kcal} / \mathrm{mol} \\
& =68.11 \mathrm{~kJ} / \mathrm{mol}
\end{aligned}
$$

The heat of reaction can also be obtained by first calculating the heat of formation of the species involved in the reaction. This is a long process but is straightforward, as outlined by Curtiss ${ }^{31}$ (see Chapter 2, Section 2.2.2).

For MA/MMA hindered internal rotations are a concern if one is dealing with the transition state. For dealing with the reactants and products the effects cancel out so the correction for the hindered rotors is negligible. Both the frequency-scaling factor and the internal rotation can be specified in the input file so that Gaussian automatically gives as output the information that is required to do the necessary 
corrections. Where Gaussian does not encounter any hindered rotations in the molecule, the output specifies.

\subsubsection{Isodesmic Reaction Method}

The example below calculates heats of reaction for production of the dimeric radical MAMA* using the isodesmic reaction method. The reactions taking part in the calculation and the molecules involved are labelled with small letters and capital letters respectively. This method is described in Section 2.2.3. Combining the quantum-chemical heat of reaction with the experimentally measured heat of reaction for one of the reactions in the scheme allows estimation of the heat of reaction for the formation of the species that has an unknown heat of formation. Using isodesmic reactions is advantageous because the conservation of bonds in the two reactions is similar, and thus will be subject to similar calculational error. The difference between the calculated and experimental heats of reaction for the isodesmic reaction can be used as a correction factor for the calculated heat of reaction for the reaction of interest.

$M A+M A^{*} \longrightarrow M A-M A^{*}$

$\begin{array}{lll}\text { (A) (B) } & \text { (C) }\end{array}$ 
Isodesmic Reactions

a)<smiles>[CH2+]</smiles>

Methyl radical

(D)<smiles>C</smiles>

Methyl radical

(D)<smiles>C=CC(=O)OC</smiles>

+ Eq a) (LHS)

Methyl Acrylate

(A)

$(\mathrm{D}, \mathrm{E}, \mathrm{F})$

c)<smiles>CCCOC=O</smiles>

+ MA*

Methane

(G)

(B)

(F)<smiles>C=CC(=O)OC</smiles>

Methyl Acrylate

(A)

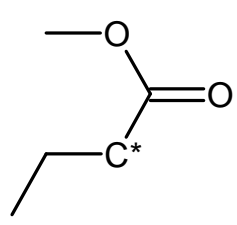

$\mathrm{CH}_{3}$-MA*

(H)

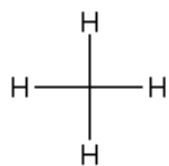

+ MA-MA*

Methane

(G)

(C) 
IDR $(\operatorname{expt})=26.64 \mathrm{kcal} / \mathrm{mol}$

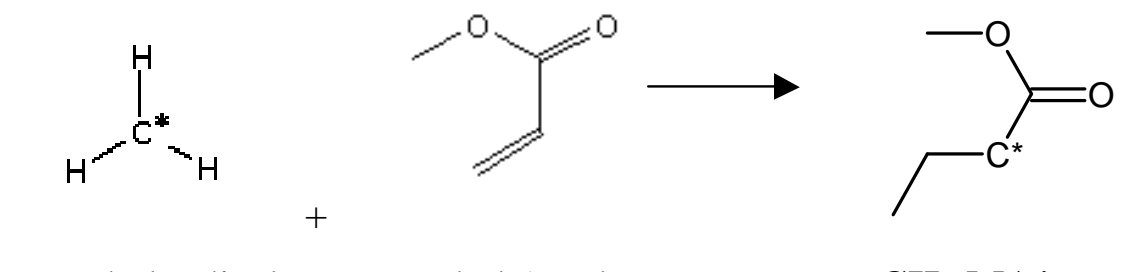

$$
\begin{aligned}
\Delta \mathrm{H}_{\mathrm{rxn}}(\mathrm{a})[\mathrm{B} 3 \mathrm{LYP}] & =\mathrm{Hg}+\mathrm{Hb}-(\mathrm{Hd}+\mathrm{He}+\mathrm{Hf}) \\
{[\mathrm{EXPT}] } & =\Delta \mathrm{Hg}+\Delta \mathrm{Hb}-(\Delta \mathrm{Hd}+\Delta \mathrm{He}+\Delta \mathrm{Hf}) \\
\Delta \mathrm{Hb} & =\mathrm{Hg}+\mathrm{Hb}-\Delta \mathrm{Hg}-(\mathrm{Hd}+\mathrm{He}+\mathrm{Hf})+(\Delta \mathrm{Hd}+\Delta \mathrm{He}+\Delta \mathrm{Hf})
\end{aligned}
$$

$$
\begin{aligned}
& \Delta \mathrm{H}_{\mathrm{rxn}}(\mathrm{b})[\mathrm{B} 3 \mathrm{LYP}]=\mathrm{Hd}+\mathrm{Ha}-\mathrm{Hh} \\
& {[\mathrm{EXPT}] }=\Delta \mathrm{Hd}+\Delta \mathrm{Ha}-\Delta \mathrm{Hh} \\
& \Delta \mathrm{Ha}=\mathrm{Hd}+\mathrm{Ha}-\Delta \mathrm{Hd}-\mathrm{Hh}+\Delta \mathrm{Hh} \\
& \Delta \mathrm{H}_{\mathrm{rxn}}(\mathrm{c})[\mathrm{B} 3 \mathrm{LYP}]=\mathrm{Hc}+\mathrm{Hg}-(\mathrm{Hd}+\mathrm{He}+\mathrm{Hf}+\mathrm{Ha}) \\
& {[\mathrm{EXPT}]=\Delta \mathrm{Hc}+\Delta \mathrm{Hg}-(\Delta \mathrm{Hd}+\Delta \mathrm{He}+\Delta \mathrm{Hf}+\Delta \mathrm{Ha}) } \\
& \Delta \mathrm{Hc}=\mathrm{Hc}+\mathrm{Hg}-\Delta \mathrm{Hg}-(\mathrm{Hd}+\mathrm{He}+\mathrm{Hf}+\mathrm{Ha})+(\Delta \mathrm{Hd}+\Delta \mathrm{He}+\Delta \mathrm{Hf}+\Delta \mathrm{Ha})
\end{aligned}
$$

$$
\begin{aligned}
\Delta \mathbf{H}_{\mathbf{r x n}} & =\Delta \mathbf{H c}-(\Delta \mathbf{H a}+\Delta \mathbf{H b}) \\
& =\mathrm{Hc}+\mathrm{Hg}-\Delta \mathrm{Hg}-(\mathrm{Hd}+\mathrm{He}+\mathrm{Hf}+\mathrm{Ha})+(\Delta \mathrm{Hd}+\Delta \mathrm{He}+\Delta \mathrm{Hf}+\Delta \mathrm{Ha})-[\mathrm{Hd}+\mathrm{Ha}
\end{aligned}
$$$$
-\Delta \mathrm{Hd}-\mathrm{Hh}+\lambda \mathrm{Hh} \nmid \mathrm{Hg} \backslash \mathrm{Hb}-\Delta \mathrm{Hg}-\mathrm{Hd}-\mathrm{He}-\mathrm{Hf}+\Delta \mathrm{Hd}+\Delta \mathrm{He}+\Delta \mathrm{Hf}]
$$$$
=\mathrm{Hc}+\mathrm{Hg}-\Delta \mathrm{Hg}-\mathrm{Hd}-\mathrm{He}-\mathrm{Ha}+\Delta \mathrm{Hd}+\Delta \mathrm{He}+\Delta \mathbb{N}+\Delta \mathrm{Ha}-\mathrm{Hd}-\mathrm{Ha}+\Delta \mathrm{Hd}+\mathrm{Hh}
$$$$
-\Delta \mathrm{Hh}-\mathrm{Hg}-\mathrm{Hb}+\Delta \mathrm{Hg}+\mathrm{Hd}+\mathrm{He}+\mathrm{Hf}-\Delta \mathrm{Hd}-\Delta \mathrm{He}-\Delta \mathrm{Hf}
$$$$
=(\mathrm{Hc}-\mathrm{Ha}-\mathrm{Hb})+(\mathrm{Hh}-\mathrm{Ha}-\mathrm{Hd})-(\Delta \mathrm{Hh}-\Delta \mathrm{Ha}-\Delta \mathrm{Hd})
$$ 
$=\Delta \mathrm{H}_{\mathrm{rxn}}[\mathrm{B} 3 \mathrm{LYP}]+\Delta \mathrm{H}_{\mathrm{rxn}}(\mathrm{IDR})[\mathrm{B} 3 \mathrm{LYP}]-\Delta \mathrm{H}_{\mathrm{rxn}}(\mathrm{IDR})[\mathrm{EXPT}]$

$=-16.9+-28.41--26.64$

$=-18.67 \mathrm{kcal} / \mathrm{mol}$

$=-78.10 \mathrm{~kJ} / \mathrm{mol}$

Therefore the heat of reaction for monomer ( MA) addition to monomeric radical MA* is $-78.10 \mathrm{~kJ} / \mathrm{mol}$. Although no experimental value is available, this value is identical to the experimental value of $78 \mathrm{~kJ} / \mathrm{mol}$ for MA monomer addition to polymeric MA radicals. $^{12}$

\subsubsection{Verification of computational technique.}

Upon developing the computational approach it is necessary to assess if the approach is adequate for the study. There is credible experimental data that can be used to compare the computational results generated using the methods described. There are also some previous computational results that can be used to verify if the tools are being used correctly. Fischer and Radom ${ }^{24}$ provide calculational results for addition of a methyl radical to ethylene using three different levels of theory, Hartree Fock $(\mathrm{HF} / 6-31 \mathrm{~g}(\mathrm{~d}))$, Moller-Plesset (MP2/6-31g(d)) and a density functional method (DFT) B3LYP/6-31g(d). The internal rotation effects are not taken into consideration. The comparison summarized in Table 3.1 indicates that the calculations in this work match the published data within $1 \mathrm{~kJ} / \mathrm{mol}$. 
Table 3.1: Reproducibility of Gaussian values for Ethylene addition to a methyl radical

\begin{tabular}{lll}
\hline Level & $\Delta \mathrm{H}_{\mathrm{r}}$ at $0 \mathrm{~K}(\mathrm{~kJ} / \mathrm{mol})$ & $\begin{array}{l}\text { Existing Results } \\
(\mathrm{kJ} / \mathrm{mol})\end{array}$ \\
\hline UB3LYP/6-31g(d) & -119.1 & -119.8 \\
UHF/6-31g(d) & -106.9 & -107.7 \\
UMP2/6-31g(d) & -121.7 & -122.0 \\
\hline
\end{tabular}

Fischer and $\operatorname{Radom}^{24}$ also report $\Delta \mathrm{H}_{\mathrm{r}}$ for the addition of MA to a methyl radical of $-123.7 \mathrm{~kJ} / \mathrm{mol}$ using UB3LYP/6-31g(d), which agrees well to my calculated value of $-123.3 \mathrm{~kJ} / \mathrm{mol}$.

A second check on methodologies is to calculate MA heat of formation using various procedures, including group additivity based on published group values ${ }^{43}$ (Section 2.2.4), Curtiss atomization energy method, ${ }^{31}$ (Section 2.2.2), and isodesmic reaction method (Section 3.2.1).

Table 3.2 contains $\Delta \mathrm{H}_{f}$ from Group Additivity, Gaussian output (Curtiss atomization method) and the average from three isodesmic reactions. The values calculated computationally are within $1.26 \mathrm{~kJ} / \mathrm{mol}$ of the value found in the NIST webook database, while the group additivity value deviates by $25.1 \mathrm{~kJ} / \mathrm{mol}$. This indicates that computational techniques should provide increased accuracy over GA methods. Further work examining the applicability of group additivity methods is shown in Appendix A. 
Table 3.2 Estimated heats of formation for MA using different methods.

\begin{tabular}{llll}
\hline Molecule & Method & $\begin{array}{l}\text { Calculated value } \\
(\mathrm{kJ} / \mathrm{mol})\end{array}$ & $\begin{array}{l}\text { NIST value Exptal. } \\
(\mathrm{kJ} / \mathrm{mol})\end{array}$ \\
\hline Methyl acrylate & Group Additivity & -303.17 & -328.81 \\
& Curtiss & -327.39 & \\
& Isodesmic rxn & -327.64 & \\
\hline
\end{tabular}

\subsection{Monomer Reactivity Ratio Calculation}

After having calculated the heats of reaction, monomer reactivity ratios, $r_{1}$ and $r_{2}$ as well as $r_{11}, r_{12}, r_{22}, r_{21}$ and the penultimate unit effect $s_{1}$ and $s_{2}$ can be calculated.

From the Evans Polanyi relationship, $E_{a}=\alpha \Delta H_{r}+E_{0}$ and the Arrhenius equation $k=A \exp \left(-\mathrm{E}_{\mathrm{a}} / \mathrm{RT}\right)$,

$$
k=A \exp \left\{-\left(\mathrm{E}_{0}+\alpha \Delta \mathrm{H}_{r}\right) / \mathrm{RT}\right\}
$$

Taking into consideration the assumptions that $A$ is the same for a particular radical and $\mathrm{E}_{0}$ is constant for a family group, $r$ and $s$ can be easily calculated. Scheme 3.1 summarizes the required $\Delta \mathrm{H}$ values for monomer adding to monomeric radical.

$$
\begin{array}{cc}
\mathrm{A}^{*}+\mathrm{A} \stackrel{\mathrm{k}_{11}}{\longrightarrow} \mathrm{A}-\mathrm{A}^{*} & \Delta H_{11} \\
\mathrm{~A}^{*}+\mathrm{B} \stackrel{\mathrm{k}_{12}}{\longrightarrow} \mathrm{A}-\mathrm{B}^{*} & \Delta H_{12} \\
\mathrm{~B}^{*}+\mathrm{B} \stackrel{\mathrm{k}_{22}}{\rightarrow} \mathrm{B}-\mathrm{B}^{*} & \Delta H_{22} \\
\mathrm{~B}^{*}+\mathrm{A} \stackrel{\mathrm{k}_{21}}{\longrightarrow} \mathrm{BA}^{*} & \Delta H_{21}
\end{array}
$$

Scheme 3.1 Monomer addition to a monomeric radical for a copolymerization reaction. Assuming Evans-Polanyi, the monomer reactivity ratios are calculated according to: 


$$
\begin{aligned}
r_{1}=k_{p_{11}} / k_{p_{12}} & =\frac{\operatorname{Aexp}\left[-\left(\mathrm{E}_{0}+\alpha \Delta \mathrm{H}_{\mathrm{r} 11}\right) / \mathrm{RT}\right]}{\operatorname{Aexp}\left[-\left(\mathrm{E}_{0}+\alpha \Delta \mathrm{H}_{\mathrm{r} 12}\right) / \mathrm{RT}\right] .} \\
& =\exp \left[-\alpha\left(\frac{\left.\Delta \mathrm{H}_{\mathrm{r} 11}-\Delta \mathrm{H}_{\mathrm{r} 12}\right)}{\mathrm{RT}}\right)\right] \\
r_{2}=k_{p_{22}} / k_{p_{21}} & =\exp \left[-\alpha\left(\frac{\left.\Delta \mathrm{H}_{\mathrm{r} 22}-\Delta \mathrm{H}_{\mathrm{r} 21}\right)}{\mathrm{RT}}\right)\right]
\end{aligned}
$$

For the penultimate model it is necessary to consider monomer addition to dimeric radical as summarized in Scheme 3.2.

$$
\begin{aligned}
& \mathrm{A}-\mathrm{A}^{*}+\mathrm{A} \stackrel{\mathrm{k}_{111}}{\longrightarrow} \mathrm{A}-\mathrm{A}-\mathrm{A}^{*} \quad \Delta H_{111} \\
& \mathrm{~A}-\mathrm{A}^{*}+\mathrm{B} \stackrel{\mathrm{k}_{112}}{\longrightarrow} \mathrm{A}-\mathrm{A}-\mathrm{B}^{*} \quad \Delta H_{112} \\
& \mathrm{~A}-\mathrm{B} *+\mathrm{A} \stackrel{\mathrm{k}_{121}}{\longrightarrow} \mathrm{A}-\mathrm{B}-\mathrm{A} * \quad \Delta H_{121} \\
& \mathrm{~A}-\mathrm{B}^{*}+\mathrm{B} \stackrel{\mathrm{k}_{122}}{\longrightarrow} \mathrm{A}-\mathrm{B}-\mathrm{B}^{*} \quad \Delta H_{122} \\
& \mathrm{~B}-\mathrm{B} *+\mathrm{B} \stackrel{\mathrm{k}_{222}}{\longrightarrow} \mathrm{B}-\mathrm{B}-\mathrm{B} * \quad \Delta H_{222} \\
& \mathrm{~B}-\mathrm{B} *+\mathrm{A} \stackrel{\mathrm{k}_{221}}{\longrightarrow} \mathrm{B}-\mathrm{B}-\mathrm{A}^{*} \quad \Delta H_{221} \\
& \mathrm{~B}-\mathrm{A}^{*}+\mathrm{B} \stackrel{\mathrm{k}_{212}}{\longrightarrow} \mathrm{B}-\mathrm{A}-\mathrm{B} * \quad \Delta H_{212} \\
& \mathrm{~B}-\mathrm{A}^{*}+\mathrm{A} \stackrel{\mathrm{k}_{211}}{\longrightarrow} \mathrm{B}-\mathrm{A}-\mathrm{A}^{*} \quad \Delta H_{211}
\end{aligned}
$$

Scheme 3.2 Monomer addition to dimeric radical for copolymerization.

$$
r_{11}=k_{p_{111}} / k_{p_{112}}=\exp \left[-\alpha\left(\frac{\Delta \mathrm{H}_{\mathrm{r} 111}-\Delta \mathrm{H}_{\mathrm{r} 112}}{\mathrm{RT}}\right)\right]
$$




$$
\begin{aligned}
& r_{12}=k_{p_{121}} / k_{p_{122}}=\exp \left[-\alpha\left(\frac{\Delta \mathrm{H}_{\mathrm{r} 121}-\Delta \mathrm{H}_{\mathrm{r} 122}}{\mathrm{RT}}\right)\right] \\
& r_{22}=k_{p_{222}} / k_{p_{221}}=\exp \left[-\alpha\left(\frac{\Delta \mathrm{H}_{\mathrm{r} 222}-\Delta \mathrm{H}_{\mathrm{r} 221}}{\mathrm{RT}}\right)\right] \\
& r_{21}=k_{p_{211}} / k_{p_{212}}=\exp \left[-\alpha\left(\frac{\Delta \mathrm{H}_{\mathrm{r} 211}-\Delta \mathrm{H}_{\mathrm{r} 212}}{\mathrm{RT}}\right)\right]
\end{aligned}
$$

Radical reactivity ratios are calculated as:

$$
\begin{aligned}
& s_{1}=k_{p_{211}} / k_{p_{111}}=\exp \left[-\alpha\left(\frac{\Delta \mathrm{H}_{\mathrm{r} 211}-\Delta \mathrm{H}_{\mathrm{r} 111}}{\mathrm{RT}}\right)\right] \\
& s_{2}=k_{p_{221}} / k_{p_{222}}=\exp \left[-\alpha\left(\frac{\Delta \mathrm{H}_{\mathrm{r} 221}-\Delta \mathrm{H}_{\mathrm{r} 222}}{\mathrm{RT}}\right)\right]
\end{aligned}
$$

Some structures of the molecules and radicals used for the calculations done in this work are shown in Figure 3.2. The rest of the structures used for the calculations are presented in Appendix B.
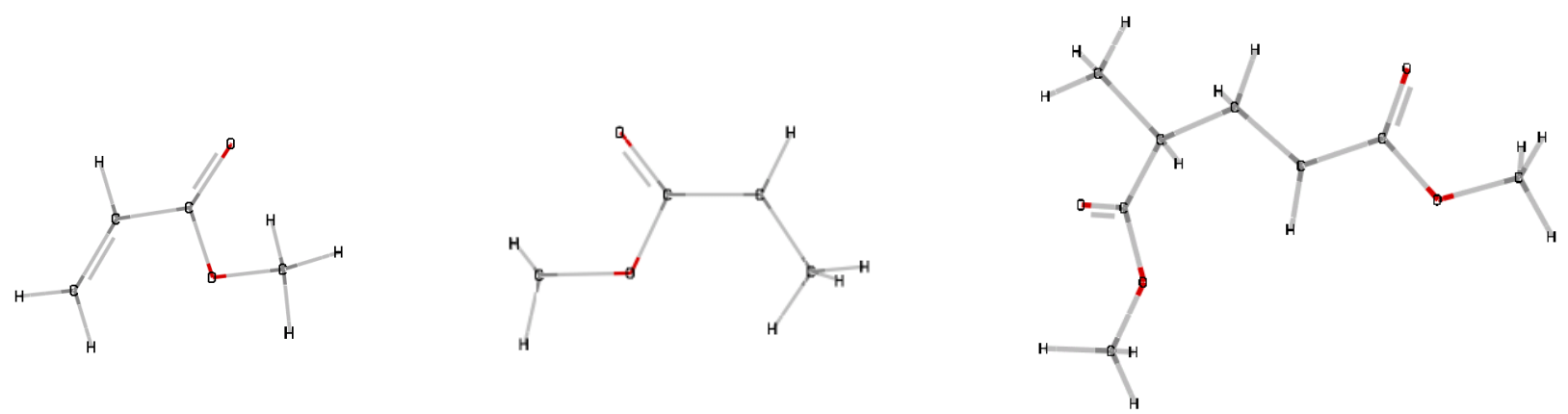
MA monomer

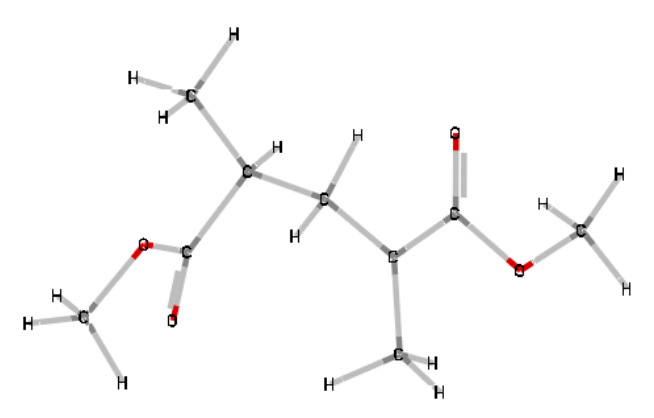

MA-MMA dimeric radical
MA radical

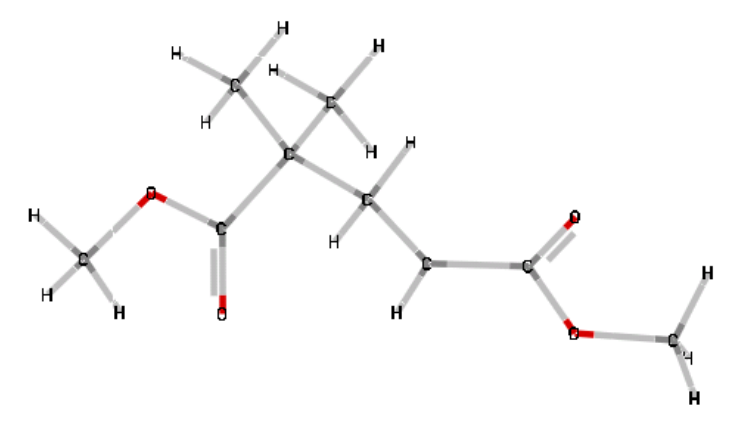

MMA-MA dimeric radical

Figure 3.2 Monomer and radical structures used for the calculation of the reactivity ratios for the terminal model in the MA/MMA copolymerization system 


\section{Chapter 4}

\section{Results}

\subsection{Monomer addition to monomeric radicals}

Given a particular starting geometry, the combined method of conventional optimization followed by relaxed dihedral scans was successful in finding lower energy structures, even for relatively small molecules such as methyl methacrylate monomer. As shown in Figure 4.1, the conformation of methyl methacrylate from the combined method is only subtly different from that derived from the conventional method, but the energy of the conformation obtained from the combined optimization scheme is $6.36 \mathrm{~kJ} / \mathrm{mol}$ lower; with the energy difference caused by the rotation of the methyl group on the vinyl group; In the conventional optimization conformation (Fig. 4.1.a), the dihedral of atoms 1-4-6-7 is $300.2^{\circ}$, while in the combined optimization conformation (Fig. 4.1b), the dihedral of atoms 1-4-6-7 is $121.1^{\circ} .^{9}$ The combined approach was used for all results reported below.

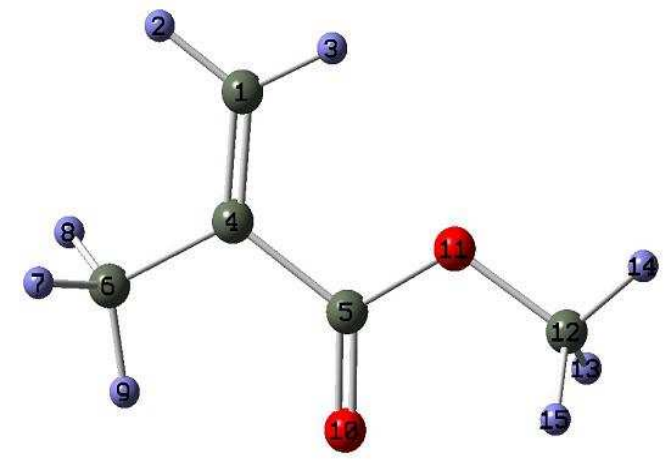

a. Conventional optimization

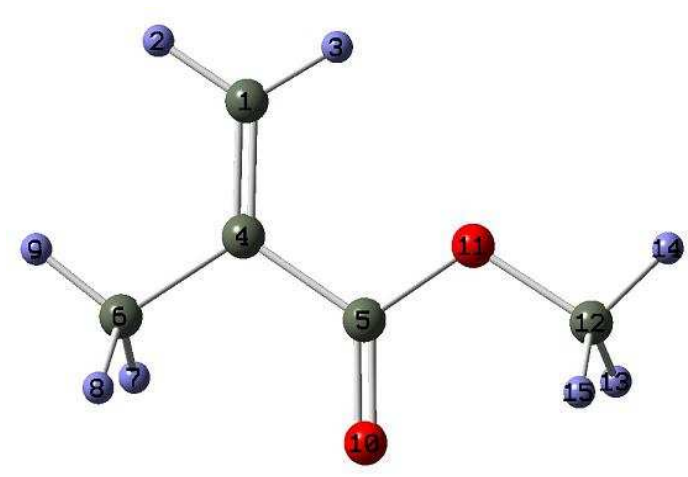

b. Combined optimization

Figure 4.1. Conformations of MMA from different optimization schemes. 
As this study seeks to develop a methodology to estimate reactivity ratios for acrylic based systems, MA and MMA were chosen as a starting point for the investigation. As well as being well-studied systems, the radicals have similar structure to the EEst and PEst radicals (Figure 2.2) used by Fischer and Radom in their experimental investigation of radical chemistry. ${ }^{23,24}$ Their experimental results, discussed more fully later in this chapter, show that the relative reactivity of monomers to small radicals is very similar to that observed for long chain radicals during polymerization. These experimental findings ${ }^{24,55}$ suggest that, if computational techniques can be applied to accurately estimate relative reactivities for small molecule radical reactions, the results will also carry over to FRP.

In this chapter this assertion will be systematically explored. In Section 4.1 reactivity ratios for common monomers (e.g. ethylene, vinyl acetate, styrene, acrylates, methacrylates) are calculated using the Evans-Polanyi (E - P) relationship, based on heats of reaction values estimated computationally using different methods. Comparison with known experimental values indicate that, while accurate for some systems, the methodology has shortcomings for other common systems. Various hypotheses for this mismatch are explored before further examining computationally the effect of temperature (Section 4.2) and substituents (Section 4.3) on reactivity. 


\subsection{Reactivity Ratios}

Table 4.1 summarizes the $\Delta H_{r}$ estimates calculated for monomer addition to monomeric radicals, calculated using density functional theory (DFT) methods. Also tabulated are the reactivity ratios, calculated from the difference in $\Delta H_{r}$ (homopropagation - crosspropagation) values according to Equations 3.2 and 3.3. The last column of the table contains experimental values for the polymer systems, with the ranges based upon compiled data. ${ }^{12}$ As well as MA and MMA, the corresponding butyl esters, BA and BMA were also studied. Methyl ethacrylate (MEA) was added in order to examine the effect of the size of the alkyl group attached to the radical. Ethylene and vinyl acetate are also included in this first set of results; styrene will be considered later in this section. Three different computational techniques were used to calculate $\Delta H_{r}$ values. The criteria used to choose these methods are their cost effectiveness (computational speed) while giving satisfactory results, as is discussed in Chapter 2.

The methods are single point calculations after AM1 geometry optimization, using B3LYP/6-31G(d), ${ }^{38,56}$ B3P86/6-311G(2d,2p $)^{37,56}$ and B971/6-311G(2d,2p) ${ }^{37,56}$ The larger basis sets facilitate flexibility of the electron movement in the orbitals. Generally, the approximate Schrödinger equation solution improves when greater flexibility is given to the electron movement: the bigger the size of the basis set the more accurate the solution but the higher the cost of the computation. These methods are done in a "spin unrestricted" manner by default; while there is a small amount of spin contamination in less conjugated molecules it has an insignificant effect on the total energy. ${ }^{39}$ 
Table 4.1 Calculated $-\Delta H_{r}(\mathrm{~kJ} / \mathrm{mol})$ and reactivity ratios (in brackets) for monomer addition to monomeric radicals compared to literature values for polymer systems. ${ }^{\text {a,b }}$

\begin{tabular}{|c|c|c|c|c|c|c|c|c|}
\hline & Reaction & $\mathrm{Me}$ & hod 1 & $\mathrm{Me}$ & hod 2 & $\mathrm{Me}$ & hod 3 & Experiment $^{12}$ \\
\hline I & MA* + MA & 72.4 & & 84.6 & & 79.6 & & $78-84$ \\
\hline & $\mathrm{MA}^{*}+\mathrm{MMA}$ & 79.8 & (0.49) & 93.8 & $(0.41)$ & 89.8 & $(0.37)$ & $(0.20-0.50)$ \\
\hline & MMA* + MMA & 50.0 & & 65.0 & & 60.8 & & $53-58$ \\
\hline & MMA* + MA & 52.0 & $(\mathbf{0 . 8 3})$ & 65.3 & $(0.97)$ & 60.2 & (1.06) & $(2.0-2.5)$ \\
\hline II & $\mathrm{BA}^{*}+\mathrm{BA}$ & 66.9 & & 79.3 & & 74.4 & & \\
\hline & $\mathrm{BA}^{*}+\mathrm{BMA}$ & 75.3 & $(0.44)$ & 88.8 & $(0.40)$ & 84.9 & $(0.36)$ & $(0.20-0.50)$ \\
\hline & $\mathrm{BMA}^{*}+\mathrm{BMA}$ & 50.3 & & 64.9 & & 60.8 & & \\
\hline & $\mathrm{BMA}^{*}+\mathrm{BA}$ & 52.2 & $(0.84)$ & 65.4 & $(0.94)$ & 60.2 & (1.06) & $(2.0-2.5)$ \\
\hline III & $\mathrm{MA}^{*}+\mathrm{MA}$ & 72.4 & & 84.6 & & 79.6 & & \\
\hline & $\mathrm{MA}^{*}+\mathrm{BA}$ & 71.5 & (1.09) & 84.1 & (1.04) & 79.3 & (1.04) & \\
\hline & $\mathrm{BA}^{*}+\mathrm{BA}$ & 66.9 & & 79.3 & & 74.4 & & \\
\hline & $\mathrm{BA}^{*}+\mathrm{MA}$ & 68.1 & $(\mathbf{0 . 8 9})$ & 79.6 & $(0.97)$ & 74.7 & $(0.97)$ & \\
\hline IV & $\mathrm{MMA}^{*}+\mathrm{MMA}$ & 50.0 & & 65.0 & & 60.8 & & \\
\hline & $\mathrm{MMA}^{*}+\mathrm{BMA}$ & 49.9 & $(0.99)$ & 64.8 & (1.02) & 60.6 & (1.02) & (1.00) \\
\hline & $\mathrm{BMA}^{*}+\mathrm{BMA}$ & 50.3 & & 64.9 & & 60.8 & & \\
\hline & $\mathrm{BMA}^{*}+\mathrm{MMA}$ & 50.4 & (1.01) & 65.1 & (0.99) & 61.0 & (0.99) & (1.00) \\
\hline $\mathrm{V}$ & $\mathrm{MA}^{*}+\mathrm{MA}$ & 72.4 & & 84.6 & & 79.6 & & \\
\hline & $\mathrm{MA}^{*}+\mathrm{MEA}$ & 78.6 & $(0.55)$ & 91.3 & $(0.52)$ & 86.3 & $(\mathbf{0 . 5 3})$ & \\
\hline & $\mathrm{MEA}^{*}+\mathrm{MEA}$ & 34.5 & & 50.5 & & 46.2 & & 31 \\
\hline & $\mathrm{MEA}^{*}+\mathrm{MA}$ & 44.4 & $(\mathbf{0 . 3 8})$ & 59.3 & $(0.42)$ & 54.9 & $(0.42)$ & \\
\hline VI & $\mathrm{MMA}^{*}+\mathrm{MMA}$ & 50.0 & & 50.5 & & 60.8 & & \\
\hline & MMA $*$ MEA & 43.7 & (1.85) & 60.9 & $(2.10)$ & 53.9 & (1.96) & \\
\hline & $\mathrm{MEA}^{*}+\mathrm{MEA}$ & 50.0 & & 65.0 & & 46.2 & & \\
\hline & MEA* + MMA & 43.7 & $(0.40)$ & 57.1 & $(0.37$ & 54.8 & $(0.43)$ & \\
\hline VII & $\mathrm{MA}^{*}+\mathrm{MA}$ & 72.4 & & 84.6 & & 79.6 & & \\
\hline & $\mathrm{MA}^{*}+\mathrm{VAc}$ & 52.7 & (6.76) & 64.8 & $(6.77)$ & 60.1 & $(6.62)$ & $(6.30-7.30)$ \\
\hline & $\mathrm{VAc} *+\mathrm{VAc}$ & 82.4 & & 91.2 & & 86.8 & & \\
\hline & $\mathrm{VAc} *+\mathrm{MA}$ & 106.1 & $(\mathbf{0 . 1 0})$ & 115.6 & $(0.10)$ & 111.1 & $(0.10)$ & $(0.03-0.04)$ \\
\hline VIII & MMA* + MMA & 50.0 & & 65.0 & & 60.8 & & \\
\hline & $\mathrm{MMA}^{*}+\mathrm{VAc}$ & 26.5 & $(9.76)$ & 39.4 & (11.9) & 34.2 & (13.14) & $(22-30)$ \\
\hline & $\mathrm{VAc} *+\mathrm{VAc}$ & 82.4 & & 91.2 & & 86.8 & & \\
\hline & VAc $*$ MMA & 98.3 & $(0.22)$ & 109.9 & $(0.16)$ & 105.9 & $(0.16)$ & $(0.03-0.07)$ \\
\hline IX & Eth* + Eth & 87.8 & & 94.3 & & 88.8 & & 102 \\
\hline & $\mathrm{Eth}^{*}+\mathrm{VAc}$ & 98.5 & $(0.36)$ & 106.3 & $(0.31)$ & 102.3 & $(0.29)$ & $(0.13-0.88)$ \\
\hline & $\mathrm{VAc}^{*}+\mathrm{VAc}$ & 82.4 & & 91.2 & & 86.8 & & \\
\hline & VAc* + Eth & 76.1 & $(\mathbf{1 . 8 6})$ & 84.9 & (1.85) & 78.7 & (2.19) & $(0.72-3.74)$ \\
\hline
\end{tabular}

${ }^{a}$ Methods AM1 opt with single point calculation by: Method 1 B3LYP/6-31G(d);

Method 2 B3P86/6-311G(2d,2p); Method 3 B971/6-311G(2d,2p).

${ }^{\mathrm{b}} \mathrm{MA}=$ methyl acrylate; $\mathrm{MMA}=$ methyl methacrylate; $\mathrm{BA}=$ butyl acrylate; $\mathrm{BMA}=$ butyl methacrylate; $\mathrm{MEA}=$ methyl ethacrylate; $\mathrm{VAc}=$ vinyl acetate; $\mathrm{Eth}=$ ethylene. The added $*$ indicates the corresponding monomeric radical species. 
It has been shown that the effect of the hindered rotor (HR) model on $\Delta S_{r}$ can be significant, particularly at high temperatures, ${ }^{9}$ but that $\Delta H_{r}$ is relatively insensitive to which model is used. ${ }^{9}$ The results in Table 4.1 confirm this conclusion, as the method used has little impact on the reactivity ratios. This is consistent with the work of Van Speybroeck et al. ${ }^{57}$ who observed that calculated values of activation energy for ethylene propagation, which can be related to enthalpic changes, were insensitive to choice of harmonic oscillator $(\mathrm{HO})$ or HR models.

Table 4.2 The effect of radical chain length on computed $-\Delta H_{r}(\mathrm{~kJ} / \mathrm{mol})$ values for homopropagation of methyl acrylate (MA). (Expt value $=78-84 \mathrm{~kJ} / \mathrm{mol})$

\begin{tabular}{lcc}
\hline Reaction & $\begin{array}{c}\text { Product Chain } \\
\text { Length }\end{array}$ & $\begin{array}{c}-\Delta H_{r} \\
\text { Method 1 }\end{array}$ \\
\hline MA* + MA $^{*}$ & 2 & 72.40 \\
MA-MA* + MA & 3 & 72.26 \\
MA-MA-MA* + MA & 4 & 72.53 \\
\hline AM1 opt with single point calculation by: Method 1 B3LYP/6-31G(d)
\end{tabular}

Although the $\Delta H_{r}$ values calculated using the different computational methods show small differences, most are within the acceptable computational error of $\pm 10 \mathrm{~kJ} / \mathrm{mol}^{58}$ compared with homopolymerization $\left(\Delta H_{p}\right)$ experimental values, summarized in the last column of Table 4.1. ${ }^{12}$ Further calculations for MA addition to MA radicals of increasing length indicate that the enthalpy of reaction is not a strong function of radical chain length (Table 4.2). These encouraging results suggest that addition to monomeric radicals provides a reasonable model for polymeric systems, and thus computations may provide an efficient means to estimate relative addition rates, i.e., reactivity ratios. Fischer and 
Radom reach the same conclusion from their experimental investigations of monomer addition to small radicals. ${ }^{23,24}$

It is important to note that computing relative kinetic rate coefficients does not require a high level of theory; ${ }^{17,}{ }^{59}$ much of the systematic error introduced through computational assumptions cancels out when calculating monomer reactivity ratios. Figure 4.2 plots the Mayo-Lewis relation ${ }^{14}$ between polymer and monomer composition for the MMA/VAc system (Table 4.1, System IX) based upon reactivity ratios calculated in this study as well as from literature. While there is some variation in $\Delta H_{r}$ values with method, the variation in reactivity ratios is much smaller. Figure 4.2 indicates little difference between the predicted composition curves using $r$ values estimated by the various computational methods, although the larger basis sets combined with the B3P86 and B971 methods provide slightly more accurate values; the remaining copolymer composition results discussed in this chapter are calculated using reactivity ratio values computed using Method 3 (B971/6-311G(2d,2p)). The MMA/VAc computed values are not as extreme as stated in the literature $\left(r_{\mathrm{MMA}}=25, r_{\mathrm{VAc}}=0.05\right)$, but capture the tendency of producing methacrylate-rich copolymer. 


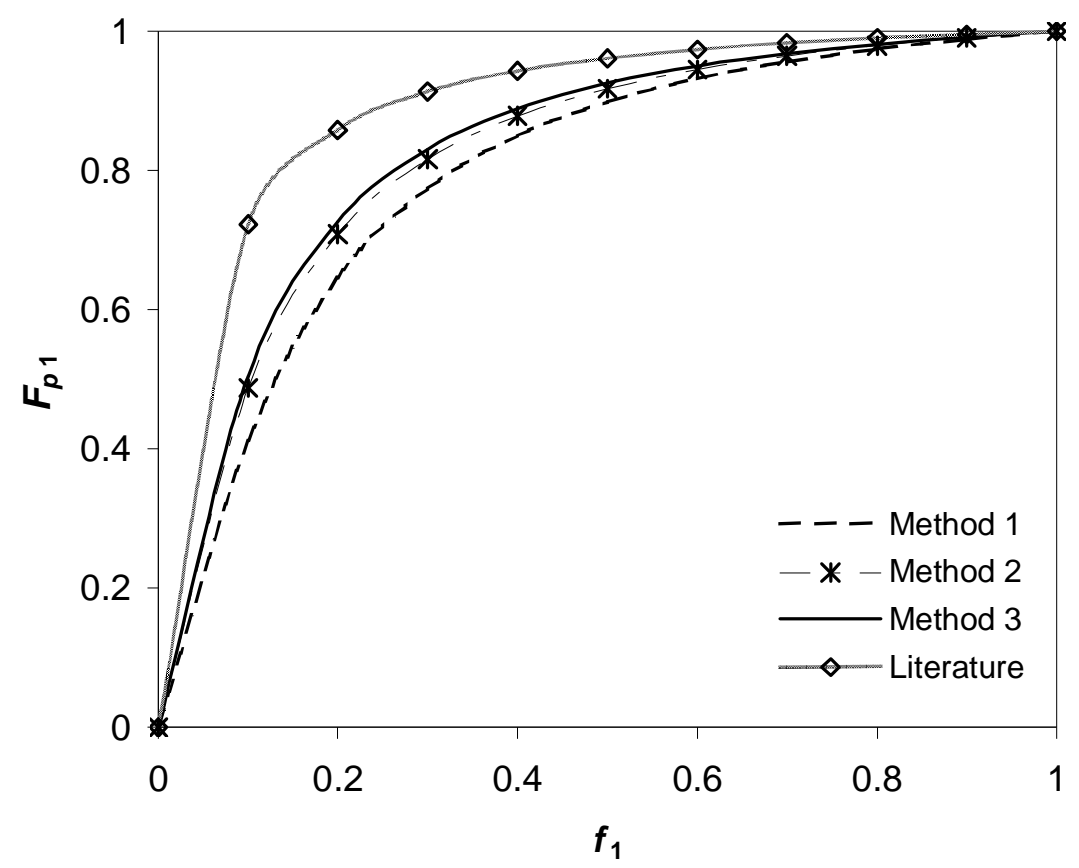

Figure 4.2. Relationship between MMA(1)/VAc(2) copolymer $\left(F_{p 1}\right)$ and monomer $\left(f_{1}\right)$ composition, calculated from computed reactivity ratios summarized in Table 1 (System IX), and from literature values $\left(r_{1}=25 ; r_{2}=0.05\right)$.

Figure 4.3 plots copolymer composition for some monomer pairings that exhibit good agreement between computational results and literature. Reactivity ratios are close to unity for the situation where the monomers differ only in the alkyl ester group (e.g.; MMA/BMA and MA/BA, Systems III and IV in Table 4.1). Changing the alkyl ester group from methyl to butyl also has no effect on the calculated reactivity ratios for acrylate/methacrylate copolymerization (compare MMA/MA and BMA/BA, Systems I and II). This result is contrasted to the change computed as monomer changes from acrylate (MA or BA) to methacrylate (MMA or BMA) to ethacrylate (methyl ethacrylate, MEA); the homopropagation reaction becomes less exothermic, and reactivity ratios also 
deviate substantially from unity. Unfortunately, no literature values could be found for copolymerization of MEA with acrylates or methacrylates. In general, many of the results obtained by computation are consistent with observed structure-reactivity trends for most of the pairs examined, as also seen in the good agreement with literature results for Eth/VAc and MA/VAc in Figure 4.3. There is a wide range for the $r$ values for the Eth/VAc system, ${ }^{12}$ and the values used to plot the relationship between the copolymer and monomer composition were $r_{\mathrm{Eth}}=0.3$ and $r_{\mathrm{VAc}}=2.0$

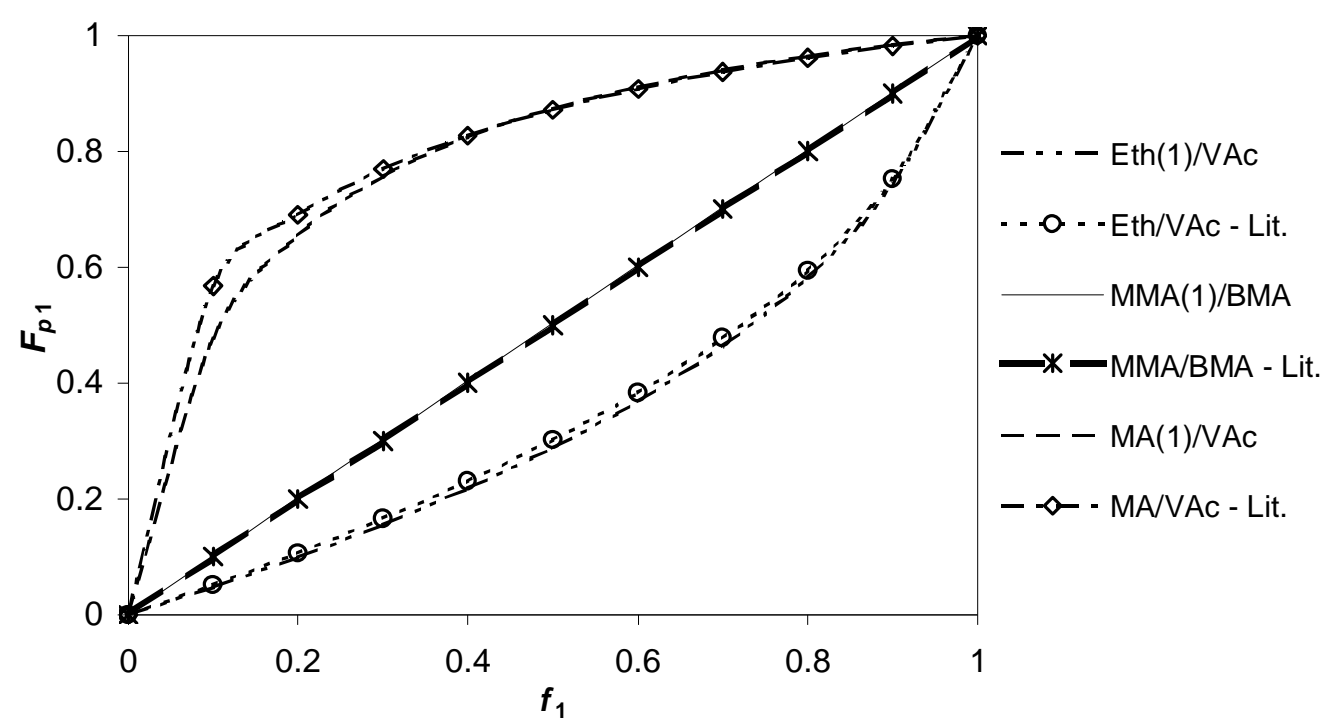

Figure 4.3. Relationship between copolymer $\left(F_{p 1}\right)$ and monomer $\left(f_{1}\right)$ composition, calculated from computed reactivity ratios summarized in Table 1 (Systems IV, $V I I, I X)$, and from literature values. 
Table 4.3 Calculated $-\Delta H_{r}(\mathrm{~kJ} / \mathrm{mol})$ and monomer reactivity ratios for styrene $(\mathrm{S})$ copolymerized with methyl acrylate (MA) and methyl methacrylate (MMA), compared to literature values for polymer systems. B3LYP optimized.

\begin{tabular}{|c|c|c|c|c|}
\hline Reaction & $\begin{array}{l}-\Delta H_{r} \\
\text { Method 1 }\end{array}$ & $r$ & $\begin{array}{l}-\Delta H_{p} \\
\text { (expt) }\end{array}$ & $r(\mathrm{expt})$ \\
\hline MA* + MA & 78.31 & 0.43 & $78-84$ & $0.15-0.3$ \\
\hline $\mathrm{MA}^{*}+\mathrm{S}$ & 87.02 & & & \\
\hline $\mathrm{S}^{*}+\mathrm{S}$ & 60.34 & 2.02 & 73 & $0.7-0.8$ \\
\hline $\mathrm{S}^{*}+\mathrm{MA}$ & 53.04 & & & \\
\hline $\mathrm{MMA}^{*}+\mathrm{MMA}$ & 53.84 & 0.47 & $53-58$ & $0.4-0.6$ \\
\hline $\mathrm{MMA}^{*}+\mathrm{S}$ & 61.63 & & & \\
\hline$S^{*}+S$ & 60.34 & 1.74 & & $0.4-0.6$ \\
\hline $\mathrm{S}^{*}+\mathrm{MMA}$ & 54.61 & & & \\
\hline
\end{tabular}

B3LYP opt with single point calculation by: Method 3 .

Exceptions to the good agreement found between experiment and literature $r$ values are the MMA/MA (System I in Table 4.1), MA/S and MMA/S pairings (in Table 4.3), with copolymer vs. monomer composition plotted in Figure 4.4. Although the calculated value for $r_{\mathrm{MA}}$ is close to the experimental value of 0.4 , the calculated value for $r_{\mathrm{MMA}}(\sim 1)$ differs substantially from the literature values of $2.0-2.5$. The addition of MMA to MMA* is less exothermic than MMA addition to MA*, as is expected from the donating effect of the $\mathrm{CH}_{3}$ group that makes MMA* less electrophilic than MA*. It is also expected that electron rich MMA should add more readily (more exothermic reaction) to an electrophilic radical than MA. However, while this was found for addition to MA* (computed $r_{\mathrm{MA}}$ value of 0.4 is in good agreement with literature), the calculations did not show this difference for addition to MMA*. Instead, it is calculated that the heats of reaction are almost identical, resulting in a reactivity ratio of close to unity instead of the experimental value of 2-2.5. Identical results were obtained for BMA/BA. Note also that the experimental and calculated value for MA versus MMA addition to the EEst* radical 
are close to the experimental values for $r_{\mathrm{MA}}$ from polymerization studies (Table 4.4); thus it is not expected that the mismatch for $r_{\mathrm{MMA}}$ can be attributed to chain length effects. This deviation from experimental observation may arise from a problem in application of DFT methods for total resolution of energy associated with molecules that have steric crowding, such as MMA. ${ }^{34-36}$ Steric crowding refers to the unfavourable spatial arrangement of atoms in a molecule due to space limitation. Molecular or radical reactivity is influenced to an extent by this phenomenon. Once there is steric crowding around the spin centre of a radical or molecule, the reactivity is greatly reduced. Addition of a free radical becomes sluggish. Since DFT does not include dispersion effects, it tends to overestimate steric repulsions and would thus destabilize the radical relative to the monomer. Due to the steric strain on the molecule or radical, the total energy computed can be significantly altered. Dispersion effects are the only forces of interaction in nonpolar molecules, and arise from a temporary dipole inducing a complementary dipole in an adjacent molecule. These dipoles are always shifting, but are induced in phase and give a net attraction. They depend on the polarizability of the molecule. Although the discrepancy is sufficient to cause a significant deviation in calculated copolymer

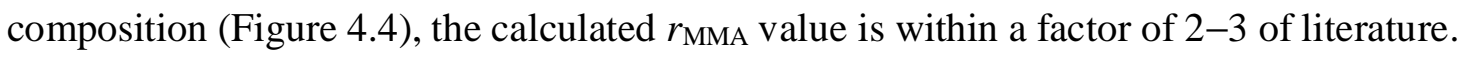




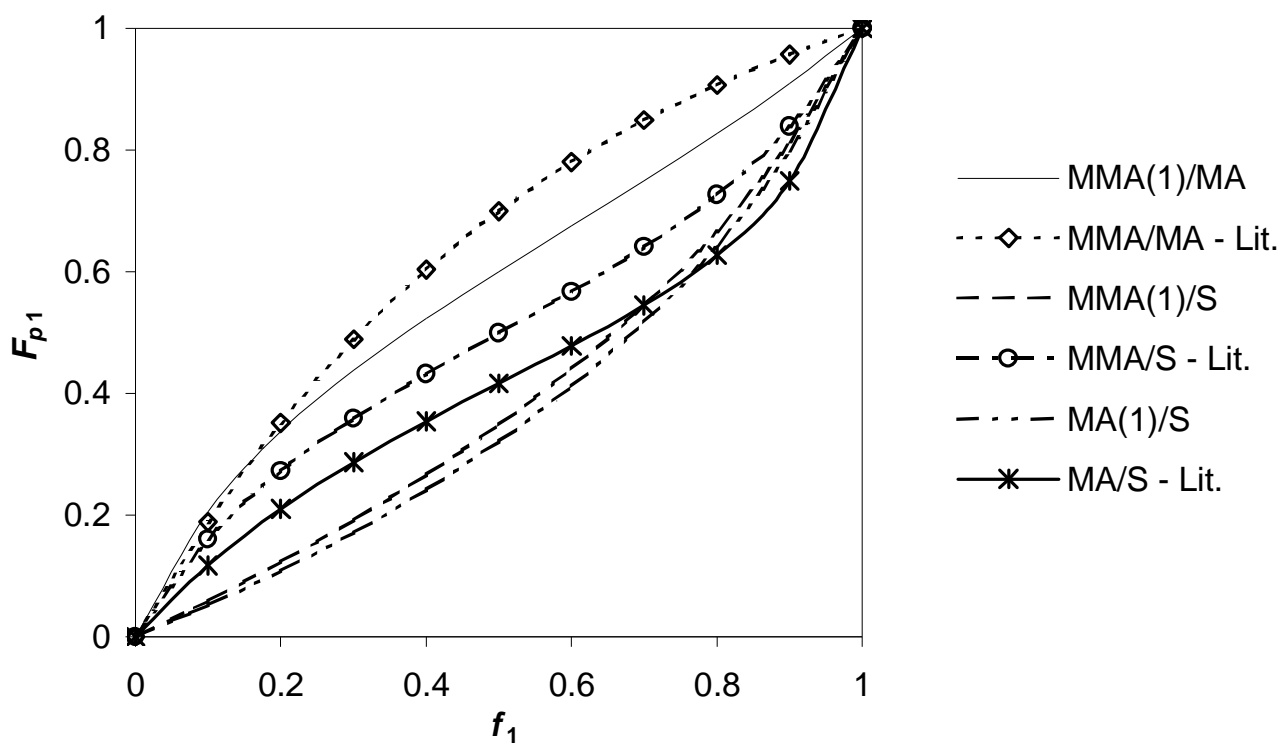

Figure 4.4 Relationship between copolymer $\left(F_{p 1}\right)$ and monomer $\left(f_{1}\right)$ composition calculated from computed reactivity ratios for MMA/MA (Table 4.1, System I) and styrene with MMA and MA (Table 4.3). Curves are compared to those calculated using $r$ values from literature.

Most of the radicals under study are electrophilic, and the effects discussed for MMA and MA monomer and radical activity apply. Styrene, however, is an electron donor substituted radical (nucleophilic) that reacts quickly with electron deficient monomers; ${ }^{23,24}$ thus, it is expected that MMA (or MA) should add more quickly (reaction more exothermic) to $\mathrm{S}^{*}$ than electron-rich styrene. While this is observed experimentally $(r<1),{ }^{7,12,}$ the computational results summarized in Table 4.3 exhibit the reverse trend, with $r>1$. The second reactivity ratios computed for the same pairings are close to experimental values: adding the electron rich $\mathrm{S}$ monomer to either MA* or MMA* is more exothermic than the corresponding homopolymer additions. The mismatch in 
styrene reactivity ratios leads to significant deviations in the copolymer composition predictions, as shown in Figure 4.4.

Chain length effects can be ruled out as a possible explanation for the deviation of results from experimental data based upon the good agreement of computation with literature values for some systems, as can be observed in Figure 4.2. Investigating effects for addition of MA to MA radicals of increasing chain length (Table 4.2) supports the conclusion that chain length is not an important issue in the investigation. A review of Fischer and Radom's work, ${ }^{23}$ (Table 4.4) shows agreement between small molecule $r$ values measured experimentally and the corresponding polymerization $r$ values, also indicating that small radicals are representative of the polymeric radical. In order to determine the minimum sized chemical system that can be representative of a propagating radical of a polymer, one should find at what length of the polymer chain the heat of reaction converges to that of the experimental polymeric value. Amoung systems that have been studied before, for ethylene ${ }^{60}$ convergence of the rate coefficient occurs at the hexyl radical stage (ie. after addition of the third monomer; $\mathrm{n}=3$ ). For the acrylonitrile ${ }^{55}$ and vinyl chloride ${ }^{55}$ studies the radical that could reliably mimic the polymerization system appeared to be $n=1.5$ and the rate coefficients calculated produced absolute values that agree within a factor of 1.6 with literature values. This gives a good reason to justify why the values of this work can be taken as reasonable for $\mathrm{n}=1$, and more so we are just interested in relative, not absolute rate coefficients. Chain length effects will be discussed further in Chapter 5. 
It should also be noted that possible solvent effects are not accounted for in the computational calculations done for gas-phase reactions. Most polymerization processes are carried out in the solution phase. From previous computational studies ${ }^{55}$ it has been shown that for homopropagation reactions the solvent effects are very insignificant, probably because the transition state of the studied molecules comes early and the solvation energy is expected to be similar to that of the reactants. Solvent effects may be significant to some cross-propagation reactions, where there are electrostatic solutesolvent interactions. These can be parameterized with a very sophisticated treatment. In this work, the transition state is not taken into consideration while estimating relative rates. This should not be a major source of error for nonpolar molecules, as most experimental studies find that reactivity ratios do not vary with solvent choice. ${ }^{12}$

As discussed earlier in this chapter, another breakdown to achieving results that agree with experimental values could be attributed to the computational calculational errors related to chemistry of the molecules. In the most recent studies, ${ }^{55}$ an assessment of the accuracy of the calculations has been made. The most common errors could be attributed to the accuracy of the electronic structure calculations and the model used. From their work Coote et al. ${ }^{55}$ found out that the low cost DFT methods such as B3LYP have errors of over $20 \mathrm{~kJ} / \mathrm{mol}$ in reaction enthalpies and these errors are variable depending on the molecular structure. However, from our work it would seem that the errors in the reaction enthalpies are not as pronounced because of the large basis sets employed. The presence 
of these non-systematic errors has also been demonstrated for the case of radical addition to $\mathrm{C}=\mathrm{O}$ double bonds and also bond dissociation energies in simple closed-shell systems. ${ }^{61}$ This becomes a concern if the results calculated using DFT are used to study substituent effects and absolute values. For this work, the $\mathrm{HO}$ approximation with the partition functions based on the thermodynamics of an ideal gas is used as the model. This model seems to be yielding reasonable results for systems such as MA/VAc, Eth/VAc and MMA/MBA but for systems like MA/St there are problems associated with steric crowding and the assumption that $A$ is the same when applying the $\mathrm{E}-\mathrm{P}$ relationship. The HO model is inadequate for big molecules such as styrene where the radical is highly delocalized. The model has a tendency to overestimate or underestimate the entropy and $H_{\text {therm }}$ values compared with the HR model. However, other work shows that for small molecules like those involved in the addition of MMA monomeric radical to monomer, the absolute values of entropy and $H_{\text {therm }}$ are not very sensitive to the model used, with the deviations well within $10 \% .^{9}$

Despite the good agreement for some systems in this work, a shortfall could arise from the assumption that the pre-exponential factor $A$ is constant for a family of reactions when applying the Evans-Polanyi (E-P) relationship. This seems to be not valid for some systems, especially where polar effects are predominant, ${ }^{23,62}$ as has been noted in studies where polar effects, in addition to the usual enthalpy effects, dramatically enhance the reactivity of aminoalkyl radicals toward an acrylate monomer. ${ }^{63}$ In an extensive review, ${ }^{23}$ experimental and theoretical work on the major factors controlling the addition 
of carbon-centred radicals to alkenes was used to plot the activation energy versus the reaction enthalpy. From the experimental data the role of the reaction enthalpy was empirically evaluated as an upper limiting factor. The contribution of the polar effects was then taken into account by turning to a multiplicative factor of the activation energy taken from the experimental data. This contribution of polar effects is not considered in this work and as such, for some systems where these effects are prevalent, the relationship between $E_{a c t}$ and $\Delta \mathrm{H}$ is less valid (Figure 4.5).

Table 4.4 Calculated $\mathrm{E}_{\text {est }}(\mathrm{kJ} / \mathrm{mol})$ and reactivity ratios (in brackets) for monomer addition to PEst* and EEst* compared to literature values from Fischer and Radom's work $^{23}$.

\begin{tabular}{llllllc}
\hline Reaction & $A$ & $\begin{array}{l}E \\
(\mathrm{~kJ} / \mathrm{mol})\end{array}$ & $\begin{array}{l}k(\mathrm{~L} / \mathrm{mol}-\mathrm{s}) \\
@ 20 \mathrm{C}\end{array}$ & $\begin{array}{l}(-\Delta H) \\
(\mathrm{kJ} / \mathrm{mol})\end{array}$ & $r$ lit & $\begin{array}{l}E_{\text {est }} \\
(\mathrm{kJ} / \mathrm{mol})\end{array}$ \\
\hline PEst* + MMA & $3.16^{*} 10^{7}$ & $\mathbf{2 2 . 4}$ & 3710 & 87 & & $\mathbf{3 0 . 9}$ \\
PEst* + MA & $3.16^{*} 10^{7}$ & $\mathbf{2 5 . 3}$ & 1150 & $85(\mathbf{3 . 2 3})$ & $\mathbf{( 2 . 2 4 )}$ & \\
\hline EEst* + MA & $7.9 * 10^{7}$ & $\mathbf{2 1 . 1}$ & $1.5 * 10^{4}$ & 80 & & \\
EEst* + MMA & $7.9 * 10^{7}$ & $\mathbf{1 7 . 9}$ & $6.0^{*} 10^{4}$ & $82(\mathbf{0 . 2 5})$ & $\mathbf{( 0 . 2 7 )}$ & $\mathbf{3 1 . 3}$ \\
\hline PEst* + MMA & $3.16^{*} 10^{7}$ & $\mathbf{2 2 . 4}$ & 3710 & 87 & & \\
PEst* + St & $3.16^{*} 10^{7}$ & $\mathbf{2 1 . 5}$ & 5500 & $118(\mathbf{0 . 6 7})$ & $\mathbf{( 0 . 6 0 )}$ & $\mathbf{3 2 . 4}$ \\
\hline EEst* + MA & $7.9 * 10^{7}$ & $\mathbf{2 1 . 1}$ & $1.5 * 10^{4}$ & 80 & & \\
EEst* + St & $7.9 * 10^{7}$ & $\mathbf{1 6 . 7}$ & $9.3^{*} 10^{4}$ & $113(\mathbf{0 . 1 6})$ & $\mathbf{( 0 . 2 0 )}$ & $\mathbf{3 2 . 0}$ \\
\hline
\end{tabular}

Table 4.4 shows an analysis of Fischer and $\operatorname{Radom}^{23}$ results in their study of addition of monomers MA, MMA and St to PEst and EEst radicals. The experimentally measured rate constants $(k)$ of the reactions were combined with estimated frequency factors to calculate the activation energies $(E)$ and the monomer reactivity ratios $(r)$. The heats of reaction were deduced from the reaction enthalpy for the addition of the methyl radical to each alkene and the differences between the reaction enthalpies for the addition of methyl and for the PEst and EEst radicals. When comparing the calculated reactivity ratios of the 
small molecules with that of the polymeric reactions from literature $\left(r_{l i t}\right)$, we learn that the small molecule radical kinetics can reasonably represent the long chain radical kinetics in polymerization.

$E_{\text {est }}$ the estimated activation energy in the last column of the Table 4.4 was calculated using the Evans- Polanyi relationship from the equation;

$$
E_{a}=\alpha \Delta H+E_{0}
$$

where $\alpha$ is the reaction transfer coefficient and $E_{0}$ is termed the intrinsic barrier to reaction. It is determined from this analysis that while some estimated $r$ values agree well with literature, $\mathrm{E}-\mathrm{P}$ relationship does a poor job at estimating activation energies. This is where the polar effects have to be taken into consideration.

A structure reactivity trend can be seen from the heats of reaction. The heats of reaction show that the electrophilic radicals readily react with MMA and styrene monomers compared to MA monomer, because of the $\mathrm{CH}_{3}$ electron donating effect for the former and an electron donation from the electron cloud from the ring for the latter. Having established this with the results of this work and that of Fischer it can be mentioned that the assumptions made when applying the $\mathrm{E}-\mathrm{P}$ relationship can be a factor responsible for the deviation of computational results in this work. Further investigations on the effects of steric crowding and dispersion effects by DFT methods should be carried out to further elucidate the problems of deviation. In conclusion, two main factors cause the difference between experimental and calculated reactivity ratios; steric crowding 
(methacrylates), and the breakdown of the $\mathrm{E}-\mathrm{P}$ relationship for systems containing styrene.

\subsection{Reactivity ratios - Temperature Dependency}

From the literature reviewed ${ }^{92}$ it has been seen that rate coefficients for some copolymerization systems are temperature dependent. Computational work ${ }^{9}$ done on the addition of MMA monomer to the MMA radical has illustrated that there is indeed some temperature dependency on the entropy and enthalpy of molecules. However, calculations show that $\Delta \mathrm{H}$ for a particular reaction does not change significantly with temperature and that the difference in $\Delta \mathrm{H}$ between two reactions will be even smaller. When looking at relative parameters such as reactivity ratios, the difference in the total energy of the system does reflect the change of $\Delta \mathrm{H}$ due to temperature differences. More so the level of theory used to calculate $H_{\text {therm }}$ (AM1) compared to the level of theory used to calculate the total energy of the molecule (B971/6-311G $(2 \mathrm{~d}, 2 \mathrm{p})$ is low such that the correction to enthalpy becomes very negligible.

Using different levels of theory for the purposes of calculating $r$ values has shown to be a less expensive way to do the investigations computationally, as shown by recent studies. ${ }^{34-36,50}$ However for the purposes of showing temperature dependency it can be

concluded that this approach is not adequate. Moreover recent studies by Coote et al. ${ }^{61,65}$ have illustrated that low cost DFT methods are not appropriate for studying absolute values for radical addition reactions. Calculating $H_{\text {therm }}$ using the highest level of theory, 
that is used to calculate the total energy, would likely show some temperature dependency but this would be significantly more expensive computationally.

\subsection{Heats of Reaction - Structure reactivity trends}

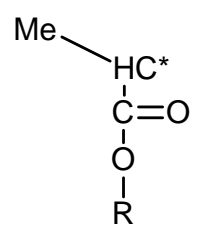

Acrylate radical

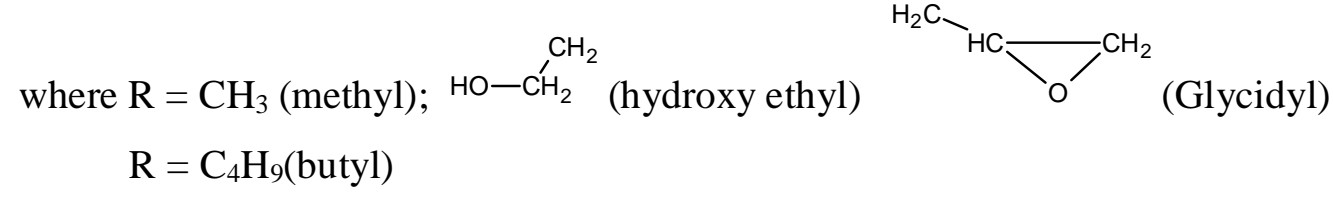

Figure 4.5: Structures of acrylate radicals used to study relative reactivities computationally.

Radical polymerization processes occur through many simultaneous reactions that may be complex. It has been shown in many studies that reactivity is closely related to monomer structure. Computational quantum chemistry has become a powerful tool to study directly individual reactions within complex processes and to extract useful information such as geometries and trends that give the ability to predict reaction kinetics. In this section, the reactivity of the different acrylates and methacrylates is examined using $\Delta H_{r}$ with the aim of understanding the effect of the pendant size, the 
polarity and the nature (linear versus cyclic) of the pendant group on their reactivity. The acrylate radical structure considered in this section are shown in Figure 4.5.

Recent investigation on monomer structure and the reactivity relationship of acrylates by Decker et al. ${ }^{66}$ highlighted electronic effects as a potential contributor to high reactivity. In this study we look at how electronic effects (withdrawal and donation) affect reactivity and heats of reaction.

Table 4.5 Calculated $-\Delta H_{r}(\mathrm{~kJ} / \mathrm{mol})$ for different monomer addition to different monomeric radicals with varying pendant groups.

\begin{tabular}{|l|l|c|}
\hline & Reaction & $-\Delta H_{r}$ \\
\hline I & MA* + MA & 72.4 \\
& MA* + MMA & 78.6 \\
& MA* + MEA & 79.8 \\
& MMA* + MA & 52.0 \\
& MEA* + MA & 44.4 \\
\hline II & MA* + MA & 72.4 \\
& MA* + HEA & 72.1 \\
& MA* + BA & 71.5 \\
& MA* + GA & 70.7 \\
& HEA* + MA & 76.3 \\
& BA* + MA & 68.1 \\
& GA* + MA & 65.4 \\
\hline \multicolumn{2}{|l}{ AM1 opt with single point calculation by B3LYP/6-31G(d) }
\end{tabular}

Table 4.5 shows how changing the structure of the different reacting monomers and radical affect the heats of reaction. In group I, it is observed that when the same radical reacts with monomers having different pendant groups (increasing with size) on the reactive $\mathrm{C}$, there is some impact on the calculated $-\Delta H_{r}$ values which increase as the pendant group increases in size from $\mathrm{H}$ to $\mathrm{CH}_{3}$ to $\mathrm{C}_{2} \mathrm{H}_{5} . \mathrm{CH}_{3}$ and $\mathrm{C}_{2} \mathrm{H}_{5}$ have an electron 
donating effect to the electron deficient carbon and thus renders the molecule more reactive with the electrophilic MA radical. Therefore in comparison to reaction with MA monomer, the MA radical will react more readily with the monomers MMA and MEA, so that the corresponding reactivity ratios are less than unity. On the other hand the trend is reversed when observing the radicals. Changing the pendant group that is on the radical $\mathrm{C}$ from $\mathrm{H}$ to $\mathrm{CH}_{3}$ to $\mathrm{C}_{2} \mathrm{H}_{5}$, in addition to steric effects, makes the radical less electrophilic due to the donation of electrons, and thus the $-\Delta H_{r}$ becomes smaller in magnitude as the size increases. The larger the pendant group, the greater this effect and hence the less exothermic the reaction. Consequently the radical reactivity trend can be summarized as MA $>$ MMA $>$ MEA. These results are consistent with other studies of structure and reactivity relationships of acrylates. ${ }^{57,66,67}$

In group II of Table 4.5, the pendant group that is attached to the ester is varied in size and nature. There is a small effect on $-\Delta H_{r}$ when the change is made on the monomer but it is not as pronounced as the effect seen when the change is made on the radical. The observation that $-\Delta H_{r}$ values for the same radical reacting with different monomers are similar is most likely due to the separation between the pendant group on the ester and the reactive site of the monomer.

Changing the pendant group on the radical has a larger effect on the $-\Delta H_{r}$ values. The hydroxyl in HEA has a tendency to withdraw electrons such that the radical reacts more readily with the MA compared to the other acrylate radicals in the group. The methyl, 
and butyl groups in MA and BA have electron donating and steric effects and these render the radical less electrophilic, such that $-\Delta H_{r}$ decreases in magnitude and the reaction is less exothermic. Although the oxygen in the glycidyl ring has withdrawal tendencies, the electrons in the ring are likely to be dominating in their donating nature such that the radical becomes less electrophilic than the MA and BA radicals. Hence we observe a heat of reaction less negative than for MA and BA radical reactions with MA. The radical reactivity can then be summarized as HEA>MA>BA $>$ GA. Although not examined for the methacrylates due to steric crowding effects discussed earlier, similar trends are expected.

The computational study of the structure- reactivity trends in this work sheds some light on how the size and nature of the pendant groups on the radical carbon enhance the reactivity of the radicals toward acrylate monomer, an effect also studied by Laleve'e et al. ${ }^{59,63}$ Unfortunately there is no available experimental data to compare these predicted trends. However it is interesting to look at available experimental data for systems similar to the ones discussed above.

Table 4.6 Experimental reactivity ratio data for different copolymerization systems

\begin{tabular}{llcc}
\multicolumn{4}{c}{ showing the effect of change in pendant groups. } \\
\hline & Reaction System & $r_{1}$ & $r_{2}$ \\
\hline I & BA/ HEMA & 0.1 & 4.8 \\
& BA/ MMA & $0.3-0.5$ & $1.8-3.0$ \\
& BA/ GMA & 0.1 & 2.16 \\
\hline II & MMA/HEMA & $0.19-0.82$ & 1.5 \\
& MMA/GMA & $0.69-0.8$ & 1.05 \\
\hline
\end{tabular}


Despite the experimental uncertainty, the monomer reactivity ratios summarized in Table 4.6 for BA with various methacrylates provide some evidence that the reacting monomer structure has little effect on the reactivity ratios. The monomer reactivity ratio of the different monomers with the BA radical species is between 0.1 and 0.5 for all the reactions, implying that that the cross-propagation rate is roughly identical regardless of what the pendant group on the reacting monomer is. This concurs with the observations from computation results: the pendant group is far enough removed from the reactive site of the monomer such that it has little or no effect on the reactivity of to the acrylate radical. However, when the pendant group is changed on the methacrylate radical, there is a significant change in the reactivity with BA monomer. The homopropagation of the various methacrylate radicals is always faster than the cross-propagation reaction, but electronic effects affect the radical and thus the relative addition of BA. The GMA and HEMA radicals, because of the oxygen electron withdrawal effect from the ring and from the hydroxyl part of the molecules respectively, show higher monomer reactivity ratios, with HEMA having a higher value than GMA. The same trend is observed for group II of the table. The monomer reactivity ratio of the different monomers with the BA radical species is about the same while the reaction of the different radical species with MMA has different monomer reactivity ratios, with HEMA showing a higher value that GMA as expected. This can be explained by the different magnitudes of electron withdrawal effects by the oxygens on the different radical species. This experimental result is in agreement with the trends calculated computationally and summarized in Table 4.5. 
Further experimental investigations need to be done to confirm that radical reactivity is more affected by change in structure than monomer. 


\section{Chapter 5 \\ Results}

\subsection{Monomer addition to dimeric radicals}

The methodology of this thesis was to validate the computational techniques against well known experimental values such as reactivity ratios, then to apply the techniques to estimate kinetic coefficients for mechanisms that are difficult to study experimentally, such as monomer addition to midchain radicals and penultimate chain growth kinetics. Chapter 4 shows that there are still limitations to the application of computational chemistry to radical reactions. Nonetheless, some simulations have been done to examine more complex reactions, as summarized in this chapter.

Although it has been generally recognized that the terminal model fails to describe the copolymerization rate, it is still useful for modeling many systems as a starting point. The attractions of the terminal model are its simplicity and its ability to represent polymer composition. For most copolymerization systems, the polymer composition can be well described by the terminal model, but the $k_{p, c o p o}$ values must be evaluated according to the penultimate model. In this work, some $r$ values and $s$ values are determined using calculated $\Delta H_{r}$ values in conjunction with the E-P relationship. The reactivity ratio results are compared to existing literature values. This is done so as to also evaluate if this methodology developed will distinguish penultimate unit effects. 
A very important factor to note for this study is the significant time and effort required to perform geometry optimizations in order to get the global minimum structure of the molecules, before any calculations are done. Identification of the minimum energy conformations for the species involves a potential energy scan (relaxed) of the backbone dihedral angles of the molecule. The number of the dihedral angles grows exponentially with the size of the system, and for larger molecules a full search can rapidly become impossible. As the size grows, the system becomes more complex. For instance with a trimeric methyl methacrylate species, 25 dihedral angles are considered. In the systems studied, it has to be noted that the possibility of anchimeric effects ${ }^{55}$ cannot be ruled out and an extra effort has to be applied to screen possible conformations thoroughly. It would take approximately three weeks to a month to come up with just the minimum energy conformation of one molecule. The dihedral scans for each molecule are done using (B3LYP/6-31G(d), as AM1 is unable to handle large molecules. Single point calculations are performed on the minimum geometries obtained from the scans using B3LYP/6-31G(d) in order to get the global minimum structure.

\subsection{Reactivity Ratios - Penultimate Model}

Table 5.1 summarizes the $\Delta H_{r}$ estimates calculated for monomer addition to dimeric radicals, calculated using density functional theory (DFT) methods. Also tabulated are the reactivity ratios, calculated from the difference in $\Delta H_{r}$ (homopropagation - crosspropagation) values as described in Chapter 3 of this work. The last column of the table 
contains experimental values for the polymer systems, with the ranges based upon compiled data. ${ }^{12}$

Penultimate unit effects are examined for three systems; MA/MMA, MMA/MEA and MA/St. Of the three, MA/MEA has no experimental data to compare with, while for the other two systems calculated monomer reactivity ratio values deviate from the known experimental values. The potential reasons and an outlook on how the problem may be solved are discussed at length in Chapter 4 and later in the future work suggestions. Despite these deviations, some trends can be extracted from the data obtained.

The $r$ values calculated for the MMA/MEA system (System II in Table 5.1) indicate there is no explicit penultimate unit effect for this system. This system was examined to further check the cancellation effect of the steric crowding effects on the MMA and MEA observed in the terminal model. Although the results seem reasonable, there is no experimental data to compare with. The monomer reactivity ratio for each radical species is the same; e.g., Dimeric MMA* species in IIA and IIB have the same $r$ and dimeric MEA* species in IIC and IID also have the same $r$. Referring back to Table 4.1, it can be observed that $r$ values for the monomeric MMA* and MEA* species are approximately the same, although it has to be noted that the optimization of the minimum structure is done at a different level of theory. This agreement further supports the conclusion that chain length has negligible effect on the monomer reactivity ratios. The results are consistent with the implicit penultimate model, that is $r_{1} \approx r_{11} \approx r_{12}$. It is not conclusive 
that there is a cancellation of steric negative effects in MMA/MEA, but this could be a case for further investigation. Coote et al. ${ }^{55}$ cite that although there might be a slight difference between $r_{l}$ and the corresponding penultimate model monomer reactivity ratios, it is very insignificant for acrylonitrile and vinyl chloride system.

However there are differences in the $r_{i j}$ and $r_{j j}$ values for MA/MMA and MA/St, as would be expected for an explicit penultimate unit effect. For example, for MA versus MMA addition to a MA monomeric radical, the reactivity ratio was calculated to be 0.37 in chapter 4 (see Table 4.1). The relative monomer reactivity ratios are calculated to be 0.63 for addition to an MMA-MA dimeric radical and 0.35 for addition to MA-MA radical. The effect of these differences are small when examining a plot of polymer vs. monomer composition curves calculated using the computational $r$ values, as shown in Figure 5.1. This result is in agreement with Coote and Davis, ${ }^{68}$ who argue that an explicit penultimate unit effect should exist, but may be too subtle to be observed experimentally from polymer composition data. Both curves calculated using the computational values differ from literature; as discussed in Chapter 4, this can be attributed to steric crowding for the MMA component of the dimeric radical. 


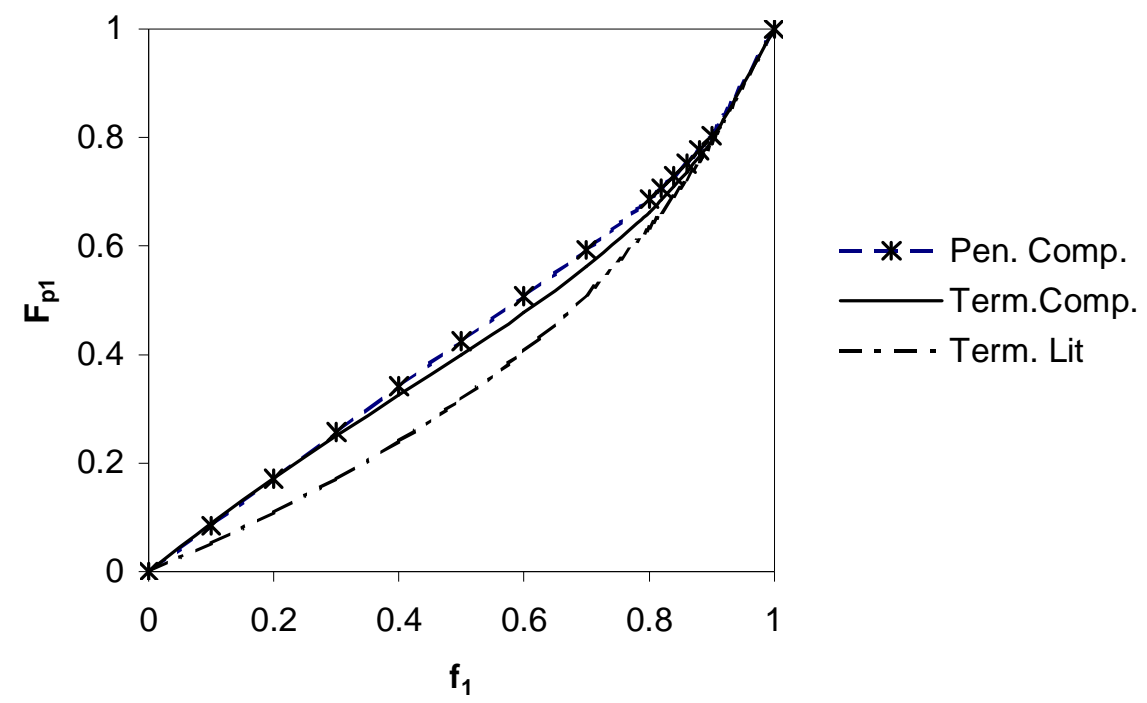

Figure 5.1 Relationship between copolymer $\left(F_{p 1}\right)$ and monomer $\left(f_{1}\right)$ composition calculated from computed reactivity ratios for MA/MMA (Table 4.1, System I and Table 5.1, system 1A). Curves are compared to those calculated using values $\left(r_{1}=0.4\right.$ and $r_{2}$ $=2.0 ; 1=$ MA) from literature.

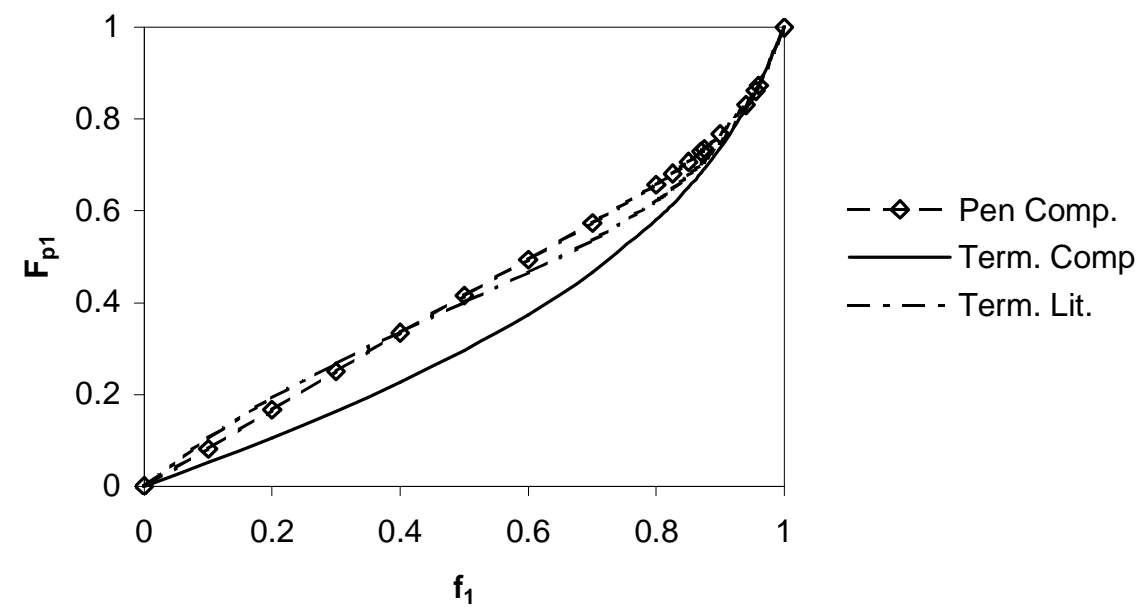

Figure 5.2 Relationship between copolymer $\left(F_{p 1}\right)$ and monomer $\left(f_{1}\right)$ composition calculated from computed reactivity ratios for MA/St (Table 4.2, System I and Table 5.1, system IIIA). Curves are compared to those calculated using $r$ values $\left(r_{l}=0.25\right.$ and $r_{2}=0.87 ; 1=M A$ ) from literature. 
The MA/St system composition plots show a different pattern from the MA/MMA system. Because the calculated monomer reactivity ratios of the St-MA radical varies substantially from the experimental values, computational results for the terminal model and penultimate model values give curves that are different. Surprisingly, the polymer composition curve calculated using the penultimate model with computational values agrees reasonably well with experimental data represented by the "term lit." curve. The agreement is likely coincidental, due to the issues with St discussed in chapter 4 .

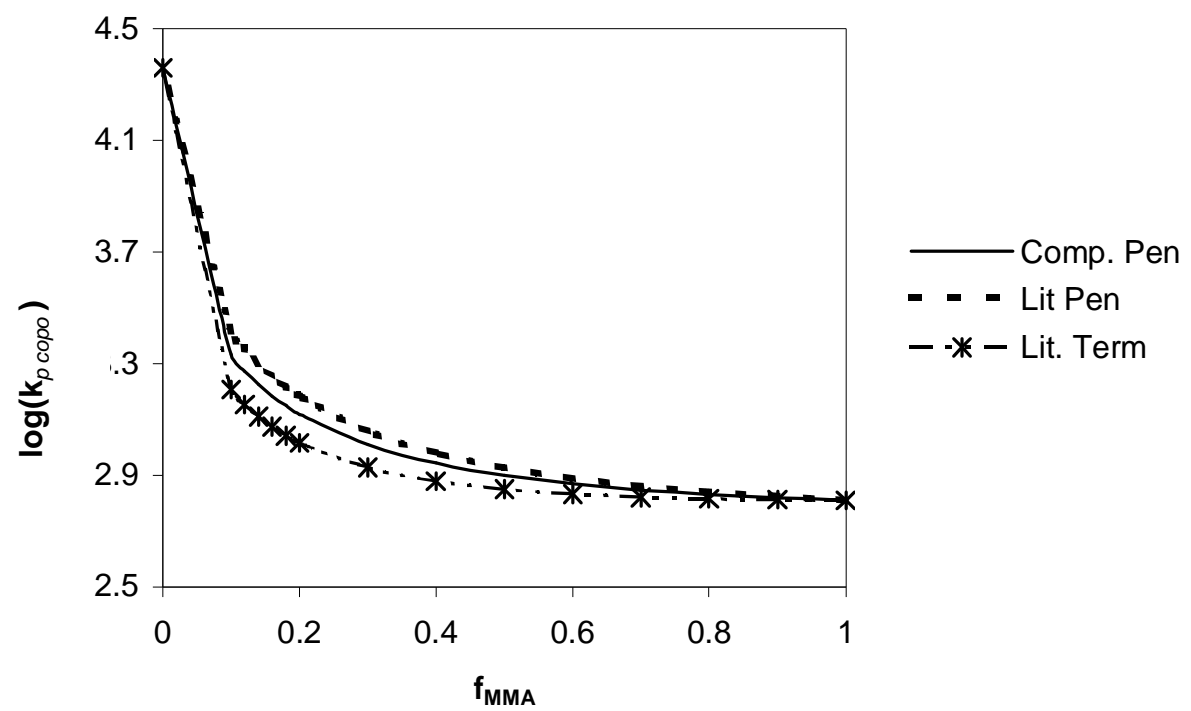

Figure 5.3 Relationship between rate of copolymerization ( $\left.k_{p, c o p o} L / m o l-s\right)$ and monomer $\left(f_{1}\right)$ composition, calculated from computed radical reactivity ratios for MA/MMA systems compared to literature ratios for the penultimate and terminal models $\left(r_{1}=r_{11}=r_{12}=0.4 ; r_{2}=r_{22}=r_{21}=2.0 ; s_{1}=0.5 ; s_{2}=2.0 ; k_{p 1}=22900 ; k_{p 2}=648 ; 1=M A ; 2=\right.$ $M M A)$ 
Table 5.1 Calculated $-\Delta H_{r}(\mathrm{~kJ} / \mathrm{mol})$ and reactivity ratios ( $r$ and $s$ in brackets) for monomer addition to dimeric radicals compared to literature values for polymer systems.

\begin{tabular}{|c|c|c|c|c|}
\hline & Reaction & Met & $\operatorname{hod} 1 \mathrm{~A}$ & Experiment $^{12}$ \\
\hline \multirow[t]{2}{*}{ IA } & MA-MA* + MA & 73.4 & & $(0.20-0.50)$ \\
\hline & MA-MA*+MMA & 84.3 & $(\mathbf{0 . 3 5})$ & \\
\hline \multirow[t]{2}{*}{ B } & MMA-MA* + MA & 64.0 & & \\
\hline & MMA-MA* +MMA & 68.8 & $(\mathbf{0 . 6 3})$ & $(0.20-0.50)$ \\
\hline \multirow[t]{2}{*}{$\mathrm{C}$} & MMA-MMA* + MMA & 42.0 & & \\
\hline & MMA-MMA* +MA & 40.1 & $(1.20)$ & $(2.0-2.50)$ \\
\hline \multirow[t]{2}{*}{ D } & MA-MMA* + MMA & 46.4 & & \\
\hline & MA-MMA* +MA & 47.0 & $(\mathbf{0 . 9 3})$ & $(2.0-2.50)$ \\
\hline \multirow[t]{2}{*}{$\mathrm{E}$} & MA-MA* + MA & 73.4 & & \\
\hline & MMA-MA* +MA & 64.0 & $(0.40)^{*}$ & $(0.50)^{*}$ \\
\hline \multirow[t]{2}{*}{$\mathrm{F}$} & MMA-MMA* + MMA & 42.0 & & \\
\hline & MA-MMA* +MMA & 46.4 & $(1.52)^{*}$ & $(2.0)^{*}$ \\
\hline \multirow[t]{2}{*}{ IIA } & MEA-MEA* + MEA & 26.8 & & \\
\hline & MEA-MEA* +MMA & 31.8 & $(0.62)$ & \\
\hline \multirow[t]{2}{*}{ B } & MMA-MEA* + MEA & 29.8 & & \\
\hline & MMA-MEA* +MMA & 35.0 & $(0.61)$ & \\
\hline \multirow[t]{2}{*}{$\mathrm{C}$} & MMA-MMA* + MMA & 42.0 & & \\
\hline & MMA-MMA $*+$ MEA & 38.0 & (1.36) & \\
\hline \multirow[t]{2}{*}{ D } & MEA-MMA* + MMA & 35.3 & & \\
\hline & MEA-MMA* +MEA & 31.8 & (1.39) & \\
\hline \multirow[t]{2}{*}{$\mathrm{E}$} & $\mathrm{MEA}-\mathrm{MEA}^{*}+\mathrm{MEA}$ & 26.8 & & \\
\hline & MMA-MEA* +MEA & 29.8 & $(0.75)^{*}$ & \\
\hline \multirow[t]{2}{*}{$\mathrm{F}$} & MMA-MMA* + MMA & 42.0 & & \\
\hline & MEA-MMA* +MMA & 35.3 & $(1.92) *$ & \\
\hline \multirow[t]{2}{*}{ IIIA } & MA-MA* + MA & 73.4 & & \\
\hline & MA-MA* +St & 88.6 & $(0.23)$ & $(0.14-0.3)$ \\
\hline \multirow[t]{2}{*}{ B } & St $-\mathrm{MA}^{*}+\mathrm{MA}$ & 78.5 & & \\
\hline & $\mathrm{St}-\mathrm{MA}^{*}+\mathrm{St}$ & 80.57 & $(\mathbf{0 . 8 2})$ & $(0.14-0.3)$ \\
\hline \multirow[t]{2}{*}{$\mathrm{C}$} & St-St* + St & 62.9 & & \\
\hline & $\mathrm{St}-\mathrm{St} *+\mathrm{MA}$ & 60.6 & $(1.26)$ & $(0.65-0.87)$ \\
\hline \multirow[t]{2}{*}{ D } & $\mathrm{MA}-\mathrm{St} *+\mathrm{St}$ & 61.0 & & \\
\hline & $\mathrm{MA}-\mathrm{St} *+\mathrm{MA}$ & 59.9 & (1.11) & $(0.65-0.87)$ \\
\hline \multirow[t]{2}{*}{$\mathrm{E}$} & MA-MA* + MA & 73.4 & & \\
\hline & St-MA* + MA & 78.5 & $(1.64)^{*}$ & $(0.9)^{*}$ \\
\hline \multirow[t]{2}{*}{$\mathrm{F}$} & $\mathrm{St}-\mathrm{St}^{*}+\mathrm{St}$ & 62.9 & & \\
\hline & $\mathrm{MA}-\mathrm{St} *+\mathrm{St}$ & 61.0 & $(0.83)^{*}$ & $(0.11)^{*}$ \\
\hline
\end{tabular}

Method 1A - B3LYP/631G(d) opt freq@298.15 K *denotes the $s$ value

While differences are found in $r$ values, the calculated radical reactivity ratios ( $s$ values) 
for the MA/MMA system are in agreement with the experimental values. A plot of the $\left(k_{p, \text { copo }}\right)$ versus $f_{i}$ for the penultimate model using the calculated $s$ values is plotted in Figure 5.3, with monomer reactivity ratios and homopolymerization $k_{p}$ values taken from literature. The curve agrees very well with the experimentally measured $k_{p, c o p o}$ values, which are represented by the "literature penultimate" curve; the "literature terminal" curve on the plot represents the predictions when penultimate effects are not accounted for when calculating $k_{p, \text { copo }}$. The computational techniques combined with the EvansPolanyi relationship is able to predict the change in radical reactivity caused by the penultimate unit in the MA/MMA chain, even though it fails in predicting radical selectivity ( $r$ values).

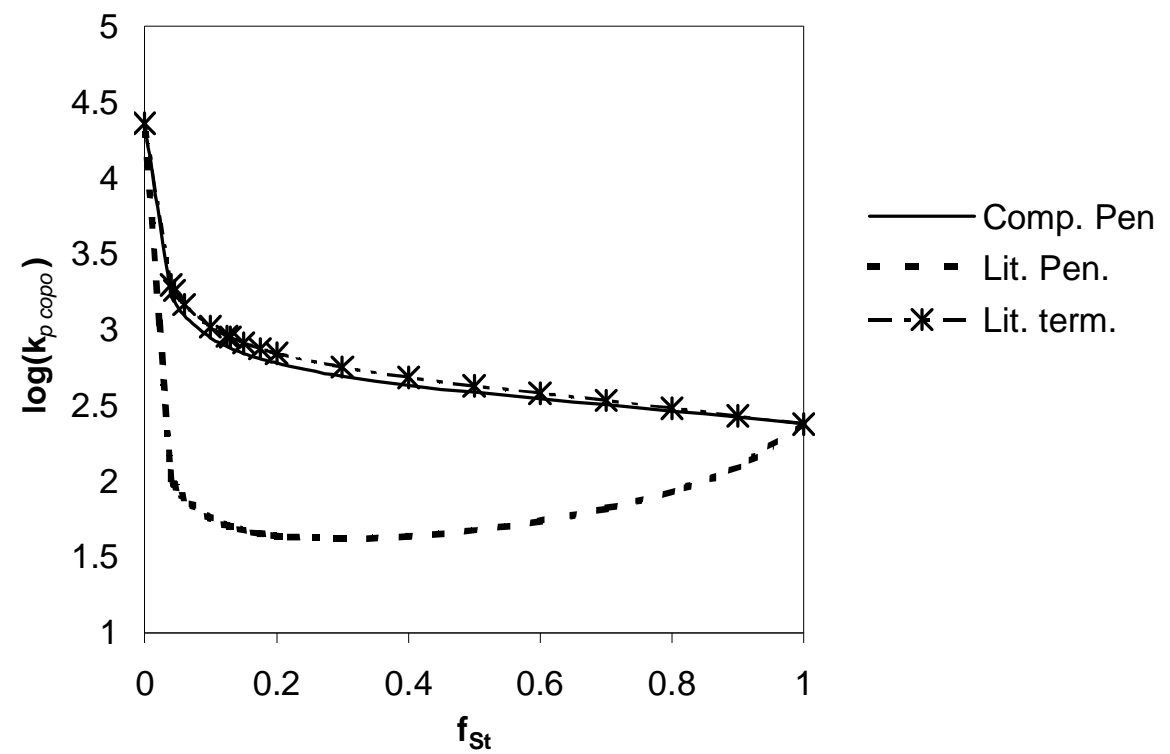

Figure 5.4 Relationship between rate of copolymerization $\left(k_{p}\right.$ cop-L/mol-s) and monomer $\left(f_{S t}\right)$ composition, calculated from computed reactivity ratios for MA/St system compared to literature ratios for the penultimate modeland terminal model $\left(r_{1}=r_{11}=r_{12}=0.25\right.$; $\left.r_{2}=r_{22}=r_{21}=0.8 ; s_{1}=0.9 ; s_{2}=0.11 ; k_{p 1}=22900 ; k_{p 2}=238 ; 1=M A ; 2=S t\right)$ 
The same conclusion, however, cannot be drawn for the MA/St system. As shown in Figure 5.4, the calculated $s$ values result in a curve that more closely follows that predicted by the terminal model, and fails to represent the experimental data reflected by the "literature penultimate" curve. This result may arise from the breakdown of the E-P relationship for systems with styrene, discussed in Chapter 4.

While the impact of penultimate effects may not always be in agreement with experiment, it is evident that this methodology does distinguish penultimate unit effects. The trend seen in the $\Delta \mathrm{H}_{r}$ results support the proposition of Fukuda et al. ${ }^{13}$ that the penultimate unit can affect the stability of the propagating radical. As seen on Table 5.1 IE, as soon as the penultimate unit changes from MA to MMA the $\Delta \mathrm{H}_{r}$ changes from $73.4 \mathrm{~kJ} / \mathrm{mol}$ to $-64 \mathrm{~kJ} / \mathrm{mol}$, as expected. The reaction becomes less exothermic as the methyl group on the penultimate unit helps to stabilize the radical by electron donation. Reaction IF exhibits the same trend. As soon as the penultimate unit changes from MMA to MA the $\Delta \mathrm{H}_{r}$ changes from $-42 \mathrm{~kJ} / \mathrm{mol}$ to $-46.4 \mathrm{~kJ} / \mathrm{mol}$. Accordingly the reaction becomes more exothermic showing that the radical is more reactive compared to when the stabilizing methyl group was available.

The $s$ values obtained in the calculations are close to the experimental values for MA/MMA, but the monomer reactivity ratios deviate. This is very encouraging for some systems but still leaves a question as to whether the E-P relationship can be used in all 
cases. Importantly, a factor to consider is the use of the absolute $A$ values to see if the $\mathrm{E}-$ P relationship will hold for non-polar systems. For MMA, chain length effects might be a problem as the longer the chain the more steric crowding there is and the worse the heat of reaction prediction is. This is evident when the results of heat of reaction on adding monomer to the monomeric species $(-50.0 \mathrm{~kJ} / \mathrm{mol})$ is more negative than when adding monomer to the dimeric radical $(-42.0 \mathrm{~kJ} / \mathrm{mol})$. The heat of polymerization of MMA is 53 to $-58 \mathrm{~kJ} / \mathrm{mol} .{ }^{12}$ However when looking at the chemistry of the molecule, the electron donation effect of the $\mathrm{CH}_{3}$ groups on the backbone chain implies that the MMA radical becomes less electrophilic, with increasing chain length, hence the less negative heat of reaction. We know that DFT methods have a tendency to underestimate dispersion effects in molecules that have steric crowding, and a way to account for these is required to study these trends with greater accuracy.

It has been suggested that radical substituents that are strong electron donors or acceptors are associated with strong polar interactions, especially when the substituents appear on the monomer. Therefore, since it is known that polar interactions undermine the $\mathrm{E}-\mathrm{P}$ relationship, ${ }^{23}$ it could be a possibility that for MA/St, the penultimate unit effects are likely to be explicit not implicit and assumptions made for family group $A$ values do not apply. In particular, an explicit penultimate unit effect occurs when both the terminal and penultimate units of the growing radical affect the radical selectivity. With the presence of the delocalized electrons of the styrene ring, radical stabilization effects are significant on the propagating radical and it appears that the assumptions of the radical stabilization 
$\operatorname{model}^{29}\left(r_{1} r_{2}=s_{1} s_{2}\right)$ are not satisfied for this system. Thus the explicit rather than the implicit penultimate model may provide a better insight to the copolymerization kinetics of this system. As seen on the results obtained (Table 5.1 III A- F) and the plot produced, $r_{1} r_{2} \neq s_{1} s_{2}$. In their work using ab initio calculations to study effects of substitution on the addition of $1-\mathrm{Y}, 3$-X-disubstituted propyl radicals $(\mathrm{X}=\mathrm{H}, \mathrm{F}$ or $\mathrm{CN}$; $\mathrm{Y}=\mathrm{F}$ or $\mathrm{CN})$ to ethylene, Coote et al. ${ }^{46}$ found that the penultimate unit effects were explicit because the stabilization model did not hold. Studies on the copolymerization of acrylonitrile (AN) with styrene $(\mathrm{St})^{69}$ have been done taking into account the explicit penultimate unit effect and it is found that $A$ is different for the different reactions in the model and thus this would disqualify the $\mathrm{E}-\mathrm{P}$ relationship for this system. However to disqualify $\mathrm{E}-\mathrm{P}$ relationship for MA/St system, the A values for the different reactions in the model would have to be determined.

The heats of reaction values show a consistent value at chain length three for styrene which is less than the polymeric radical by $10 \mathrm{~kJ} / \mathrm{mol}$ (DFT acceptable difference), and this could mean that the styrene radical is representative of the polymeric radical. However, with the advent of powerful techniques, while $k_{p}$ is frequently considered independent of radical chain length, some studies have shown that the propagation constant is a function of degree of polymerization. ${ }^{70,71}$ This dependence is restricted to the first propagation steps until the chain length reaches the value of three or four monomer units. This is consistent with the work of Moscatelli ${ }^{69}$ where the chain length effects in the polymerization of acrylonitrile are investigated. Indeed the propagation rate 
changes with the growing chain to length 7 . Heats of reaction, however, for the AN remain constant as the chain grows. What this could mean is that the $A$ for the first propagation steps would not be constant and that would affect the assumption that we make for $\mathrm{E}-\mathrm{P}$ relationship for some systems in our studies. This observation by Moscatelli ${ }^{69}$ could also be the reason why the terminal model is not adequate for some copolymerization systems. The issue comes into effect where steric effects affect the energetics of the system like for MMA as the chain grows. Moscatelli et al ${ }^{69}$ find that in their studies of AN/St system the computationally predicted reactivity ratio results are affected by chain length, another potential problem for the MA/St system. Other than the breakdowns mentioned, the $\mathrm{HO}$ model is known to be inadequate for big molecules such as styrene where the radical is highly delocalized therefore this could be contributing in a way to the deviation.

In conclusion, penultimate unit effects exist on a molecular level and they should be investigated in order to explain deviations from the predictions of the terminal model. It has been assumed that the penultimate unit effects in most comonomer systems are solely enthalpic but considering the results in this study, these effects may also contain a steric contribution. This steric penultimate unit effect can arise if certain internal motions in the energy resolution are hindered by the substituents in the penultimate unit. If there is a large difference in size between the two comonomers, the penultimate unit effect is likely to be large and it can even be so large that it is observed in the monomer reactivity ratios and give rise to an explicit penultimate unit effect. The work in this study also 
suggests that systems in which the two comonomers have similar sizes (e.g.,MA/MMA and MMA/MEA) are not likely to display an explicit penultimate unit effect, but that this is the case in systems where the two monomers are very different in size sterically (e.g., $\mathrm{MA} / \mathrm{St}$ ). In the latter systems the $\mathrm{E}-\mathrm{P}$ relationship does not hold and this could be the ultimate cause of the deviation in the results reported for the system.

\subsection{Reactivity Ratios - Midchain Reactions}

Scheme 5.1 describes the midchain reactions that have been studied in this work in which $\mathrm{n}=3$. The corresponding endchain reactions also have $\mathrm{n}=3$.<smiles>COC(=O)CCC(=O)CC(C)C(=O)OC</smiles><smiles>COC(=O)CCC(CC(C)=O)(CC(C)C(=O)OC)C(=O)OC</smiles><smiles>COC(=O)CCC(=O)CC(C)C(=O)OC</smiles><smiles>COC(=O)CCC(CC(C)C(=O)OC)(CC(C)C(=O)OC)C(=O)OC</smiles><smiles>COC(=O)CC[C](CC(C)C)C(=O)OC</smiles><smiles>COC(=O)CCC(CC(C)OC(C)=O)(CC(C)C(=O)OC)C(=O)OC</smiles>

Scheme 5.1 MA midchain radicals reacting with different monomers of varying structure. 
In the above reactions, we are comparing reaction of the monomers to tertiary carbon radical versus secondary carbon radical. One would expect a reactivity ratio that is similar to the one obtained with the terminal radical of the corresponding system. Unfortunately results obtained are contra thermodynamic as will be explored later in the section.

Table 5.3 Calculated $-\Delta H_{r}(\mathrm{~kJ} / \mathrm{mol})$ and reactivity ratios for monomer addition to $\sim \mathrm{MA}$ midchain radical and $\sim \mathrm{MA}$ endchain radical ( $\sim \mathrm{MA}$ represents a trimeric species)

\begin{tabular}{|c|c|c|c|c|}
\hline Reaction & $\begin{array}{l}\Delta \mathrm{H}_{\mathrm{r}} \text { mid } \\
(\mathrm{kJ} / \mathrm{mol})\end{array}$ & $\begin{array}{l}\Delta \mathrm{H}_{\mathrm{r}} \text { end } \\
(\mathrm{kJ} / \mathrm{mol})\end{array}$ & midchain & endchain \\
\hline$\sim \mathrm{MA}+\mathrm{MA}$ & -26.88 & -72.89 & & \\
\hline$\sim \mathrm{MA}+\mathrm{MMA}$ & -15.00 & -80.25 & $\begin{array}{l}\mathrm{r}_{\mathrm{MA} / \mathrm{MMA}} \\
3.16\end{array}$ & $\begin{array}{l}\mathrm{r}_{\mathrm{MA} / \mathrm{MMA}} \\
0.49\end{array}$ \\
\hline$\sim \mathrm{MA}+\mathrm{VAc}$ & -13.97 & -53.10 & $\begin{array}{l}\mathrm{r}_{\mathrm{MA} / \mathrm{VAc}} \\
3.48\end{array}$ & $\begin{array}{l}\mathrm{r}_{\mathrm{MA} / \mathrm{VAc}} \\
6.81\end{array}$ \\
\hline
\end{tabular}

The heats of reaction for monomer addition to the midchain radicals are less exothermic than that of the endchain radicals, showing that that the midchain radical is more stable than the endchain radical (Table 5.3). It is easier for the secondary carbon chain-end radical to react with the monomer than it is for the tertiary midchain radical. The heat of reaction for adding MMA and VAc to the radical are almost the same but significantly less in magnitude than addition of MA to the midchain acrylate radical. Monomer reactivity for the endchain radical follows the same trend as in the terminal models examined in this work and lie within the range of the known experimental values.

For the stabilized tertiary midchain radical, which has much smaller $\Delta H_{r}$ values, we see a difference in the calculated $r$ values for addition to MMA compared to MA. Note that the 
structure of the midchain radical and that of the endchain MMA radical are similar, as both are tertiary radicals. One might expect the heat of reaction when reacting with the same species to be similar, but in this case the values are significantly different. $\Delta H_{r}$ for MMA addition to MMA radical is calculated to be $-53.8 \mathrm{~kJ} / \mathrm{mol}$ while addition of MMA to a MA midchain radical is only $-15 \mathrm{~kJ} / \mathrm{mol}$ (B3LYP/6-31G(d) optimized). These unexpected values could be a result of the limitations in DFT where steric crowding is an issue. It would be interesting to find what the reaction barriers, frequency factors and the activation energies are, for the different radicals in question. There could be contra thermodynamic elements in the results similar to what has been observed by GómezBalderas et al. ${ }^{72}$ on the addition of methyl radical to ethene and ethyne. 


\section{Chapter 6 \\ Conclusions and Future Work}

\subsection{Conclusions}

It is clear that computational calculations for free radical polymerization kinetics are becoming a viable alternative to experiment in instances where model-free experimental determination of rate coefficients is difficult or impossible. In this work, a cost effective computational way of estimating reactivity ratios has been developed. Results that are comparable to available experimental data are obtained for some systems. For systems for which experimental data to compare with is lacking, the results provide preliminary values that may be used as a starting point for kinetic modelling.

The primary interest in chemical studies is often concerned with trends rather than absolute quantities; this study has shown that the developed computational method can provide structure reactivity trends by examining the estimated heats of reaction. It has been established that as the pendant side group is varied, the heat of reaction changes according to the nature of the group (electrophilic or nucleophilic). The most remarkable trend that has been noted for the systems studied in the terminal model, is that substitution of pendant side groups in cross polymerization reactions affect the radical reactivity more than the monomer reactivity. This trend has been confirmed with existing monomer reactivity ratio experimental data. 
Chain length effects have been seen not to be a drawback for most of the systems studied. Heats of reactions for most systems have been observed to be the same or lie within the range of the polymeric radical for the monomeric radical. As $\Delta H_{r}$ is the parameter that is used for the reactivity ratio calculation, it is sensible to assume that the monomeric radical can adequately represent the polymeric radical for these calculations using this methodology.

Penultimate unit effects can be discriminated using this methodology. Heats of reaction show the effects of varying the size and nature of the penultimate unit. The identity of the penultimate unit has little effect on radical selectivity $\left(r_{1} \approx r_{11} \approx r_{12}\right)$ for MA/MMA system and MA/MEA system and these comply with the implicit penultimate unit effect model. For MA/St system, the methodology has breakdowns because of the difference in size and nature (electrophilic and nucleophilic) of the monomers involved, thus making the one of the assumptions made that $A$ is the same for the different cross propagation reactions of the system not valid. Polar effects in the cross propagation steps of reactions undermine the validity of the $\mathrm{E}-\mathrm{P}$ relation.

For some systems where polar effects are not a problem (for example MA/MMA system), a deviation is observed in the results due to the steric crowding within the molecules and the limitations of DFT methods for molecules that have steric crowding. For this system the $\mathrm{E}-\mathrm{P}$ relationship does not break down, the deviation is attributed to DFT since it does not include dispersion effects and tends to overestimate steric repulsions. For 
midchain radicals, the same problem leads to unexpected result of the monomer reactivity ratio and the calculated heat of reaction. These reactions should be studied further using transition state theory.

The computational methodology developed in this work is cost effective and has identified trends that can serve as a basis of a starting point for further investigations. It has been applied to improve our general understanding of the reaction mechanisms involved in radical polymerization systems, and is able to show the subtle explicit penultimate unit effects that cannot be observed experimentally. This methodology assumes that the $\mathrm{E}-\mathrm{P}$ relationship, correlating activation energies to heats of reaction, is valid. Thus, while the computational techniques can provide some insight to kinetic trends for these complex systems, it must be used with caution and a good understanding of computational methods. As this important field continues to develop, improved computational methodology will help in product formulation and optimizing manufacturing processes, and will serve as a basis for future studies for other polymerization systems. 


\subsection{Future Work}

In relation to the computational bottleneck of the DFT limitations of energy resolution, a suggestion to split the molecule into different components and add up the energy has come up in discussions. Moscatelli et al. ${ }^{50}$ have used such a method successfully for their studies, and on this could be applied to the MA/MMA system. Another interesting study would be to look at the effect of electron donating groups in the energy resolution for these calculations. Studying the chain length effects on $\Delta H_{r}$ for MMA radical would give an insight as to what causes the contra thermodynamic results for this molecule. As suggested by Moscatelli ${ }^{69}$ it is recommended to study one or two systems with extended chain lengths so as to see whether that makes a difference in the calculated reactivity ratios and improves comparison with experimental values.

As far as the $\mathrm{E}-\mathrm{P}$ relation breakdown for some systems, calculation of the $A$ values for the monomer systems that do not have molecules that fall in the same family group would be useful. This can be done by optimizing the transition state of the monomer addition reaction and applying the transition state theory to estimate absolute rate coefficients. These $A$ values would then be used in the calculation of the monomer reactivity ratios to see if that would address the deviation from the experimental monomer reactivity values. Such an approach would also provide a means to further examine the penultimate unit effects for the different systems, and compare to known experimental trends. 
A novel structure reactivity trend in heats of reaction was observed in this study, where radical reactivity is influenced more than the monomer reactivity by the nature of the pendant side group. A similar trend is seen in available experimental results for monomer reactivity ratios. This is not conclusive as reactivity ratios are relative values of the homopropagation and crosspropagation reactions. To conclusively declare this a valid trend, only crosspropagation experimental values of the different monomers and radicals would have to be studied, for example for the copolymerization of MA with HEMA and GMA. 


\section{References}

(1) Grady, M.C.; Simonsick, W. J.; Hutchinson, R. A. Macromol. Symp. 2002, 182, 149168.

(2) Rudin, A. The Elements of Polymer Science and Engineering; $2^{\text {nd }}$ Ed. Academic Press: New York, 1999

(3) Lebduska, J.; Snuprek, J., Jr.; Kaspar, K.; Cermák, V. J. Polym. Sci., Part A: Polym. Chem. 1986, 24, 777 - 782.

(4) Li, D.; Grady, M. C.;Hutchinson, R. A. Ind. Eng. Chem. Res. 2005, 44, 2506-2517.

(5) Hutchinson, R.A.; McMinn, J. H.; Paquet, D. A, Jr.; Beuermann, S.; Jackson, C. Ind. Eng. Chem. Res. 1997, 36, 1103-1113.

(6) Peck, A.N.F.; Hutchinson, R. A. Macromolecules 2004, 37, 5944-5951.

(7) Li, D.; Li, N.; Hutchinson, R. A. Macromolecules 2006, 39, 4366-4373.

(8) Li, D.; Hutchinson, R. A. Macromol. Rapid Commun. 2007, 28, 1213-1218.

(9) Bebe, S.; Hutchinson, R.A.; Yu, X.; Broadbelt, L. Macromol. Symp. 2006, 243,179-189.

(10) Beuermann, S.; Buback, M. Prog. Polym. Sci. 2002, 27, 191-254.

(11) Hutchinson, R.A.; McMinn, J. H.; Paquet, D. A, Jr.; Beuermann, S.; Jackson, C. Ind. Eng. Chem. Res. 1997, 36, 1103-1113.

(12) Brandrup, J.; Immergut, E.H.; Grulke, E.A. Polymer Handbook; 1999. 
(13) Fukuda, T.; Kubo, K.; Ma, Y. D. Prog. Polym. Sci. 1992, 17, 875-916.

(14) Mayo, F. R.; Lewis, F. M., J. Am. Chem. Soc. 1944, 66, 1594.

(15) Alfrey, T. Jr.; Goldfinger, G., J. Chem. Phys. 1944, 66, 1594

(16) Jenkins, A.D.; O'Driscoll, K. F. J. Polym. Sci., Part A: Polym. Chem. 1995, 33, 1189-1190.

(17) Coote, M.L.; Davis, T. P. Macromolecules 1999, 32, 4290-4298.

(18) Buback, M.; Gilbert, R. G.; Hutchinson, R. A.; Klumperman, B.; Kuchta, F.;

Manders, B. G.; O'Driscoll, K. F.; Russell, G. T.; Schweer, Macromol. Chem. Phys. 1995, 196, 3267-3280.

(19) Beuermann, S.; Buback, M.; Davis, T. P.; Gilbert, R. G.; Hutchinson, R. A.;Olaj, O. F.; Russell, G. T.; Schweer, J.; Van Herk, A. M. Macromol. Chem. Phys. 1997, 198, 1545-1560.

(20) Buback, M.; Feldermann, A.; Barner-Kowollik, C.; Lacik, I. Macromolecules 2001, $34,5439-5448$.

(21) Hutchinson R.A., Handbook of Polymer Reaction Engineering Chapter 4, WileyVCH, 2004.

(22) Sánchez-Chaves, M.; Martińez, G.; Madruga, E.L. J. Polym. Sci., Part A: Polym. Chem. 1999, 37, 2941-2948

(23) Fischer, H.; Radom, L. Angew. Chem. Int. Ed. 2001, 40, 1340-1371.

(24) Fischer, H.; Radom, L. Macromol. Symp. 2002, 182, 1-14. 
(25) Ydens I.; Degeé, P.; Haddleton, D. M.; Dubois, P. Eur. Polym. J. 2005, 41, 22552263.

(26) M. J. Frisch, G. W. Trucks, H. B. Schlegel, G. E. Scuseria, M. A. Robb, J. R. Cheeseman, J. A. Montgomery, Jr., T. Vreven, K. N. Kudin, J. C. Burant, J. M. Millam, S. S. Iyengar, J. Tomasi, V. Barone, B. Mennucci, M. Cossi, G. Scalmani, N. Rega, G. A. Petersson, H. Nakatsuji, M. Hada, M. Ehara, K. Toyota, R. Fukuda, J. Hasegawa, M. Ishida, T. Nakajima, Y. Honda, O. Kitao, H. Nakai, M. Klene, X. Li, J. E. Knox, H. P. Hratchian, J. B. Cross, C. Adamo, J. Jaramillo, R. Gomperts, R. E. Stratmann, O. Yazyev, A. J. Austin, R. Cammi, C. Pomelli, J. W. Ochterski, P. Y. Ayala, K. Morokuma, G. A. Voth, P. Salvador, J. J. Dannenberg, V. G. Zakrzewski, S. Dapprich, A. D. Daniels, M. C. Strain, O. Farkas, D. K. Malick, A. D. Rabuck, K. Raghavachari, J. B. Foresman, J. V. Ortiz, Q. Cui, A. G. Baboul, S. Clifford, J. Cioslowski, B. B. Stefanov, G. Liu, A. Liashenko, P. Piskorz, I. Komaromi, R. L. Martin, D. J. Fox, T. Keith, M. A. Al-Laham, C. Y. Peng, A. Nanayakkara, M. Challacombe, P. M. W. Gill, B. Johnson, W. Chen, M. W. Wong, C. Gonzalez, and J. A. Pople, Gaussian, Inc., Pittsburgh PA, 2003.

(27) Babu, G. N.; Deshpande, A.; Deshpande, D. D., Angew. Makromol. Chem. 1982, $105,83-90$

(28) Herhre, W.J.; Radom L.; Schleyyer P.v.R. and J.A. Pople.Ab Initio Molecular Orbital Theory, Chapter 2, Wiley: NewYork, 1986.

(29) Leach, L.R. Molecular Modelling (Principles and Applications); $2^{\text {nd }}$ Ed. Prentice Hall: New York, 2001.

(30) Kruse, T.M.; Woo, O. S.; Broadbelt, L. J., Chem. Eng. Sci. 2001, 56, 971-979.

(31) Curtis, L.A.; Redfern, C.P.; Fruirip, D. J. Rev. Comput. Chem.; John Wiley \& Sons, Inc: New York, 2000, 15. 
(32) Pilar, F.L. Elementary Quantum Chemistry; $2^{\text {nd }}$ Ed. McGraw-Hill: Singapore, 1990.

(33) Gomez-Balderas, R.; Coote, M. L.; Henry, D. J.; Fischer, H.; Radom, L. J. Phys. Chem., 2003, 107, 6082 - 6090

(34) Johnson E. R.; Clarkin O J.; DiLabio G. A., J. Phys. Chem. A 2003, 107, 9953-9963.

(35) DiLabio G. A.; Pratt D. A. J. Phys. Chem. A 2000, 104, 1938-1943.

(36) DiLabio G. A.; Pratt D. A.; LoFaro A. D. and Wright J. S., J. Phys. Chem. A 1999, $103,1653-1661$

(37) Becke, A. D. J. Chem. Phys.; 1993, 98, 5648-5652.

(38) Lee, C.; Yang, W.; Parr, R. G. Phys. Rev. B: Condens. Matter 1988, 37, 785-789.

(39) Becke, A. Private communication, 2004.

(40) Scott A. P.; Radom L. J. Phys. Chem. 1996, 100, 16502-16513.

(41) Curtiss, L. A.; Raghavachari, K. ACS Symp. Ser. 1998, 677, 176-196.

(42) Arnaud, R.; Bugaud, N.; Vetere, V.; Barone, V. J. Amer. Chem. Soc. 1998, 120, 5733-5740.

(43) Khan, S. S.; Broadbelt, L. J. Atmos. Environ. 2004, 38, 1015-1022.

(44) Tedder, J. M. React. Mech. Struct. Polym. Chem. 1974, 31-51.

(45) Heuts, J. P. A.; Matyjaszewski, K., Davis, T. P. Handbook of Radical Polymerization; Chapter 1, John Wiley \& Sons, Inc. 2002, 1-75.

(46) Coote, M. L.; Davis, T. P.; Radom, L. Macromolecules 1999, 32, 2935-2940. 
(47) Coote, M. L.; Davis, T. P.; Radom, L. Macromolecules; 1999, 32, 5270-5276.

(48) Heuts, J. P. A.; Gilbert, R. G.; Radom, L. Macromolecules 1995, 28, 8771-8781.

(49) Lin, C. Y.; Coote, M. L.; Petit, A.; Richard, P.; Poli, R., Matyjaszewski, K. Macromolecules 2007, 40, 5985-5994.

(50) Moscatelli, D.; Cavallotti, C.; Morbidelli, M., Macromolecules 2006, 39, 96419653.

(51) Deng, L.; Woo, T. K.; Cavallo, L.; Margl, P. M.; Ziegler, T. J. Am. Chem. Soc. 1997, 19, 6177-6186.

(52) Woo, T. K.; Patchkovskii, S.; Ziegler, T. Comput. Sci. Eng. 2000, 28-37.

(53) Stewart, J. J. P. J. Comput. Chem. 1989, 10, 987

(54) Pitzer, K.S.; Gwinn, W.D. J. Chem. Phys. 1942, 10, 431.

(55) Izgorodina, I. E; Coote, M. L, Chem. Phys. 2006, 324, 96-110.

(56) Becke, A. D. J. Chem. Phys. 1997, 107, 8554.

(57) Van Cauter, K.; Van Speybroeck, V.; Vansteenkiste, P.; Reyniers, M.; Waroquier, M., Chem. Phys. Chem. 2006, 7, 131.

(58) Redfern, P.C.; Zapol, P.; Curtiss, L. A.; Raghavachari, K., J. Phys. Chem. 2000, 104, $5850-5854$.

(59) Filley, J.; McKinnon, J. T.; Wu, D. T.; Ko, G. H. Macromolecules 2002, 35, 3731. 
(60) Heuts, J. P. A; Gilbert, R.G; Maxwell, I. A, Macromolecules 1996, 30, 18997.

(61) Izgorodina, I. E; Coote, M. L, J. Phys. Chem. A. 2005, 7558.

(62) Lalevee, J.; Allonas, X.; Fouassier, J. J. Phys. Chem. A. 2004, 108, 4326-4334.

(63) Lalevee, J.; Allonas, X.; Genet, S; Fouassier, J. P. J. Am. Chem. Soc. 2003, 125, 9377.

(64) Hutchinson, R. A.; Beuermann, S.; Paquet, D. A. Jr.; McMinn, J. H. Macromolecules 1997, 30, 3490-3493.

(65) Coote, M. L.; Wood, G. P. F.; Radom, L., J. Phys. Chem. A. 2002, 106, 12124.

(66) Decker, C; Moussa, K., Polym. Mater. Sci. Eng. 1989, 60, 547.

(67) Andrzejewska, E.; Andrzejewski, M. J. Polym. Sci., Part A: Polym. Chem. 1998, $36,665-678$.

(68) Coote, M.L.; Davis, T.P., Prog. Polym. Sci. 1999, 24, 1217-1251.

(69) Moscatelli, D; Dossi M.; Cavallotti, C; Storti, G., Macromol. Symp. 2007, 259, 337347.

(70) Olaj, O. F.; Bitai, I.; Hinkelmann, F., Makromol. Chem. 1987, 188,1689.

(71) Smith, G. B; Russell, T.;Yin, M.; Heuts, J. P. A., Eur. Polym. J. 2005, 41, 225-230.

(72) Gómez-Balderas, R.; Coote, L.; Henry, J. D.; Fischer, H.; Radom, L., J. Phys. Chem. 
A; 2003, 107, 6082-6090.

(73) Levine, S.; Broadbelt, L. J. Private communication, 2003.

(74) Kukulj, D.; Davis, T. P. Macromolecules 1998, 31, 5668-5680. 


\section{Appendix A \\ Application of computational approach to FRP - Group Additivity}

\section{A.1 Styrene/ $\alpha$ - Methyl Styrene}

The computational studies on small radicals can lead to the development of estimation techniques for radical and monomer reactivities using thermodynamic data by capturing the differences in the relative energies between reactants and products. Group Additivity (GA) capabilities are explored in this section using Benson group additivity values together with the values that were developed by Broadbelt et al. ${ }^{43}$ successfully, for radical groups. The styrene (S) / $\alpha$ - methyl styrene (AMS) system has been studied with the help of Broadbelt et al.

Table A1: Calculation of heats of formation and heats of reaction using Group Additivity for S/AMS system.

\begin{tabular}{|c|c|c|c|}
\hline Group & $\begin{array}{l}\Delta \mathrm{H}_{\mathrm{f}} 298 \mathrm{~K} \\
\text { Contr. }\end{array}$ & Molecule & $\Delta \mathrm{H}_{\mathrm{f}} 298 \mathrm{~K}$ \\
\hline $\mathrm{C}_{b^{-}}(\mathrm{H})$ & 3.3 & Styrene & 35.3 \\
\hline $\mathrm{C}_{\mathrm{b}}-(\mathrm{C})$ & 5.51 & $\mathrm{~S}^{*}$ & 39.6 \\
\hline $\mathrm{C}_{\mathrm{b}^{-}}\left(\mathrm{C}^{*}\right)$ & 5.51 & S-S* & 52.63 \\
\hline $\mathrm{C}_{\mathrm{b}^{-}}\left(\mathrm{C}_{\mathrm{d})}\right.$ & 5.69 & AMS & 27.01 \\
\hline $\mathrm{C}_{\mathrm{d}}-\left(\mathrm{C}_{\mathrm{b}}\right)(\mathrm{H})$ & 6.78 & AMS* & 32.41 \\
\hline $\mathrm{C}_{\mathrm{d}}-\left(\mathrm{C}_{\mathrm{d}}\right)(\mathrm{H})$ & 6.78 & AMS-AMS* & 36.83 \\
\hline $\mathrm{C}_{\mathrm{d}^{-}}(\mathrm{H})_{2}$ & 6.26 & S-AMS* & 43.24 \\
\hline $\mathrm{C}-\left(\mathrm{C}^{*}\right)(\mathrm{H})_{3}$ & -10.2 & AMS-S* & 46.2 \\
\hline $\mathrm{C}^{*}-\left(\mathrm{C}_{\mathrm{b}}\right)(\mathrm{C})(\mathrm{H})$ & 24.7 & S-S-S* & 68.74 \\
\hline 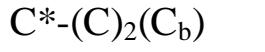 & 25.5 & S-S-AMS* & 59.35 \\
\hline $\mathrm{C}-(\mathrm{C})\left(\mathrm{C}^{*}\right)(\mathrm{H})_{2}$ & -4.95 & S*-AMS-S* & 63.12 \\
\hline $\mathrm{C}-(\mathrm{C})(\mathrm{H})_{3}$ & -10.2 & AMS-S-S* & 63.12 \\
\hline $\mathrm{C}-(\mathrm{C})_{3}\left(\mathrm{C}_{\mathrm{b}}\right)$ & 2.81 & AMS-AMS-AMS* & 48.14 \\
\hline $\mathrm{C}-\left(\mathrm{C}_{\mathrm{b}}\right)(\mathrm{C})_{2}(\mathrm{H})$ & -0.98 & AMS-AMS-S* & 57.53 \\
\hline $\mathrm{C}-\left(\mathrm{C}_{\mathrm{d}}\right)(\mathrm{H})_{3}$ & -4.76 & S-AMS-AMS* & 53.73 \\
\hline $\mathrm{C}_{\mathrm{d}^{-}}\left(\mathrm{C}_{\mathrm{d}}\right)(\mathrm{C})$ & 8.88 & AMS-S-AMS* & 53.73 \\
\hline $\mathrm{C}_{\mathrm{d}}-\left(\mathrm{C}_{\mathrm{b}}\right)(\mathrm{C})$ & 8.64 & & \\
\hline $\mathrm{C}-(\mathrm{C})_{2}(\mathrm{H})_{2}$ & -4.93 & & \\
\hline
\end{tabular}


The enthalpy of reaction is estimated using group additivity (GA), ${ }^{43,71}$ as described in section 2.3.2. Table A1 summarizes the group values required to analyze the system, and the estimated heats of formation.

From the Evans Polanyi relationship, $E_{a}=\alpha \Delta H_{r}+E_{0}$ and the Arrhenius equation $k=A \exp \left(-E_{a} / R T\right)$,

$$
k=A \exp \left\{-\left(E_{0}+\alpha \Delta H_{r}\right) / R T\right\}
$$

Taking into consideration the assumptions that $A$ is the same for a particular radical and $E_{0}$ is constant for a family group, $r$ and $s$ can be easily calculated. Scheme A1 summarizes the required $\Delta H$ values for monomer adding to monomeric radical. Assuming Evans-Polanyi, the monomer reactivity ratios are calculated according to:

$$
\begin{aligned}
& r_{1}=k_{p_{11}} / k_{p_{12}}=\frac{\operatorname{Aexp}-\left(\mathrm{E}_{0}+\alpha \Delta \mathrm{Hr}_{11}\right) / \mathrm{RT}}{\operatorname{Aexp}-\left(\mathrm{E}_{0}+\alpha \Delta \mathrm{Hr}_{12}\right) / \mathrm{RT}} \\
& =\exp \left[-\alpha\left(\Delta \mathrm{Hr}_{11}-\Delta \mathrm{Hr}_{12} / \mathrm{RT}\right)\right] \\
& r_{2}=k_{p_{22}} / k_{p_{21}}=\exp \left[-\alpha\left(\Delta \mathrm{Hr}_{22}-\Delta \mathrm{Hr}_{21} / \mathrm{RT}\right)\right]
\end{aligned}
$$

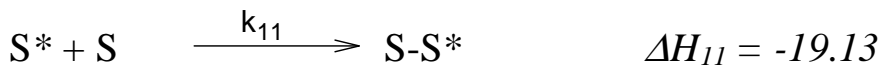

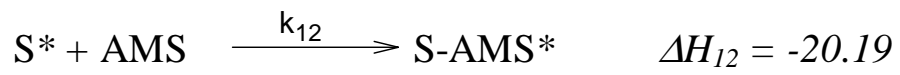

$$
\begin{aligned}
& \mathrm{AMS}^{*}+\mathrm{AMS} \stackrel{\mathrm{k}_{22}}{\longrightarrow} \text { AS-AMS* } \Delta H_{22}=-17.22
\end{aligned}
$$

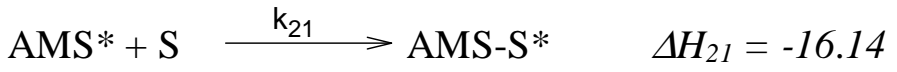

Scheme A1 Monomer addition to a monomeric radical for Styrene and $\alpha$-methyl styrene copolymerization. ( $\Delta H$ values are in $\mathrm{kcal} / \mathrm{mol}$ ) 
For the penultimate model it is necessary to consider monomer addition to dimeric radical as summarized in Scheme A2. Radical reactivity ratios are calculated as:

$$
\begin{aligned}
& s_{1}=k_{p_{211}} / k_{p_{111}}=\exp \left[-\alpha\left(\Delta \mathrm{Hr}_{211}-\Delta \mathrm{Hr}_{111} / \mathrm{RT}\right)\right] \\
& s_{2}=k_{p_{221}} / k_{p_{222}}=\exp \left[-\alpha\left(\Delta \mathrm{Hr}_{221}-\Delta \mathrm{Hr}_{222} / \mathrm{RT}\right)\right] \\
& \mathrm{S}-\mathrm{S}^{*}+\mathrm{S} \stackrel{\mathrm{k}_{111}}{\longrightarrow} \mathrm{S}-\mathrm{S}-\mathrm{S}^{*} \\
& \Delta H_{111}=-19.13 \\
& \mathrm{~S}-\mathrm{S} *+\mathrm{AMS} \stackrel{\mathrm{k}_{112}}{>} \mathrm{S}-\mathrm{S}-\mathrm{AMS}^{*} \\
& \Delta H_{112}=-20.19 \\
& \text { S-AMS* }+ \text { S } \stackrel{\mathrm{k}_{121}}{\longrightarrow} \text { S-AMS-S* } \\
& \Delta H_{121}=-16.14 \\
& \text { S-AMS* + AMS } \stackrel{\mathrm{k}_{122}}{\longrightarrow} \text { S-AMS-AMS* } \\
& \Delta H_{122}=-17.2 \\
& \text { AMS-AMS* + S } \stackrel{\mathrm{k}_{221}}{\longrightarrow} \text { AMS-AMS-S* } \\
& \Delta H_{221}=-16.14 \\
& \text { AMS-AMS* }+ \text { AMS } \stackrel{k_{222}}{\longrightarrow} \text { AMS-AMS-AMS* } \\
& \Delta H_{222}=-17.2 \\
& \text { AMS-S* }+ \text { S } \stackrel{\mathrm{k}_{211}}{\longrightarrow} \text { AMS-S-S* } \\
& \Delta H_{211}=-19.13 \\
& \text { AMS-S* + AMS } \stackrel{\mathrm{k}_{212}}{\longrightarrow} \text { AMS-S-AMS* } \\
& \Delta H_{212}=-20.19
\end{aligned}
$$

Scheme A2 Monomer addition to dimeric radical for styrene and $\alpha$-methyl styrene copolymerization. (all $\Delta H$ values are in $\mathrm{kcal} / \mathrm{mol}$ )

Calculated values are compared to experimental values in Table A2. $\alpha$ is set to 0.24 based on the findings by Broadbelt et al. ${ }^{30}$ and Fischer and Radom. ${ }^{24}$ 
Table A2: Monomer reactivity ratios and radical reactivity values for S/AMS, calculated at $323 \mathrm{~K}$

\begin{tabular}{llll}
\hline & Calculated values & \multicolumn{2}{l}{ Expt values $^{\mathrm{a}, \mathrm{b}}$} \\
\hline$r_{1}$ & 0.67 & 0.117 & 0.3 \\
$r_{2}$ & 1.49 & 0.974 & 1.1 \\
$s_{1}$ & 1 & 1 & \\
$s_{2}$ & 1 & 1 & \\
${ }^{\mathrm{a}}$ Kukulj et al. $^{72}$ & &
\end{tabular}

Calculating monomer reactivity ratios using the terminal model shows that no matter what assumptions are applied the calculated results differ from experimental. From Broadbelt's group values, the monomer reactivity ratios are: $r_{1}=0.67$ and $r_{2}=1.49$ while the literature values are $r_{1}=0.117$ and $r_{2}=0.974^{72}$ and $r_{1} \sim 0.3$ and $r_{2} \sim 1.1 .^{12}$ Although some studies have shown that the rate constant for the addition of polymeric radical to a monomer does not only depend on the terminal structure of the radical but also to some extent on its penultimate unit, ${ }^{11,73}$ this effect is not observed experimentally for S/AMS copolymerization. ${ }^{12,72}$ Calculation of $s_{1}$ and $s_{2}$ from the thermodynamic data obtained using GA method in conjunction with the Evans- Polanyi relationship, gives the same result.

Despite that the GA calculations do not compare well with the experimental values, some useful trends and information can be extracted from the results. The calculated results do not indicate any penultimate effects. Monomer reactivity ratios of the terminal model of this system are the same as the corresponding monomer reactivity ratios in the penultimate model. The difference between $\Delta H_{111}$ and $\Delta H_{211}$ is the introduction of the $\mathrm{CH}_{3}$ group to the styrene in the penultimate position. One would expect the second 
reaction to be more exothermic as the introduction of the $\mathrm{CH}_{3}$ gives more stability to the radical due to the " $+\mathrm{I}$ effect" (donating effect) as is calculated via GA. $\Delta H_{211}$ and $\Delta H_{221}$ give an illustration of the secondary and tertiary radical stability effects respectively. From the enthalpy data obtained from GA, it can be noted that the tertiary radical is more stable than the secondary radical, as is consistent with thermodynamics.

The question at this point is where the inadequacy from this method is coming from, group additivity or Evans-Polanyi theory and the assumptions applied? From the results on Table A2, it appears that Group Additivity for model compounds does not adequately capture heats of reaction. This then leads to the conclusion that the model compounds fail to capture the polymer character. Estimation for heats of reaction using Gaussian for the homopolymerization of styrene yield good result for the heat of reaction for the dimeric species whereas for the $\alpha$-methyl styrene dimeric species the estimation fail due to spin contamination. $^{73}$

\section{A.2 Methyl Acrylate/ Methyl Methacrylate}

From reviewing the work on styrene/ $\alpha$-methyl styrene one wonders how the methyl acrylate(MA)/methyl methacrylate(MMA) system would fare when GA is used in conjunction with the models. The radical structures in the St/AMS system and MA/MMA system are similar; however the groups that make up these structures have different 
chemical characteristics. Comparison of the structures from the two systems is shown in figure A1.<smiles>[CH+]CC(C)c1ccccc1</smiles><smiles>C=C[18OH]</smiles>

VS<smiles>COC(C)CC(C)CC(C)C</smiles><smiles>C=CC(=O)OC</smiles>
vs.<smiles>C=C(C)C(C)=O</smiles>

Figure A1 Comparison of St/AMS system with MA/MMA system reactions.

The differences in the structures can cause some differences in the radical reactivities of the two systems. Certainly looking at the phenyl component and the acrylate (carbonyl) component as well as the situation of the methyl groups attached to the chain backbone, different effects are expected. These effects on the chiral centres considering the electron densities and the magnetic spins would presumably play an important role in making the MA/MMA system less difficult to work with than the S/AMS system when it comes to computing enthalpies. The phenyl group diminishes the coulomb attraction by delocalising charge over the radical and therefore making the radical less subject to polar effects. It is known that polar effects have an effect on the energy barrier of a reaction. The energy of the system plays an important role in computational models, so this has to 
be kept in mind given the fact that MA/MMA system is less conjugated than S/AMS system. With this in mind an evaluation of the MA/MMA system using Group additivity was done. The results are shown in scheme A3

$$
\begin{aligned}
& \text { MA-MA* + MA } \stackrel{\mathrm{k}_{111}}{\longrightarrow} \text { MA-MA-MA* } \Delta H_{111}=-20.81 \\
& \text { MA-MA* }+ \text { MMA } \stackrel{\mathrm{k}_{112}}{\longrightarrow} \text { MA-MA-MMA* } \Delta H_{112}=-24.35 \\
& \text { MA-MMA* + MA } \stackrel{\mathrm{k}_{121}}{\longrightarrow} \text { MA-MMA-MA* } \quad \Delta H_{121}=-16.85 \\
& \text { MA-MMA* + MMA } \stackrel{\mathrm{k}_{122}}{\longrightarrow} \text { MA-MMA-MMA* } \Delta H_{122}=-20.39 \\
& \text { MMA-MMA* + MA } \stackrel{\mathrm{k}_{221}}{\longrightarrow} \text { MMA-MMA-MA* } \quad \Delta H_{221}=-16.85 \\
& \text { MMA-MMA* + MMA } \stackrel{\mathrm{k}_{222}}{\longrightarrow} \text { MMA-MMA-MMA* } \Delta H_{222}=-20.39 \\
& \text { MMA-MA* + MA } \stackrel{\mathrm{k}_{211}}{\longrightarrow} \text { MMA-MA-MA* } \Delta H_{211}=-20.81 \\
& \text { MMA-MA* + MMA } \stackrel{\mathrm{k}_{212}}{\longrightarrow} \text { MMA-MA-MMA* } \Delta H_{212}=-24.35
\end{aligned}
$$

Scheme A3 Monomer addition to dimeric radical for methyl acrylate and methyl methacrylate copolymerization. (all $\Delta H$ values are in $\mathrm{kcal} / \mathrm{mol}$ )

Table A4: Monomer reactivity ratios and penultimate unit effect for MA/MMA, calculated at $298.15 \mathrm{~K}$

\begin{tabular}{cll}
\hline & Calculated values & Expt values $^{\mathrm{b}}$ \\
\hline$r_{1}$ & 0.24 & $0.2-0.5$ \\
$r_{2}$ & 4.21 & $2.0-2.5$ \\
$s_{1}$ & 1.0 & 0.5 \\
$s_{2}$ & 1.0 & 2.0 \\
${ }^{5}$ Polymer Handbook. $^{I 2}$ & &
\end{tabular}


The monomer reactivity ratio $r_{1}$ value is the same as the experimental value and $r_{2}$ is not close to the experimental value. There is probably a breakdown in the method as indicated for the St/AMS system. The method does not distinguish penultimate unit effects that are observed experimentally.

Since it has been identified that the GA model compounds fail to capture the polymer character, ${ }^{73}$ and that estimating heats of reaction using Gaussian computational methods seems to give reasonable results for small radical molecules, ${ }^{23}$ it was our aim then to try to generate valuable kinetic data using quantum chemical methods. 


\section{Appendix B}

\section{Molecular Structures Used in this Work}

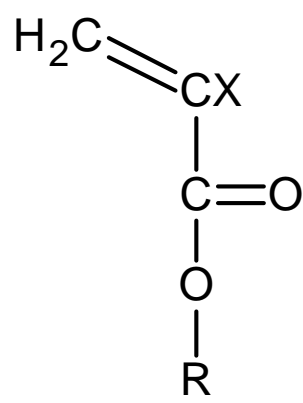

Acrylate Monomer<smiles>[14CH3]OC([14CH3])=O</smiles>

Acrylate Radical<smiles>[R]OC(=O)[C]C[Te]C(C)=O</smiles>

Dimeric Acrylate Radical species<smiles>[R]OC(=O)[Te]C[C](C)C(=O)O[R]</smiles>

Trimeric Acrylate Radical species 
where; $X$ or $\mathrm{Y}$ or $\mathrm{Z}=\mathrm{H}$ or $\mathrm{CH}_{3}$ or $\mathrm{C}_{2} \mathrm{H}_{5}$

$\mathrm{R}^{\prime}$ or $\mathrm{R}=\mathrm{CH}_{3}$ (methyl) or $\mathrm{C}_{2} \mathrm{H}_{5}$ (ethyl) or $\mathrm{C}_{4} \mathrm{H}_{9}$ (butyl) or

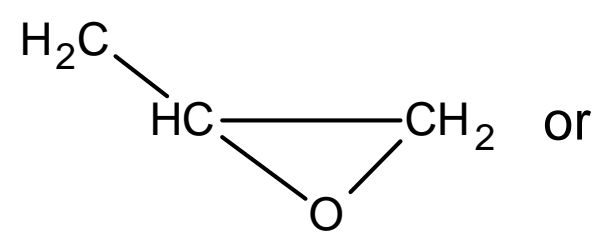

(glycidyl)<smiles>C=COC(C)=O</smiles>

Vinyl Acetate Monomer

$$
\mathrm{H}_{2} \mathrm{C}=\mathrm{CH}_{2}
$$

Ethylene Monomer<smiles>CCO</smiles>

(hydroxy ethyl)

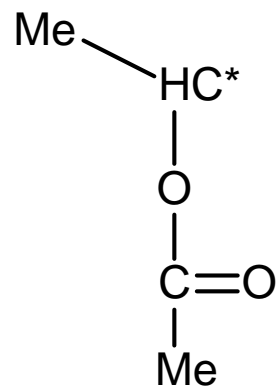

Vinyl Acetate Radical<smiles>[C+]C</smiles>

Ethylene Radical 